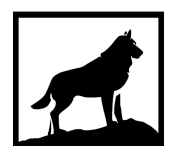

Michigan

Technological

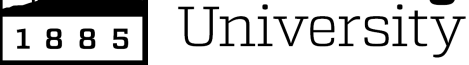

Michigan Technological University

Digital Commons @ Michigan Tech

INFLUENCE OF RAPID SOLIDIFICATION AND WROUGHT PROCESSING ON PRECIPITATION STRENGTHENING AND DEFORMATION MECHANISMS IN AL-SC-ZR ALLOYS

Yang Yang

Michigan Technological University, yyang10@mtu.edu

Copyright 2020 Yang Yang

Recommended Citation

Yang, Yang, "INFLUENCE OF RAPID SOLIDIFICATION AND WROUGHT PROCESSING ON PRECIPITATION STRENGTHENING AND DEFORMATION MECHANISMS IN AL-SC-ZR ALLOYS", Open Access Dissertation, Michigan Technological University, 2020.

https://doi.org/10.37099/mtu.dc.etdr/1107

Follow this and additional works at: https://digitalcommons.mtu.edu/etdr

Part of the Metallurgy Commons, and the Structural Materials Commons 


\title{
INFLUENCE OF RAPID SOLIDIFICATION AND WROUGHT PROCESSING ON PRECIPITATION STRENGTHENING AND DEFORMATION MECHANISMS IN AL-SC-ZR ALLOYS
}

\author{
By \\ Yang Yang \\ A DISSERTATION \\ Submitted in partial fulfillment of the requirements for the degree of \\ DOCTOR OF PHILOSOPHY \\ In Materials Science and Engineering \\ MICHIGAN TECHNOLOGICAL UNIVERSITY \\ 2020 \\ (C) 2020 Yang Yang
}


This dissertation has been approved in partial fulfillment of the requirements for the Degree of DOCTOR OF PHILOSOPHY in Materials Science and Engineering.

\section{Department of Materials Science and Engineering}

Dissertation Advisor: Paul G. Sanders

Committee Member: Stephen A. Hackney

Committee Member: Douglas J. Swenson

Committee Member: Erik G. Herbert

Committee Member: Gregory M. Odegard

Department Chair: Stephen L. Kampe 


\section{Table of Contents}

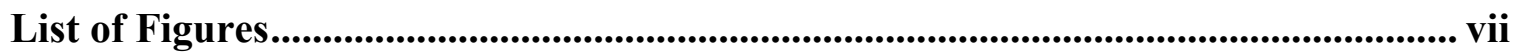

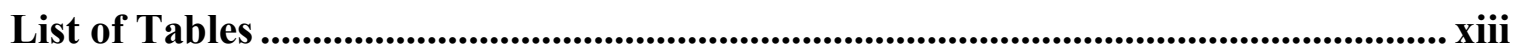

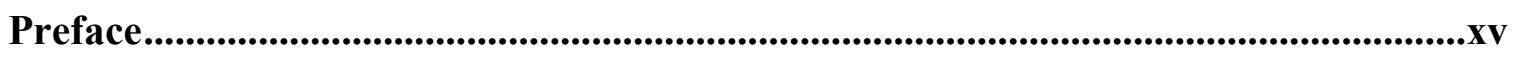

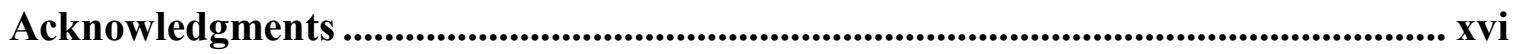

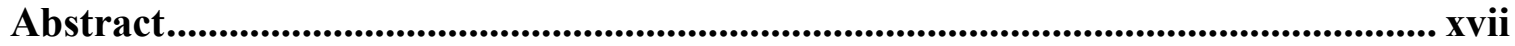

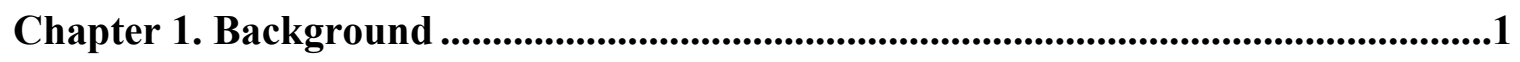

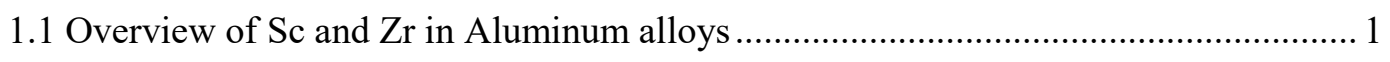

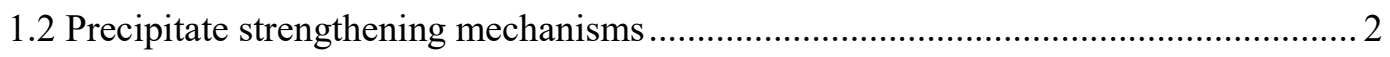

1.2.1 Strengthening at ambient temperature ................................................... 2

1.2.2 Strengthening at elevated temperature....................................................... 4

1.3 Effect of solidification rate on solute solubility........................................................ 4

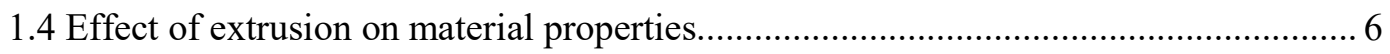

1.5 Precipitate coarsening in Aluminum alloys ......................................................... 7

Chapter 2. Experimental ....................................................................................................8

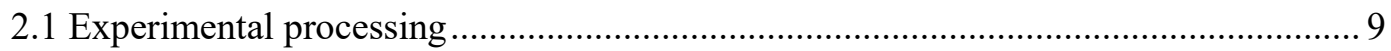

2.1.1 Vacuum Induction Melting Casting ......................................................... 9

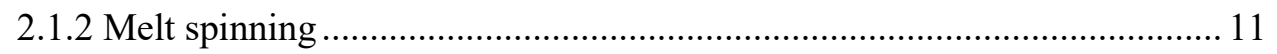

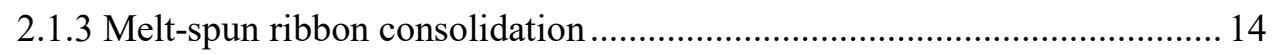

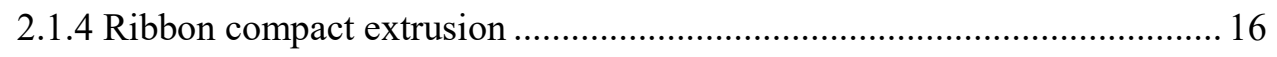

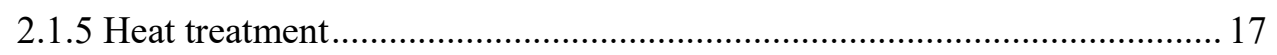

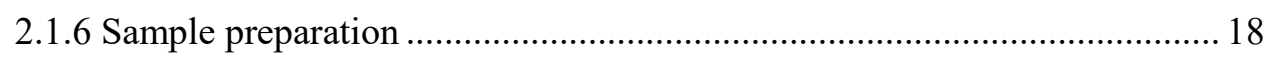

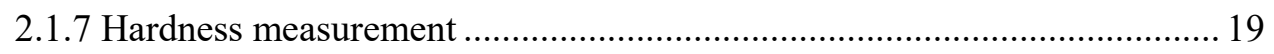

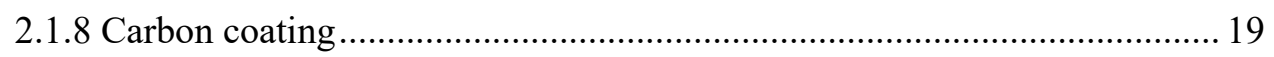

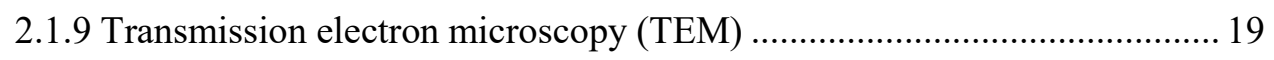

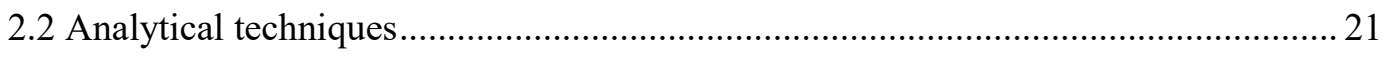

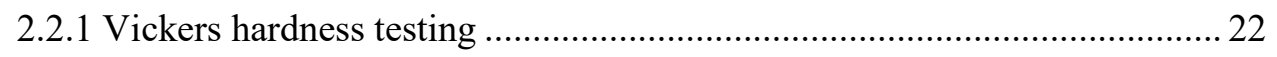

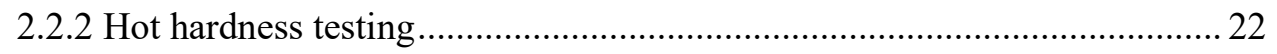

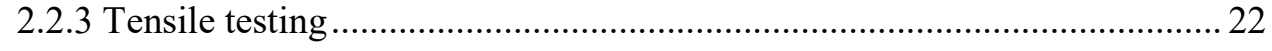

2.2.4 Hot compression testing................................................................... 23

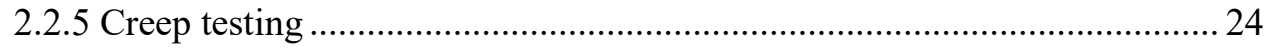


2.2.6 Scanning electron microscope (SEM) testing ....................................... 24

2.2.7 Transmission electron microscopes (TEM) testing ................................... 25

\section{Chapter 3. Improved strengthening in supersaturated Al-Sc-Zr alloy via melt-}

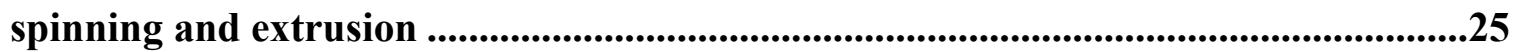

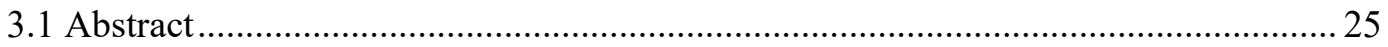

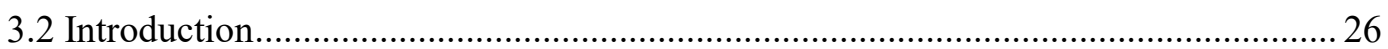

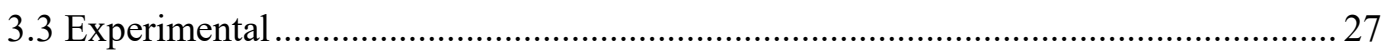

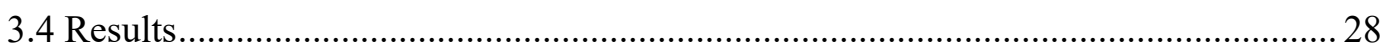

3.4.1 Microstructures of Melt-spun Ribbon and Extruded Rod.......................... 28

3.4.2 Vickers Microhardness and Tensile Strength ........................................... 29

3.4.3 Transmission Electron Microscopy ....................................................... 31

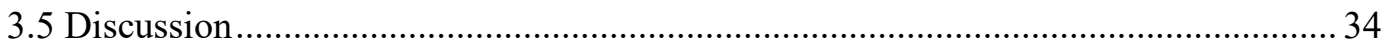

3.5.1 Microstructures of Melt-spun Ribbon and Extruded Rod.......................... 34

3.5.2 Precipitate Structure of Al3Sc1 - xZrx in Supersaturated Alloys .............. 35

3.5.3 Precipitation Strengthening Prediction in Supersaturated Alloys............... 36

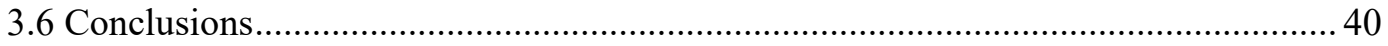

\section{Chapter 4. Coarsening behavior of precipitate Al3(Sc,Zr) in supersaturated Al-Sc-}

$\mathrm{Zr}$ alloy via melt-spun and extrusion ..................................................................41

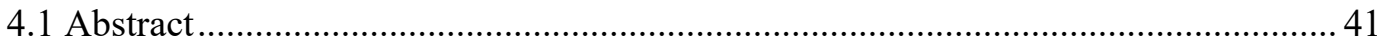

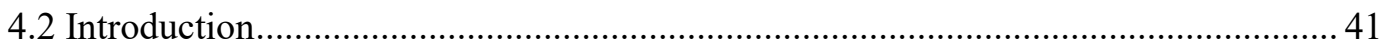

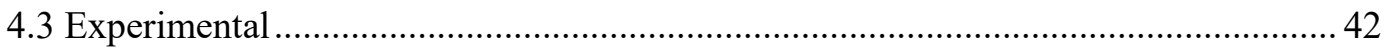

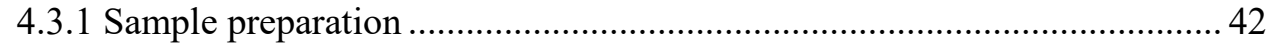

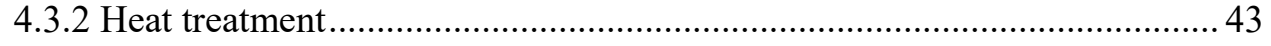

4.3.3 Transmission electron microscopy analysis............................................. 43

4.3.4 Effective diffusivity for coarsening acceleration ..................................... 44

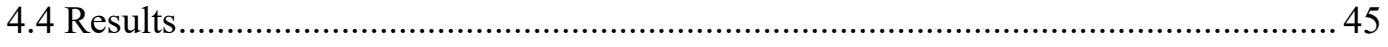

4.4.1 Coherency determination of precipitate .................................................... 45

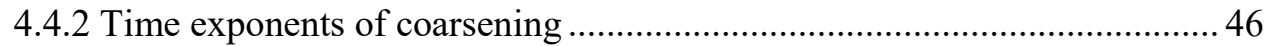

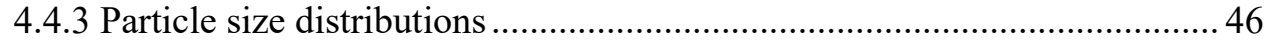

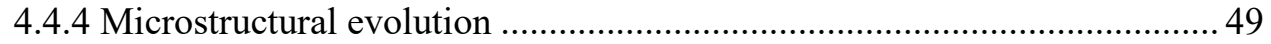

4.4.5 Composition change of precipitate ……................................................ 52

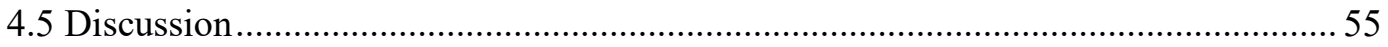

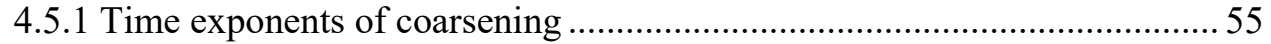


4.5.2 Effective diffusivity for coarsening acceleration .................................... 57

4.5.3 Prediction of precipitate radius coarsening evolution ................................. 58

4.5.4 Prediction of particle density evolution .................................................... 61

4.6 Conclusion

Chapter 5. High-temperature mechanical properties of supersaturated Al-Sc-Zr alloy via melt-spinning and extrusion ...................................................................................64

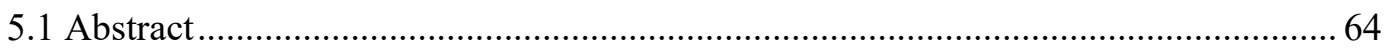

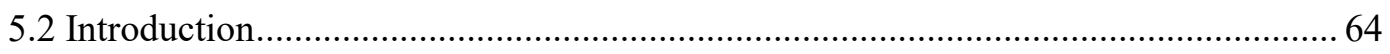

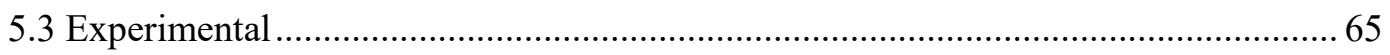

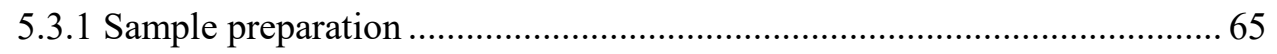

5.3.2 Hot Macro Vickers, compression, and creep testing ................................ 65

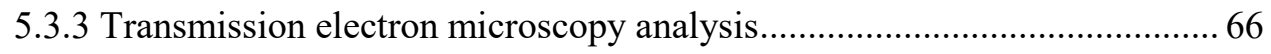

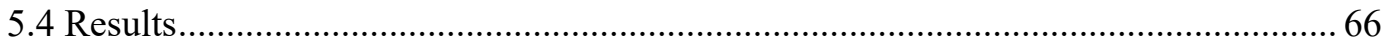

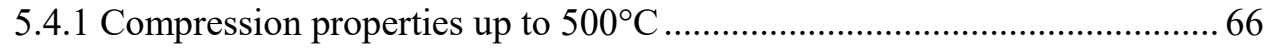

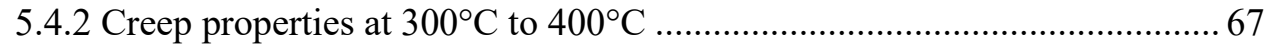

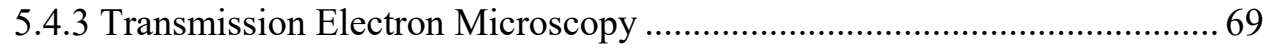

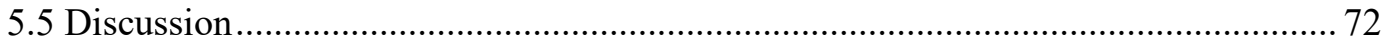

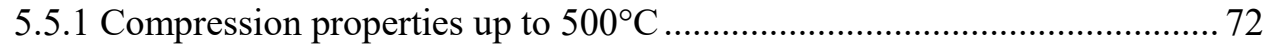

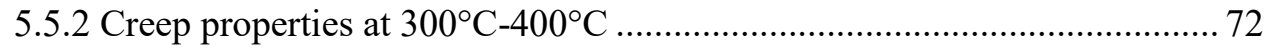

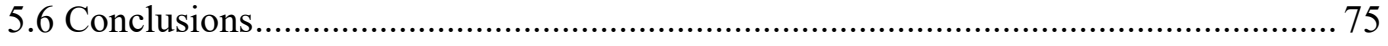

\section{Chapter 6. Nanoindentation study on supersaturated Al-Sc-Zr via melt-spinning}

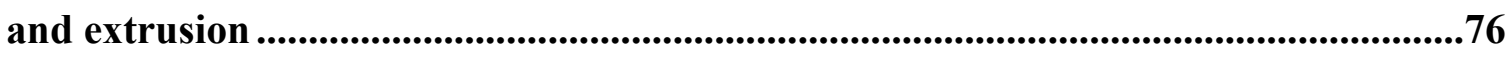

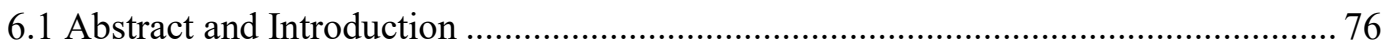

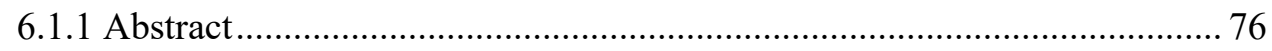

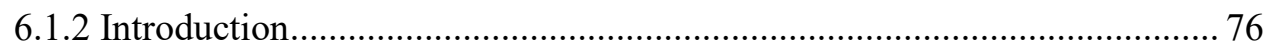

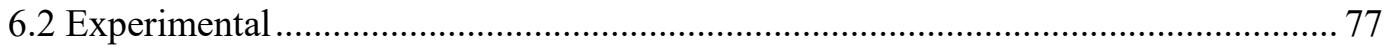

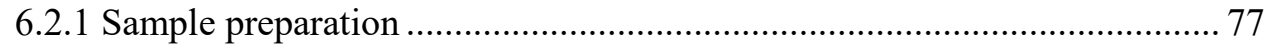

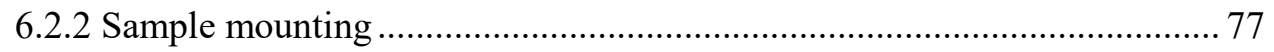

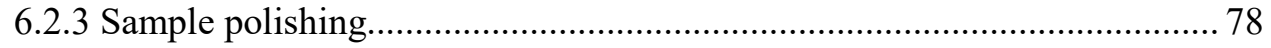

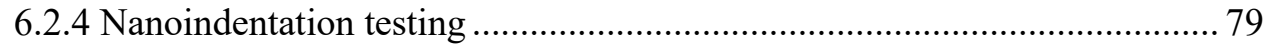

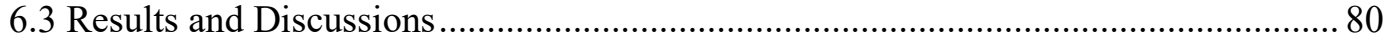

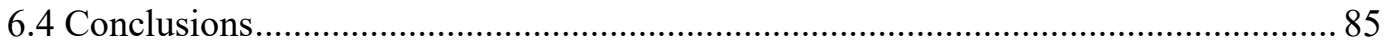

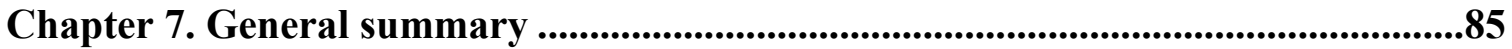


Reference

Appendix A. Increasing time exponent $n$ as a function of evolving precipitate

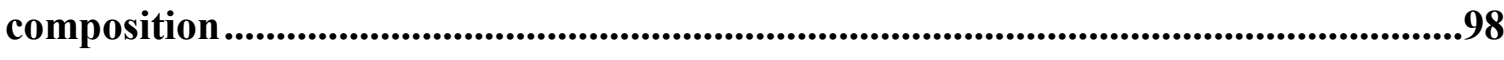
Appendix B. Increasing time exponent $n$ due to increasing precipitate volume

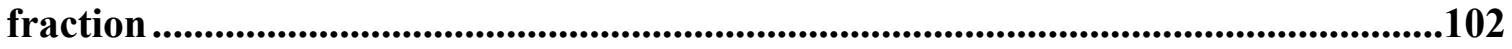

Appendix C. Copyright permission ............................................................................106 


\section{List of Figures}

Figure 1.1. The solute concentration in rapidly solidified binary Al-X alloys [23]..........6

Figure 2.1. Flow chart of the experiment design to produce, characterize and mechanically tests supersaturated Al-Sc-Zr melt-spun ribbon and extruded rod..8

Figure 2.2. (a) The cross-section of candelabra mold which has two $19 \mathrm{~mm} \varnothing$ rod and (b) graphite crucible.

Figure 2.3. The graphite crucible was loaded inside of the coils which controlled by a lever handle. The position of mold on the plate is aligned to the pouring stream's position.

Figure 2.4. (a) the schematic of melt spinner consists of heating coils, graphite crucible and copper wheel; (b) all parts mentioned above are sealed in the chamber; (c) the melt spinner chamber is connected to a glove box through a tube.

Figure 2.5. Master alloys were heated to $1100^{\circ} \mathrm{C}$ in graphite crucible (a) and ejected on the copper rolling wheel (b). The solidified ribbon was $\sim 3 \mathrm{~mm}$ wide and $\sim 50 \mu \mathrm{m}$ thick (c).

Figure 2.6. The melt-spun ribbon was compacted into the 6061 can and sealed by an airtight stainless steel rod as cap (a). A support tool steel ring and a bottom plate were used to prevent the deformation in the 6061 can (b).

Figure 2.7. The melt-spun ribbon was firstly compacted into 6061 can using a Carver press in the glove box (a). Then the can was further compacted using a Dake press (b) and the exceeded cap part was cut off (c).

Figure 2.8. The ribbon compact was preheated using a fluidized bed for $5 \mathrm{~h}$ at $350^{\circ} \mathrm{C}$ (a) and extruded out at the same temperature (b).

Figure 2.9. Melt-spun ribbon consolidation and extrusion press schematic (left) and typical microstructure (right).

Figure 2.10. The two-step aging flow of the melt-spun ribbon and extruded rod using a combination of fluidized bed and box furnace. 
Figure 2.11. Configurations of electropolisher consists of nitride liquid container, thinning cell and Metalthin controller. The nitride liquid container and thinning cell are located under the hood, Metalthin controller locates next to the hood...21

Figure 2.12. Sample preheated on the copper plate with two cartridge heaters inserted...22

Figure 2.13. Configuration of compression test using the MTS Instron 4206. Plates and samples were preheated using a tube furnace.

Figure 3.1. SEM micrograph of mechanically polished Al-0.4Sc-0.4Zr at $\%$ melt-spun ribbon (a) and extruded rod cross-sections (b). Petal-shape primary precipitates were observed and mitigated by adjusting ejection pressures and wheel rolling rate $(\mathrm{c})$.

Figure 3.2. Two-step heat treatment $\left(350^{\circ}, 5 \mathrm{~h}\right.$ and $\left.400^{\circ} \mathrm{C}, 5 \mathrm{~h}\right)$ on $\mathrm{Al}-0.4 \mathrm{Sc}-0.4 \mathrm{Zr}$ at $\%$ melt-spun ribbon, Al-0.4Sc-0.4Zr at\% extruded rod and as-cast Al-0.06Sc$0.06 \mathrm{Zr}$ at $\%$. Ambient temperature Vickers microhardness was measured (error bars are $95 \% \mathrm{CI}$ of the mean).

Figure 3.3. Ambient temperature tensile test of peak-aged Al-0.06Sc-0.06Zr at $\%\left(300^{\circ} \mathrm{C}\right.$ for $15 \mathrm{~h})$ and peak-aged $\mathrm{Al}-0.4 \mathrm{Sc}-0.4 \mathrm{Zr}$ at $\%$ extruded $\operatorname{rod}\left(350^{\circ}\right.$ for $5 \mathrm{~h}$ and $400^{\circ} \mathrm{C}$ for $\left.0.5 \mathrm{~h}\right)$.

Figure 3.4. Bright-field TEM and STEM images of (a)(c) peak-aged Al-0.4Sc-0.4Zr at\% melt-spun ribbon and (b)(d) peak-aged Al-0.4Sc-0.4Zr at\% extruded rod. The grain size of peak-aged Al-0.06Sc-0.06Zr at\% was measured using optical microscopy due to its larger size.

Figure 3.5. Grain size diameters of Al-0.4Sc-0.4Zr at $\%$ melt-spun ribbon, extruded rod at first-step, second-step and overaged step; and isothermally peak-aged Al$0.06 \mathrm{Sc}-0.06 \mathrm{Zr}$ at $\%$ at $300^{\circ} \mathrm{C}$ for $15 \mathrm{~h}$.

Figure 3.6. Mean precipitate radius, $R$, volume fraction, $\Phi$, and number density of precipitate in Al-0.4Sc-0.4Zr at\% melt-spun ribbon and extruded rod with twostep heat treatment; As-cast Al-0.06Sc-0.06Zr at $\%$ is isochronally aged at $300^{\circ} \mathrm{C}$ for $15 \mathrm{~h}$.

Figure 3.7. HAADF-STEM image of precipitate and EDS maps of Sc and Zr in over-aged melt-spun ribbon $\left(350^{\circ} \mathrm{C}, 5 \mathrm{~h}\right.$ and $\left.400^{\circ} \mathrm{C}, 5 \mathrm{~h}\right)$. The Sc-rich core and $\mathrm{Zr}$-rich shell 
were verified by EDS mapping. The line scan trend revealed that Sc atomic fraction increases between distances from $-2.7 \mathrm{~nm}$ to $2.7 \mathrm{~nm} ; \mathrm{Zr}$ atomic fraction is increased in ranges of $-4.1--2.7 \mathrm{~nm}$ and $2.7-3.8 \mathrm{~nm}$.

Figure 3.8. Calculated coherency and modulus strengthening, order strengthening and Orowan strengthening change with increasing $R$ in (a)-(c) First-step, second-step and over-aged melt-spun ribbon; (d)-(f) First-step (as-produced), second-step and over-aged extruded rod. Calculated Hall-Petch strengthening change was excluded in extruded rod (Table 3.1).

Figure 4.1. Bright-field TEM images of precipitate in the 72h-aged extruded rod. (a) The observed lobes of contrast about the precipitates are consistent with matrix strains of a coherent precipitate [73]. A small number of incoherent precipitates were found at dislocations (b) and grain boundaries (c) (arrows).

Figure 4.2. Log-log plot of (a) mean precipitate radii and (b) precipitate number density of melt-spun ribbon and extruded rod (error bars are 95\% standard error of the mean).

Figure 4.3. Normalized frequency of precipitate size distributions (PSDs) of overaged melt-spun ribbon (a-d) and extruded rod (e-h) for $12 \mathrm{~h}, 24 \mathrm{~h}, 48 \mathrm{~h}, 72 \mathrm{~h}$ at $400^{\circ} \mathrm{C}$. The LSW PSDs (lines) are shown for comparison.

Figure 4.4. TEM images of precipitates locate on $(a, b)$ dislocations and $(c, d)$ grain boundaries in $72 \mathrm{~h}$ overaged (a, c) melt-spun ribbon and (b, d) extruded rod. Some incoherent particles are indicated by arrows.

Figure 4.5. The standard deviations and kurtosis of the normalized radius in (a) melt-spun ribbon and (b) extruded rod annealed up to $72 \mathrm{~h}$ at $400^{\circ} \mathrm{C}$. The stationary LSW results are plotted as horizontal lines for comparison.

Figure 4.6. Grain diameters of peak-aged $\mathrm{Al}-0.4 \mathrm{Sc}-0.4 \mathrm{Zr}$ at. \% melt-spun ribbon and extruded rod annealed up to $72 \mathrm{~h}$ at $400^{\circ} \mathrm{C}$ (error bars are $95 \%$ standard error of the mean).

Figure 4.7. Dislocation densities of peak-aged $\mathrm{Al}-0.4 \mathrm{Sc}-0.4 \mathrm{Zr}$ at. \% melt-spun ribbon and extruded rod overaged up to $72 \mathrm{~h}$ at $400^{\circ} \mathrm{C}$ (error bars are $95 \%$ standard error of the mean). .51 
Figure 4.8. Precipitate volume fraction of the peak-aged melt-spun ribbon and extruded rod overaged for $12 \mathrm{~h}, 24 \mathrm{~h}, 48 \mathrm{~h}$ and $72 \mathrm{~h}$ at $400^{\circ} \mathrm{C}$ (error bars are $95 \%$ standard error of the mean)

Figure 4.9. Concentrations of Sc and $\mathrm{Zr}$ change as a function of distance from the interface between the $\alpha$-matrix and an $\mathrm{Al} 3(\mathrm{Sc} 1-\mathrm{xZrx})$ precipitate measured by EDS for an Al-0.4Sc-0.4Zr at $\%$ extruded rod aged at $400^{\circ} \mathrm{C}$ for $72 \mathrm{~h}$. Ten precipitates were measured for each sample condition (error bars are 95\% standard error of the mean)

Figure 4.10. Evolution in Sc and $\mathrm{Zr}$ concentration in the precipitate and the matrix for melt-spun ribbon and extruded rod annealed up to $72 \mathrm{~h}$ at $400^{\circ} \mathrm{C}$ (error bars are $95 \%$ standard error of the mean).

Figure 4.11. Evolution of the solute distribution coefficients (atomic fraction of solute in precipitate/in matrix) at $12 \mathrm{~h}, 24 \mathrm{~h}, 48 \mathrm{~h}$ and $72 \mathrm{~h}$ of annealing at $400^{\circ} \mathrm{C}$ for meltspun ribbon and extruded rod (error bars are 95\% standard error of the mean)..54

Figure 4.12. Effective diffusivities of solutes in melt-spun ribbon and extruded rod at different annealing steps up to $72 \mathrm{~h}$ at $400^{\circ} \mathrm{C}$. Bulk diffusivities of solutes are imposed for comparison (a) and effective diffusivities are plotted with an expanded scale in (b).

Figure 4.13. Experimental precipitate coarsening rate and UOKV predicted coarsening rate using bulk and effective diffusivities in melt-spun ribbon and extruded rod at different annealing steps up to $72 \mathrm{~h}$ at $400^{\circ} \mathrm{C}$ .58

Figure 4.14. The UOKV-predicted and experimentally measured precipitate radius evolution in (a) melt-spun ribbon and (b) extruded rod annealed up to $72 \mathrm{~h}$ at $400^{\circ} \mathrm{C}$. The radius change estimated using general LSW model and UOKV model with bulk diffusivity on ternary alloy were imposed for comparison (error bars are $95 \%$ standard error of the mean).

Figure 4.15. The UOKV-predicted and experimentally measured precipitate number density evolution in melt-spun ribbon (a) and extruded rod (b) annealed up to $72 \mathrm{~h}$ at $400^{\circ} \mathrm{C}$ (error bars are $95 \%$ standard error of the mean). 
Figure 5.1. Ultimate compressive strengthen of peak-aged $\mathrm{Al}-0.4 \mathrm{Sc}-0.4 \mathrm{Zr}$ at $\%$ and $\mathrm{Al}-$ $0.06 \mathrm{Sc}-0.06 \mathrm{Zr}$ at $\%$ from room temperature to $500^{\circ} \mathrm{C}$ (left scale). Also plotted is the hot macro hardness/3 for comparison (right scale) (Error bars are 95\% standard error of the mean.)

Figure 5.2. Steady-state strain rate versus applied stress for peak-aged Al-0.4Sc-0.4Zr at $\%$ and $\mathrm{Al}-0.06 \mathrm{Sc}-0.06 \mathrm{Zr}$ at $\%$ at $300^{\circ} \mathrm{C}, 350^{\circ} \mathrm{C}$ and $400^{\circ} \mathrm{C}$ (error bars are $95 \%$ standard error of the mean)

Figure 5.3. Linear plot of $\varepsilon 1 / 4.4$ vs $\sigma$ for Al-0.4Sc- $0.4 \mathrm{Zr}$ at $\%$ and $\mathrm{Al}-0.06 \mathrm{Sc}-0.06 \mathrm{Zr}$ at $\%$ at $300^{\circ} \mathrm{C}, 350^{\circ} \mathrm{C}$ and $400^{\circ} \mathrm{C}$. The values of $\sigma t h$ was obtained from the $\mathrm{x}$-axis intercept (error bars are $95 \%$ standard error of the mean).

Figure 5.4. Measured grain size (a) and precipitate radii (b) were measured from TEM/STEM images after creep at $300^{\circ} \mathrm{C}, 350^{\circ} \mathrm{C}$ and $400^{\circ} \mathrm{C}$. Measured grain size and precipitate radii in the as-prepared alloys were imposed for comparison. (Error bars are 95\% standard error of the mean.). .70

Figure 5.5. Measured precipitate number densities $(\mathrm{a}, \mathrm{b})$ and calculated volume fractions (c, d) in Al-0.5Sc-0.4Zr at \% and Al-0.06Sc-0.06Zr at\% in the as-prepared and after creep at $300^{\circ} \mathrm{C}, 350^{\circ} \mathrm{C}$ and $400^{\circ} \mathrm{C}$. (b) and (d) are enlarged plots showing the change in Al-0.06Sc-0.06Zr at\% precipitate density. (Error bars are 95\% standard error of the mean.)

Figure 5.6. Arrhenius plot of the steady-state creep strain rate vs inverse temperature at $300^{\circ} \mathrm{C}, 350^{\circ} \mathrm{C}$ and $400^{\circ} \mathrm{C}$. Strain rate for $\mathrm{Al}-0.4 \mathrm{Sc}-0.4 \mathrm{Zr}$ at $\%$ at $400^{\circ} \mathrm{C}$ and $\mathrm{Al}-$ $0.06 \mathrm{Sc}-0.06 \mathrm{Zr}$ at $\%$ at $300^{\circ} \mathrm{C}$ were tested using inconstant applied stress. The arrows stand for the trend of strain rate if constant stress applied.

Figure 6.1. Al-0.4Sc-0.4Zr at\% melt-spun ribbon was mounted with the support of two 6061 pieces and fastened by copper tape (a). Enlarged plot of mounted meltspun ribbon supported by two 6061 pieces (b).

Figure 6.2. The mounted specimen in the holder (a) and vibratory polishing is the final step for nanoindentation sample preparation (b).

Figure 6.3. iMicro nanoindenter equipment. 
Figure 6.4. Cumulative plots of hardness (a) and modulus (b) of the peak-aged Al-0.4Sc-

$0.4 \mathrm{Zr}$ at $\%$ melt-spun ribbon and extruded rod measure using the high-speed measurement.

Figure 6.5. Hardness (a) and elastic modulus (b) of Al-0.4Sc-0.4Zr at\% melt-spun ribbon as a function of depth to $1000 \mathrm{~nm}$ using continuous stiffness measurement (CSM). Indenter was held at depths of $180 \mathrm{~nm}$ and $1060 \mathrm{~nm}$ using CSM. A 177 $\mathrm{nm}$ deep High-speed testing points was imposed for comparison.

Figure 6.6. BES image of the indentation made using continuous stiffness measurement. Pile-up was observed around the indentation and contact boundary.

Figure 7.1. Representative figures of the comprehensive study of the processingstructure-properties relationships of supersaturated Al-Sc-Zr (using some of the previous figures in the dissertation).

Figure A1. Solute concentration of precipitate in melt-spun ribbon change with precipitate radius aged from $12 \mathrm{~h}$ to $72 \mathrm{~h}$ at $400^{\circ} \mathrm{C}$ (error bars are $95 \%$ standard error of the mean)

Figure A2. Precipitate radius predicted using modified LSW versus traditional LSW from $\mathrm{t}=0 \mathrm{~s}$ to $\mathrm{t}=10000 \mathrm{~s}$ at $400^{\circ} \mathrm{C}$.

Figure A3. Log-log plot of mean precipitate radii of modified LSW .102

Figure B1. Precipitate radius predicted using modified LSW versus traditional LSW from $\mathrm{t}=0 \mathrm{~s}$ to $\mathrm{t}=10000 \mathrm{~s}$ at $400^{\circ} \mathrm{C}$. .106 


\section{List of Tables}

Table 1.1. Summary of diffusivities (D) of Sc and $\mathrm{Zr}$ in aluminum matrix at $400^{\circ} \mathrm{C}$. Some general solute additions are listed for comparison.......................................1

Table 1.2. Summary of the dominant precipitation strengthening and work hardening in the melt-spun ribbon and extruded rod. .....................................................

Table 2.1. Composition of the Al-0.4Sc-0.4Zr at\% melt-spun ribbon, extruded rod and Al-0.06Sc-0.06Zr at \% dilute alloy.

Table 2.2. A summary of the comparisons between quartz and graphite crucibles. .12

Table 2.3. Melt spinner parameters and optimized levels for maximum solute solubility 13

Table 2.4. Fine polishing pads and operations sequence. .19

Table 2.5. EDM settings for sample cutting .20

Table 2.6. Metalthin controller settings for melt-spun ribbon, extruded rod and dilute alloy

Table 2.7. Testing temperatures and applied loads for creep test on supersaturated and dilute alloys. .24

Table 3.1. Calculated Hall-Petch strengthening change in extruded rod. .37

Table 3.2. Summary of mechanical properties and microstructures of Al- $0.4 \mathrm{Sc}-0.4 \mathrm{Zr}$ at $\%$ alloy processed by melt-spinning and extrusion; high Sc/Zr-content alloys processed by selective laser melting.

Table 4.1. Time exponents for precipitate radius and number density functions determined by the slopes of the Log-log plots. .46

Table 4.2. Experimental and UOKV predicted coarsening rates change from shortest (12h) to longest (72h) annealing steps.

Table 4.3. Experimental and UOKV predicted precipitate radius using effective diffusivities at shortest (12h) to longest (72h) annealing steps.

Table 5.1. Temperature range and testing numbers of Macro hot hardness, hot compression and creep tests on supersaturated and dilute alloys.

Table 5.2. Threshold stress and stress exponents for Al-0.4Sc-0.4Zr at $\%$ and $\mathrm{Al}-0.06 \mathrm{Sc}-$ $0.06 \mathrm{Zr}$ at $\%$ at $300^{\circ} \mathrm{C}, 350^{\circ} \mathrm{C}$ and $400^{\circ} \mathrm{C}$ 
Table 5.3. The calculated Orowan strength of Al-0.4Sc-0.4Zr at $\%$ and Al-0.06Sc- $0.06 \mathrm{Zr}$ at $\%$ at ambient and $300^{\circ} \mathrm{C}$.

Table 5.4. Chosen applied stress and corresponding strain rate of Al- $0.4 \mathrm{Sc}-0.4 \mathrm{Zr}$ at $\%$ and Al-0.06Sc- $0.06 \mathrm{Zr}$ at $\%$ at $300^{\circ} \mathrm{C}, 350^{\circ} \mathrm{C}$ and $400^{\circ} \mathrm{C}$.

Table 6.1. The mean hardness and modulus of the peak-aged Al-0.4Sc-0.4Zr at\% meltspun ribbon and extruded rod measured using high-speed measurement.........81

Table 6.2. The experimental and predicted hardness the peak-aged Al-0.4Sc-0.4Zr at $\%$ melt-spun ribbon measured using continuous stiffness measurement at 1000 $\mu \mathrm{m}$ depth.

Table A.1. The confidence of solutes changes for precipitate in supersaturated and dilute alloys using Thiel-Sen estimator. .100

Table A.2. Four precipitate sizes were chosen from modified LSW (Figure A2). .101 


\section{Preface}

This dissertation contains some material that has been submitted for publication or published. The status of each chapter can be summarized as:

- Chapter 3. Y. Yang, J. J. Licavoli, and P. G. Sanders, "Improved strengthening in supersaturated Al-Sc-Zr alloy via melt-spinning and extrusion," Journal of Alloys and Compounds, vol. 826, p. 154185, Jun. 2020, doi: 10.1016/j.jallcom.2020.154185.

- Chapter 4. Yang Yang, Joseph J. Licavoli, Stephen A. Hackney, Paul G. Sanders, "Coarsening behavior of precipitate $\mathrm{Al3}(\mathrm{Sc}, \mathrm{Zr}$ ) in supersaturated $\mathrm{Al}-\mathrm{Sc}-\mathrm{Zr}$ alloy via melt-spun and extrusion", Journal of Materials Science, under review.

- Chapter 5. Yang Yang, S. A. Hackney, E. G. Herbert, P. G. Sanders, "High temperature properties of supersaturated Al-Sc-Zr", In preparation.

- Chapter 6. Yang Yang, E. G. Herbert, P. G. Sanders, "Nanoindentation study on supersaturated Al-Sc-Zr via melt-spinning," In preparation.

This dissertation was written by myself, with the editorial help from Prof Sanders, Prof Hackney, Prof Swenson, Prof Herbert and Prof Odegard. Thomas Wood, Russell Stein and Paul Fraley helped with experimental work related to melt spinning and extrusion. Dr. Pinaki Mukherjee assisted in the analytical experiment of scanning transmission electron microscopy (STEM). Dr. Joseph J. Licavoli was very helpful with drafting the publication submissions. For more descriptions of the contributors, please refer to the Acknowledges section. 


\section{Acknowledgments}

First of all, I would like to thank my advisor and mentor, Dr. Paul Sanders, for his support, encouragement and guidance. I am grateful that he gave me this chance to participate in this ONR-funded project and pursue my Ph.D. degree. He was always helpful in my experimental works and academic study. I have learned a lot from him not only about the academic knowledge, but also about his diligence, conscientiousness and passion.

This work couldn't be accomplished without the generous financial support by the Office of Naval Research (N000141612878).

I would like to thank my committee members for their valuable comments and suggestions. Prof Hackney and Prof Herbert helped me a lot from experiments to technical questions from the beginning of my Ph.D. study. They were always patient with my questions and willing to help me out all the time.

I would like to thank faculty, staff and graduate students of Materials Science and Engineering. In particular thank you to Thomas Wood, Russell Stein, Paul Fraley, Dr. Pinaki Mukherjee, Dr. Joseph J. Licavoli and Dr. Daniel Seguin for helping me with various experimental and analytical works. I also want to thank my friends for useful and encouraging discussions.

I would like to thank my parents and parents-in-law for their support mentally and financially. They give everything to us instead of asking for anything. I would like to thank my son, Michael Yang, for coming to this world and bring so much happiness to our life. I will give my effort to keep him happy and healthy all the time. In the end, I would like to thank my wife, Siyu Wang, for her selfless support and accompany all the time. I wouldn't be who I am now without her support. 


\begin{abstract}
Al-Sc-Zr alloys have drawn increasing attention in the last several decades due to their strengthening and coarsening resistance. In this study, solute concentrations of $\mathrm{Sc}$ and $\mathrm{Zr}$ were increased beyond their equilibrium solubilities without primary precipitate formation using melt-spinning. The melt-spun ribbon was metallurgically bonded into bulk shape using extrusion. With the proper aging treatment, the mechanical properties of the supersaturated melt-spun ribbon and extruded rod were found to be significantly higher than a baseline dilute alloy. Increased mechanical properties include microhardness, tensile strength at ambient-temperature, and compressive strength and threshold stress at and elevated-temperature. These increases were related to the larger precipitate radius and volume fractions found in the melt-spun alloys.
\end{abstract}

Scanning transmission electron microscopy (STEM) was used to investigate the microstructural changes in the supersaturated alloys that led to the mechanical property improvements. The precipitate size and number density, precipitate volume fraction, grain size and dislocation density in the melt-spun ribbon and extruded rod were quantified in the STEM images. The elemental compositions and distributions in the precipitate and matrix were measured using the energy-dispersive X-ray spectroscopy (EDS) and elemental mapping in STEM mode.

The precipitate strengthening, threshold stress and precipitate coarsening behavior in the supersaturated melt-spun ribbon and extruded rod were modeled using the measured microstructures. The predictions of precipitate strengthening and threshold stress agreed with the observed experimental results. The precipitate coarsening rates were found to be accelerated by the supersaturated solute additions and retarded by the increasing precipitate volume fraction during overaging. 


\section{Chapter 1. Background}

\subsection{Overview of $\mathrm{Sc}$ and $\mathrm{Zr}$ in Aluminum alloys}

The addition of Sc to Al-based alloys has been studied as a potential strategy for increasing high temperature strength and creep resistance in aluminum alloys. This is due to the formation of thermally stable, nanometer-sized $\mathrm{L} 1_{2}$ precipitates with the composition of $\mathrm{Al}_{3} \mathrm{Sc}$ [1]-[6]. A shallow solubility curve for $\mathrm{Sc}$ in $\mathrm{Al}$ from 0.23 at. \% $\left(\sim 665^{\circ} \mathrm{C}\right)$ to $<0.01$ at. $\%$ (below $\left.400^{\circ} \mathrm{C}\right)$ maximizes Sc precipitate volume fractions during post solidification aging [1], [7], [8]. Additionally, the relatively slow diffusion rate of Sc and small lattice mismatch $(+1.32 \%)$ between matrix and precipitates are substantial factors in reducing precipitate coarsening up to $\sim 300^{\circ} \mathrm{C}[8]-[10]$.

$\mathrm{Zr}$ is considered an effective supplemental addition to increase Al-Sc ambient- and hightemperature performance, as $\mathrm{Zr}$ atoms have less mobility (Table 1.1) and form an ordered $\mathrm{L}_{2} \mathrm{Al}_{3}\left(\mathrm{Sc}_{1-\mathrm{x}} \mathrm{Zr}_{\mathrm{x}}\right)$ trialuminide precipitate [3], [10]-[12]. The $\mathrm{Zr}$ atoms can replace up to half the $\mathrm{Sc}$ atoms in the precipitate [13], but $\mathrm{Al}_{3} \mathrm{Zr}$ can transforms into a $\mathrm{D}_{23}$ structure as it coarsens above $475^{\circ} \mathrm{C}[14]$.

Table 1.1. Summary of diffusivities (D) of $\mathrm{Sc}$ and $\mathrm{Zr}$ in aluminum matrix at $400^{\circ} \mathrm{C}$. Some general solute additions are listed for comparison.

\begin{tabular}{c|c|c}
\hline & $D$ at $400^{\circ} \mathrm{C}\left(\mathrm{m}^{2} \cdot \mathrm{s}^{-1}\right)$ & Reference \\
\hline $\mathrm{Sc}$ & $1.98 \times 10^{-17}$ & {$[15]$} \\
\hline $\mathrm{Zr}$ & $1.2 \times 10^{-20}$ & {$[15]-[17]$} \\
\hline $\mathrm{Si}$ & $3.5 \times 10^{-13}$ & {$[18]$} \\
\hline $\mathrm{Cu}$ & $1.5 \times 10^{-15}$ & {$[19]$} \\
\hline $\mathrm{Mg}$ & $9.4 \times 10^{-15}$ & {$[15]$} \\
\hline
\end{tabular}

During artificial aging of Al-Sc-Zr alloys, Sc-rich precipitates nucleate first due in part to the higher diffusivity of Sc (Table 1.1). The Sc-rich precipitates then provide nucleation sites for $\mathrm{Al}_{3}\left(\mathrm{Sc}_{1-\mathrm{x}} \mathrm{Zr}_{\mathrm{x}}\right)$ forming an inhomogeneous "core-shell" structure [20]-[22]. Given as a smaller lattice mismatch of the $\mathrm{Zr}$ trialuminide $(+0.75 \%)$ and slower $\mathrm{Zr}$ diffusivity, the core-shell $\mathrm{Al}_{3}(\mathrm{Sc}, \mathrm{Zr})$ exhibits better coarsening resistance than $\mathrm{Al}_{3} \mathrm{Sc}$ [3], 
[4]. This coarsening resistance and increased strength levels have been reported in multiple studies [5], [10], [11], [14], [23].

\subsection{Precipitate strengthening mechanisms}

Several strengthening mechanisms in aluminum alloys are reviewed with respect to their impact on the Al-Sc-Zr systems at ambient and elevated temperatures. These strengthening mechanisms include mismatch and coherency strengthening, order strengthening and Orowan strengthening at ambient temperature; as well as dislocation and diffusional creep at elevated temperatures.

\subsubsection{Strengthening at ambient temperature}

A large number of nanometer-sized precipitates that nucleate and grow with aging contribute to alloy strengthening. Precipitate strengthening by impeding dislocations can occur through shearing, bypass via looping, or a combination of these two mechanisms depending on precipitate size and structure. Precipitate shearing is more likely with coherent and small precipitates, such as those in Al-Sc-Zr alloys. When dislocations glide toward precipitates, coherency and modulus strengthening $\left(\Delta \sigma_{\text {coh }}+\Delta \sigma_{\text {mod }}\right)$ quantify the effects of shear modulus and strain field strengthening as dislocations cut precipitates [24].

$$
\begin{array}{cc}
\Delta \sigma_{c o h}=\chi M\left(\epsilon G_{A l}\right)^{3 / 2}\left(\frac{R f}{0.18 G_{A l} b}\right)^{1 / 2} & \text { Equation } 1.1 \\
\Delta \sigma_{\text {mod }}=0.0055 M\left(G_{p}-G_{A l}\right)^{3 / 2}\left(\frac{2 f}{G_{A l} b^{2}}\right)^{1 / 2}\left(\frac{R}{b}\right)^{0.275} & \text { Equation } 1.2
\end{array}
$$

where $\chi=2.6$ is a constant fit for the average effect of all the precipitates in the crystal [24], $\epsilon$ is the lattice mismatch approximated by two-thirds $\delta$, where $\delta$ is the lattice parameter mismatch and is $1.3 \%$ for the $\mathrm{Al}_{3}\left(\mathrm{Sc}_{1-\mathrm{x}} \mathrm{Zr}_{\mathrm{x}}\right)$ precipitates estimated based on composition-dependent lattice parameter [13], [14]. $M$ is the Taylor mean orientation factor of 3.06 for multicrystalline $\mathrm{Al}$ [25], $G_{p}$ and $G_{A l}$ are the shear modulus of the 
particle and aluminum in GPa, $f$ is the precipitate volume fraction, $R$ is the precipitate radius, and $b$ is the magnitude of the Al Burger's vector.

When dislocations cut through ordered particles, order strengthening becomes the dominant strengthening mechanism for dislocations interacting with antiphase boundaries (Equation 1.3) [24], [25].

$$
\Delta \sigma_{\text {ord }}=0.44 M G_{p} \frac{\gamma_{A P B}}{b} f^{1 / 2} \quad \text { Equation } 1.3
$$

where $\gamma_{A P B}$ is the precipitate antiphase boundary energy in $J / \mathrm{m}^{2}$ for the close-packed (111) planes since this is the dominant slip plane in FCC materials.

For precipitate radii larger than $2-3 \mathrm{~nm}$, the strength enhancement of $\mathrm{Al}-\mathrm{Sc}-\mathrm{Zr}$ alloy is the result of the Orowan mechanism [26], which is estimated as:

$$
\begin{array}{cc}
\Delta \sigma_{\text {Orowan }}=M \cdot \frac{0.4 \cdot G_{A l} \cdot b}{\pi \sqrt{1-v}} \cdot \frac{\ln \left(\frac{2 \bar{R}}{b}\right)}{\lambda_{e-e}} & \text { Equation } 1.4 \\
\text { where } \lambda_{e-e}=2 \bar{R}\left(\sqrt{\frac{2 \pi}{3 f}}-\frac{\pi}{2}\right) &
\end{array}
$$

where $\bar{R}=\sqrt{2 / 3 * R}$ is the mean precipitate radius in a random plane [26]. The edge-toedge inter-precipitate spacing $\lambda_{e-e}$ is defined by the mean precipitate radius and precipitate volume fraction [24], [25], [27]. The weakest mechanism is active (Table 1.2).

Table 1.2. Summary of the dominant precipitation strengthening and work hardening in the melt-spun ribbon and extruded rod.

\begin{tabular}{c|c|c}
\hline $\begin{array}{c}\text { Strengthening } \\
\text { contribution }\end{array}$ & Mechanism & Reference \\
\hline $\begin{array}{c}\text { Coherency and } \\
\text { Modulus }\end{array}$ & $\begin{array}{c}\text { Dislocation interaction with precipitate shear } \\
\text { modulus and strain field before contact with } \\
\text { precipitate }\end{array}$ & $\begin{array}{c}{[13],[14],} \\
{[24]}\end{array}$ \\
\hline Order & $\begin{array}{c}\text { Dislocation interaction with antiphase } \\
\text { boundary }\end{array}$ & {$[24],[25]$} \\
\hline Orowan & Dislocation plastic deformation & {$[26]$} \\
\hline
\end{tabular}




\subsubsection{Strengthening at elevated temperature}

When a sample plastically deforms at higher strain rates (typically $>10^{-3} s^{-1}$ ) at elevated temperature [28], precipitate strengthening in the form of dislocation shearing and looping is still active, though the temperature-dependent shear modulus $\partial \mathrm{G} / \partial \mathrm{dT}=-13.6 \mathrm{MPa} . \mathrm{K}^{-1}$ (for Al) [28] and Young's modulus $\partial \mathrm{E} / \partial \mathrm{T}=-26 \mathrm{MPa} \cdot \mathrm{K}^{-1}$ (for $\mathrm{Al}_{3} \mathrm{Sc}$ ) [29] will decrease with rising temperature.

At stresses smaller than the yield stress at elevated temperatures, slow permanent deformation is described as creep. Unlike brittle deformation, creep of a material depends on the applied stress and duration. The steady-state strain rate is determined as $\partial \varepsilon / \partial \sigma$ in the secondary stage of the creep plot. The relationship between strain rate $\dot{\varepsilon}$ and applied stress $\sigma$ is described in the general power-law equation as [28]:

$$
\dot{\varepsilon}=A \sigma^{n} \exp \left(-\frac{Q_{c}}{R_{g} T}\right) \quad \text { Equation } 1.5
$$

where $A$ is the Dorn constant determined by the material and microstructure, $n$ is the stress exponent, $Q_{c}$ is the creep activation energy, $R_{g a s}$ is the gas constant and $T$ is the creep temperature. A matrix exponent $n=4.4$ is observed in annealed Al [28]. Some alloys show larger stress exponent than $\mathrm{n}=4.4$, and this increase is explained by the introduction of threshold stress $\sigma_{t h}$, below which the strain rate is not measurable in laboratory. Thus, the modified-power law equation becomes [30]:

$$
\dot{\varepsilon}=A\left(\sigma-\sigma_{t h}\right)^{n} \exp \left(-\frac{Q_{c}}{R_{g} T}\right) \quad \text { Equation } 1.6
$$

\subsection{Effect of solidification rate on solute solubility}

A highly supersaturated homogeneous solid solution of Al-Sc-Zr would provide better artificial aging than a more dilute supersaturation. Achieving high supersaturation in solid metals is difficult using general cooling techniques such as water quench and air cooling due to the limited cooling rate and the cooling rate will decrease dramatically away from the cooling surface [31]. High supersaturation can be achieved by rapid solidification 
techniques such as melt spinning. The Aziz-Kaplan continuous growth models (CGM) [32] states the relationship between the velocity $v$ of the interface and the Gibbs free energy $\Delta G_{e f f}$ change of solidification with temperature, thus affecting the partition coefficient $k$ of solute in the matrix (Equation 1.7\&1.8).

$$
\begin{array}{cc}
v=\frac{v_{c}\left(T_{i}\right)}{R T_{i}}\left(-\Delta G_{e f f}\right) & \text { Equation } 1.7 \\
k=\frac{k_{e}+v / v_{D}}{1+\frac{v}{v_{D}}-\left(1-k_{e}\right) X_{L}} & \text { Equation } 1.8
\end{array}
$$

where $v_{c}\left(T_{i}\right)$ is a kinetic coefficient, $T_{i}$ is the interface temperature, $k_{e}$ is the equilibrium partitioning parameter, $v_{D}$ is the diffusive coefficient, and $X_{L}$ is the molar fraction of the liquid phase. Based on the CGM continuous growth model, the solute concentration in matrix will increase as the solidification rate increases.

The amount of solute in solution can be increased by rapid solidification and powder metallurgy processes [33]-[38]. For Zr, the concentration was increased above equilibrium solubility up to 1.5 at. $\%$ with rapid solidification at rates higher than $10^{5} \mathrm{~K} / \mathrm{s}$ [33]. During melt spinning, the homogeneous melt is ejected on to a spinning copper wheel, and rapidly solidifies as a thin ribbon. A large number of $\mathrm{Al}_{3} \mathrm{Zr}$ precipitates formed in these alloys and the mechanical properties and coarsening resistance were increased at elevated temperatures [33]-[37]. Atomic motion of solute is suppressed at high solidification rates increasing a range of solute concentrations (Figure 1.1). Additionally, precipitates are distributed more homogeneously due to the fine grain structure and shortened nucleation duration. 


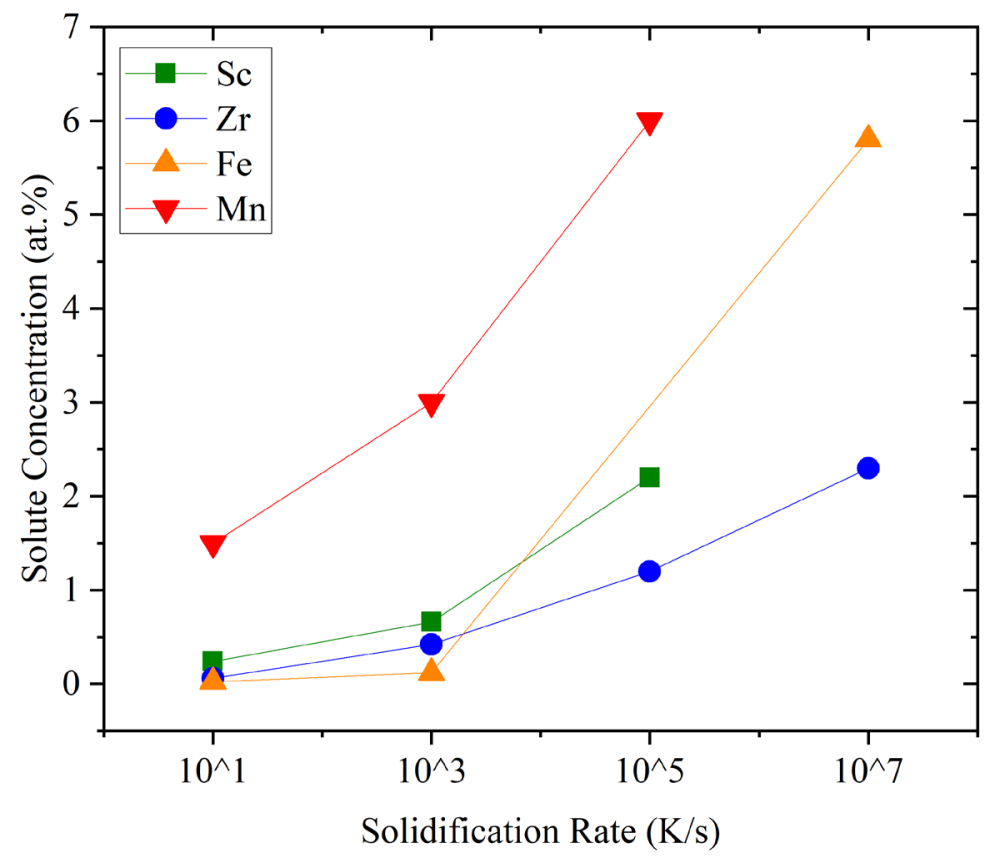

Figure 1.1. The solute concentration in rapidly solidified binary Al-X alloys [23].

\subsection{Effect of extrusion on material properties}

Melt-spinning followed by extrusion has been demonstrated to increase solute concentration in various aluminum alloys containing $\mathrm{L}_{12}$-ordered phase [38]-[43]. Beneficial aspects of extrusion include: (I) grain size refinement [40], [42]; (II) faster diffusion paths between adjacent precipitate particles from dislocations formed during plastic deformation [38]; and (III) slightly enhanced precipitate nucleation due to deformation-induced defects [43]. These features increased the alloys' mechanical properties dramatically.

The grain size is decreased after extrusion processing, which will decrease dislocation movement within grains and reduce dislocation pile-ups [44]. The strengthening difference brought by grain size change is described by Hall-Petch strengthening, $\Delta \sigma_{H P}$, using:

$$
\Delta \sigma_{H P}=K \Delta d^{1 / 2}
$$

Equation 1.9 
where $K=30 \mathrm{MPa} \cdot \mu \mathrm{m}^{1 / 2}$ for pure $\mathrm{Al}$ over the range of $30 \mu \mathrm{m}$ to $500 \mu \mathrm{m}$ [45] and $\Delta d$ is the grain size change.

With smaller grain size and higher dislocation density from extrusion, the distance from precipitates particles to fast diffusion pathways such as grain boundaries and dislocation cores will decrease. The shorter paths will not only shorten diffusion distance [46], but also accelerate solute transportation leading to lower activation energies in these domains [44]. In that way, each stage of precipitate evolution can be accelerated.

\subsection{Precipitate coarsening in Aluminum alloys}

The diffusion-controlled coarsening of precipitate radius, $R\langle t\rangle$, as a function of annealing time was first modeled for binary alloys using the approach of Lifshitz-Slyozov-Wagner (LSW) [47], [48].

$$
\langle R(t)\rangle^{3}-\langle R(0)\rangle^{3}=\frac{8 D c_{\alpha}^{e} \gamma V_{m}}{9 R_{g a s} T} t \quad \text { Equation } 1.10
$$

where $D$ is the diffusion coefficient of solute, $c_{\alpha}^{e}$ is the equilibrium solubility in the $\alpha-\mathrm{Al}$ matrix, $\gamma$ is the interfacial energy, $V_{m}$ is the molar volume of a precipitate, $R_{g a s}$ is the gas constant and $T$ is the coarsening temperature. The LSW model assumes: (i) the precipitates are spherical and fixed, (ii) only works for dilute alloy (precipitate volume fraction $V_{f} \sim 0$ ), and (iii) precipitates coarsen at a fixed volume fraction. Based on the initial LSW framework, a new model was proposed to describe a dilute multi-component alloy coarsening by Umantsev and Olson [49], in which steady-state coarsening of ternary alloys with capillary effects was developed by Kuehman and Voorhees [50]. The UOKV model describes the precipitate radius and particle number density evolution with annealing for ternary alloys assuming off-diagonal diffusion coefficients are zero [50]. The mean precipitate radius, $\langle R(t)\rangle$, increases from $\langle R(0)\rangle$ at $t=0$ with annealing time as:

$$
\begin{aligned}
\langle R(t)\rangle^{3}-\langle R(0)\rangle^{3} & \\
= & \frac{8 \gamma V_{m}}{9 R_{g a s} T\left[\frac{C_{S c}^{\alpha}\left(1-k_{S c}\right)^{2}}{D_{S c}}+\frac{C_{Z r}^{\alpha}\left(1-k_{Z r}\right)^{2}}{D_{Z r}}\right]} t \quad \text { Equation } 1.11
\end{aligned}
$$


where $V_{m}$ is the molar volume of the precipitate, $C_{i}^{\alpha}$ is the composition of solute $i$ in the $\alpha$-Al matrix, $k_{i}$ is the distribution coefficient of $i$ th component in the precipitate and matrix defined as $C_{i}^{\beta} / C_{i}^{\alpha}$, and $D_{i}$ is the diffusion coefficient of the $i$ th solute in the $\alpha-\mathrm{Al}$ matrix. The precipitate density, $N_{f}(t)$, changes with annealing as:

$$
N_{f}(t) \cong \frac{R_{g a s} T V_{f}\left[\frac{C_{S c}^{\alpha}}{D_{S c}}\left(1-k_{S c}\right)^{2}+\frac{C_{Z r}^{\alpha}}{D_{Z r}}\left(1-k_{Z r}\right)^{2}\right]}{4.21 \gamma V_{m}} t^{-1} \quad \text { Equation } 1.12
$$

where $V_{f}$ is the volume fraction of the precipitates. According to Equation 1.11 and Equation 1.12, the precipitate radius change during coarsening is determined by solute distribution and diffusivity.

\section{Chapter 2. Experimental}

Supersaturated alloys were produced with melt spinning and evaluated in the as-produce and extruded condition. The largest solute composition without primary precipitate formation was determined to be Al-0.4Sc-0.4Zr at \% (Figure 2.1). The melt-spun ribbon and extruded rod microstructure and mechanical properties were evaluated at ambient and elevated temperatures.

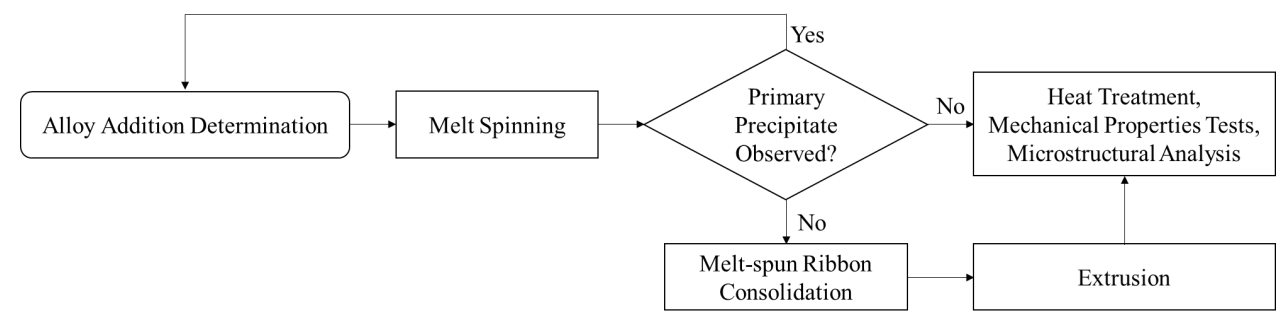

Figure 2.1. Flow chart of the experiment design to produce, characterize and mechanically test supersaturated Al-Sc-Zr melt-spun ribbon and extruded rod. 


\subsection{Experimental processing}

The supersaturated melt-spun ribbon and extruded rod were produced by melt spinning, followed by ribbon consolidation and extrusion. A dilute $\mathrm{Al}-0.06 \mathrm{Sc}-0.06 \mathrm{Zr}$ at. \% was conventionally cast using Vacuum Induction Melting (VIM) for comparison. The composition of the $\mathrm{Al}-0.4 \mathrm{Sc}-0.4 \mathrm{Zr}$ at $\%$ melt-spun ribbon, extruded rod and $\mathrm{Al}-0.06 \mathrm{Sc}-$ $0.06 \mathrm{Zr}$ at $\%$ were determined by inductively coupled plasma mass spectrometry (ICP-MS) (Lehigh Testing Laboratories, DE) (Table 2.1).

Table 2.1. Composition of the $\mathrm{Al}-0.4 \mathrm{Sc}-0.4 \mathrm{Zr}$ at $\%$ melt-spun ribbon, extruded rod and Al-0.06Sc-0.06Zr at $\%$ dilute alloy.

\begin{tabular}{l|c|c|c|c|c|c|c|c}
\hline & \multicolumn{6}{|c|}{ Nominal composition (at\%) } & \multicolumn{3}{|c}{ Verified composition (at\%) } \\
\hline & $\mathrm{Sc}$ & $\mathrm{Zr}$ & $\mathrm{Si}$ & $\mathrm{Fe}$ & $\mathrm{Sc}$ & $\mathrm{Zr}$ & $\mathrm{Si}$ & $\mathrm{Fe}$ \\
\hline $\begin{array}{l}\text { Al-0.4Sc-0.4Zr melt- } \\
\text { spun ribbon }\end{array}$ & 0.4 & 0.4 & - & - & 0.44 & 0.41 & 0.019 & $\begin{array}{c}0.0 \\
24\end{array}$ \\
\hline $\begin{array}{l}\text { Al-0.4Sc-0.4Zr } \\
\text { extruded rod }\end{array}$ & 0.4 & 0.4 & - & - & 0.43 & 0.38 & $<0.019$ & $\begin{array}{c}0.0 \\
24\end{array}$ \\
\hline Al-0.06Sc-0.06Zr & 0.06 & 0.06 & - & - & 0.05 & 0.06 & $<0.019$ & $\begin{array}{c}0.0 \\
15\end{array}$ \\
\hline
\end{tabular}

The detailed experimental operations are presented in the following subsections. Several technical challenges are discussed including modifications to the melt spinning and ribbon compaction process.

\subsubsection{Vacuum Induction Melting Casting}

The dilute $\mathrm{Al}-0.06 \mathrm{Sc}-0.06 \mathrm{Zr}$ at $\%$ alloy was conventionally processed by melting in the VIM and casting into a permanent candelabra mold (Figure 2.2(a)). The $620 \mathrm{~g}$ charge consisted of $99.99 \%$ pure $\mathrm{Al}$ (Belmont Metals) with $\mathrm{Al}-2 \mathrm{Sc}$ wt $\%$ and $\mathrm{Al}-10 \mathrm{Zr}$ wt $\%$ master alloys (KBM) in a graphite crucible with $\sim 150 \mathrm{~mm}$ height and $\sim 60 \mathrm{~mm}$ interior diameter (Figure 2.2(b)). 

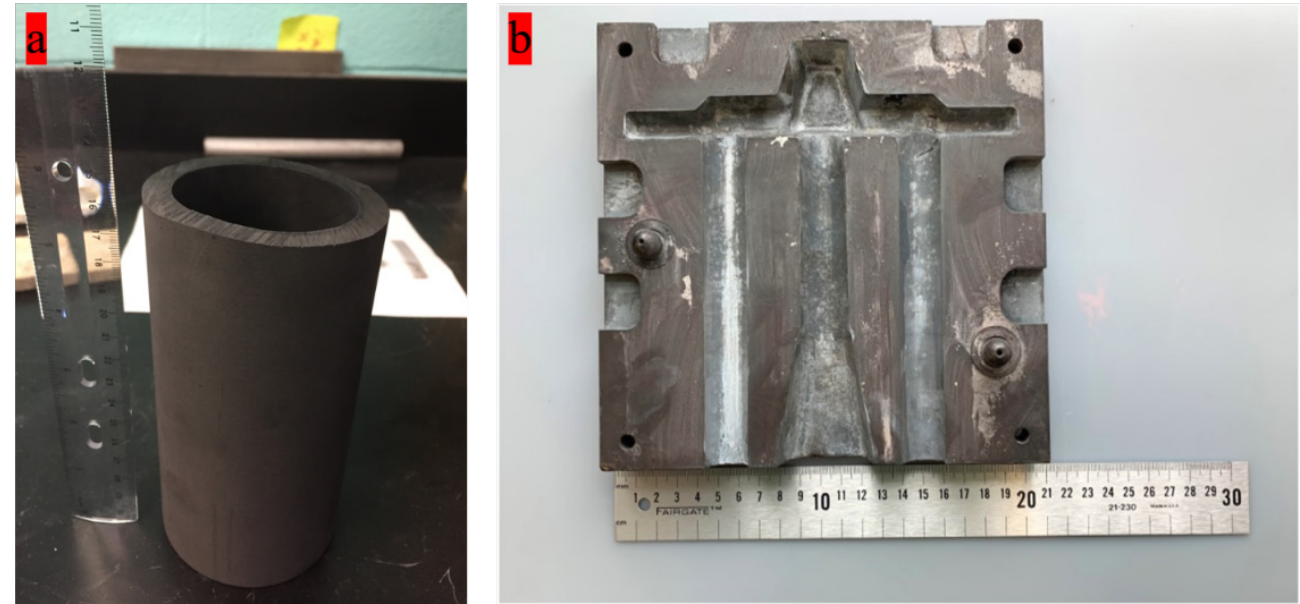

Figure 2.2. VIM processing with (a) graphite crucible and (b) candelabra mold (half) for two $19 \mathrm{~mm} \varnothing$ rods.

The loaded crucible was placed inside the induction coil which is actuated through the chamber via a lever handle (Figure 2.3). The melt temperature was monitored using an Accufiber HF-3 optical pyrometer through a quartz viewport above the crucible. The mold was placed on the plate aligned with the pouring stream center.

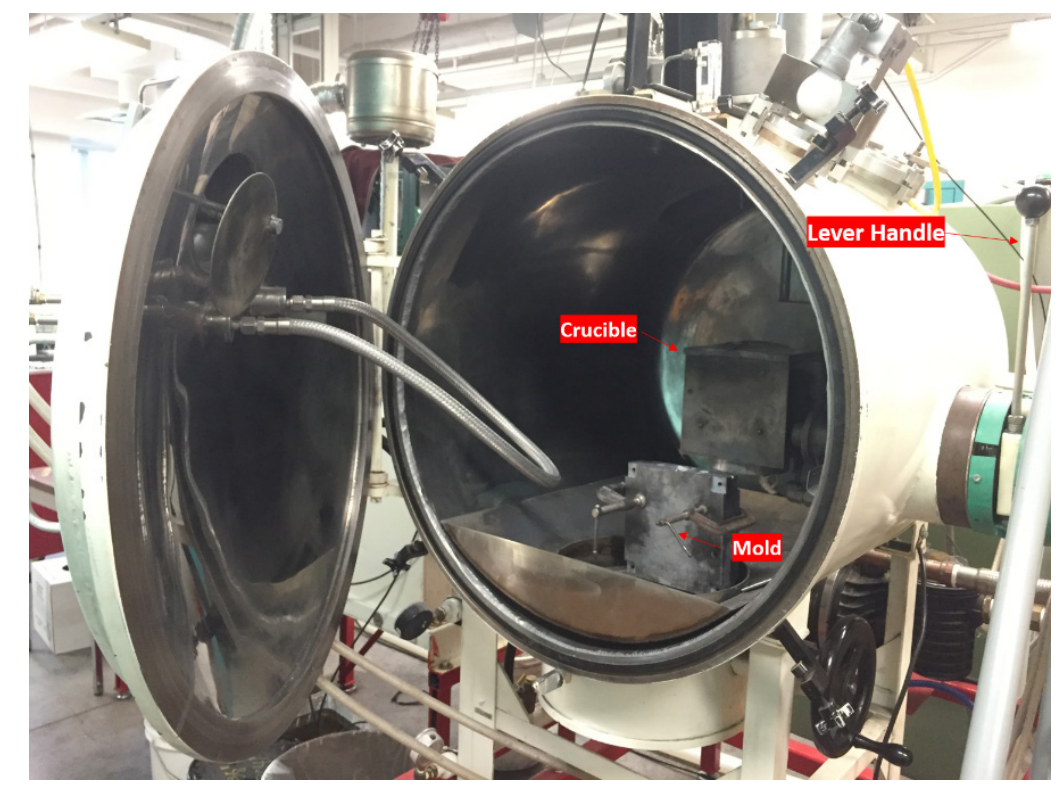

Figure 2.3. The graphite crucible was loaded inside of the coils which controlled by a lever handle. The position of mold on the plate is aligned to the pouring stream's position. 
The chamber was rough pumped to $10^{-2}$ Torr and then reached $3 \times 10^{-4}$ Torr using a diffusion pump. The induction power supply was held at $5 \mathrm{kw}$ during the heating. After the materials were warmed above $400^{\circ} \mathrm{C}$, the temperature reading started to display on the meter and the chamber was then backfilled to 680 Torr with $99.99 \%$ pure argon. It took about $30 \mathrm{~min}$ for the melt to reach $900^{\circ} \mathrm{C}$ and then it was held for 10 minutes before pouring into the permanent mold.

\subsubsection{Melt spinning}

The melt spinner consists of three major parts: induction heating coils, a crucible and a copper wheel all sealed in the vacuum chamber (Figure 2.4(a)). The temperature was monitored with a Micro-Epsilon ratio pyrometer ( $0.5 \%$ accuracy, $5 \mathrm{~ms}$ response time) targeting the crucible from directly above the crucible through a quartz viewport. The melt spinner chamber is connected to a glove box with a tube that collects most of the solidified ribbon. The tube is sealed with a hatch valve on the glove box side (Figure $2.4(b, c))$.
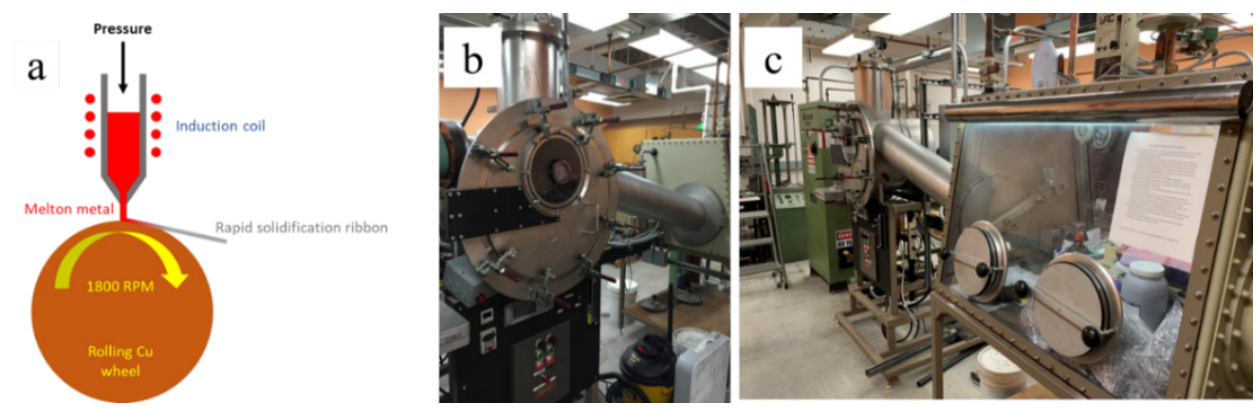

Figure 2.4. (a) Schematic of melt spinner consists of heating coils, crucible and copper wheel; (b) all parts mentioned above are sealed in the chamber; (c) the melt spinner chamber is connected to a glove box through a tube.

The crucible for material melting can be from quartz, graphite or ceramic materials. The quartz and graphite crucibles are most commonly used in the laboratory due to their low cost. Quartz and graphite crucibles have their own pros and cons according to the properties of the melting materials (Table 2.2). 
Table 2.2. A summary of the comparisons between quartz and graphite crucibles.

\begin{tabular}{ccc}
\hline Crucible type & Pros & Cons \\
\hline Quartz & $\begin{array}{c}\text { Fast heating; low cost; } \\
\text { variable orifice size }\end{array}$ & $\begin{array}{c}\text { Not reusable; limited load } \\
\text { capacity; possible silicon } \\
\text { contamination from quartz }\end{array}$ \\
\hline Graphite & $\begin{array}{c}\text { Large capacity; } \\
\text { homogeneous heating; } \\
\text { reusable }\end{array}$ & $\begin{array}{c}\text { Less temperature } \\
\text { measurement accuracy; } \\
\text { Heating resource disturb on } \\
\text { the copper wheel }\end{array}$ \\
\hline
\end{tabular}

Graphite crucibles with $1 \mathrm{~mm} \varnothing$ nozzle orifices were utilized for melt spinning. A conical tip shortens the distance from orifice to the wheel increasing cooling rate (Figure 2.5(a)). The $15 \mathrm{~g}$ charge consisted of $99.99 \%$ pure $\mathrm{Al}$ (Belmont Metals) with $\mathrm{Al}-2 \mathrm{Sc} \mathrm{wt} \%$ and $\mathrm{Al}-$ $10 \mathrm{Zr}$ wt $\%$ master alloys (KBM). All materials were cleaned using an ultrasonic ethanol bath to remove cutting fluids. The melt spinner chamber was backfilled to $\sim 320$ Torr with $99.99 \%$ Ar after initially evacuating the chamber to $8 \times 10^{-5}$ torr using rough and diffusion pumps. The loaded crucible was heated to $1100^{\circ} \mathrm{C}$ and held for $1 \mathrm{~min}$. The melt was then ejected by applying argon pressure and the metal sprayed out as a thin ribbon ( $\sim 50 \mu \mathrm{m}$ thick as shown in Figure 2.5(c)) onto the $30 \mathrm{~cm} \varnothing$ rotating copper wheel $(\sim 1500$ RPM, Figure 2.5(b)). To minimize $\mathrm{Al}_{2} \mathrm{O}_{3}$ formation on the melt-spun ribbon surface, the as-produced ribbon was stored under $99.99 \% \mathrm{Ar}$ atmosphere in the glove box attached to the melt spinner chamber.
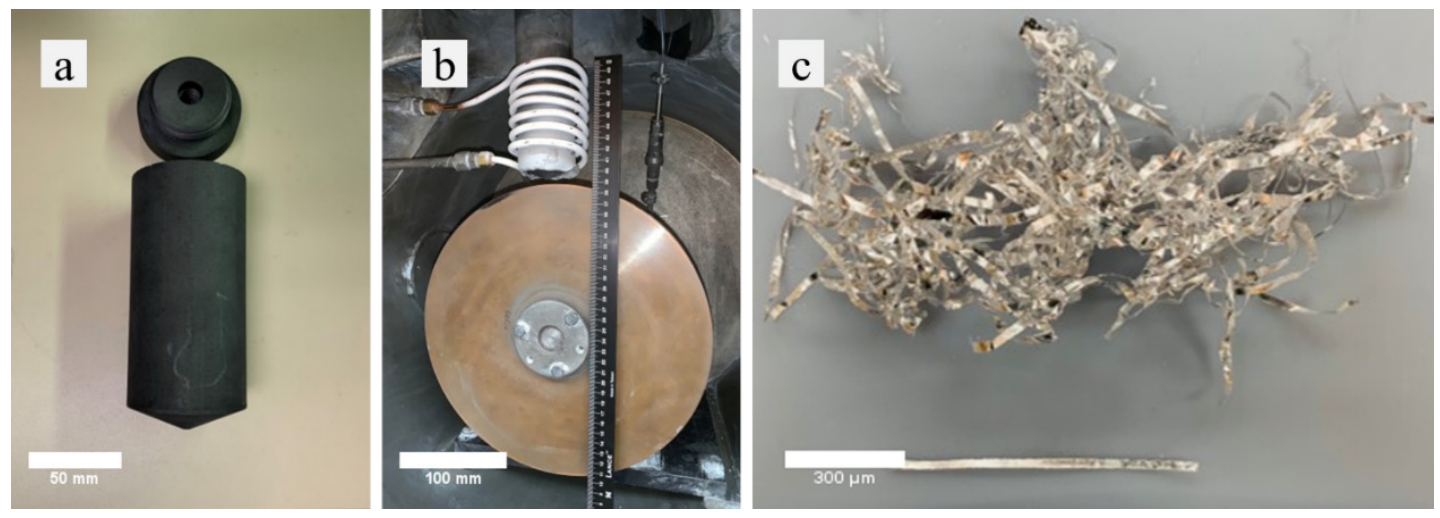
Figure 2.5. Master alloys were heated to $1100^{\circ} \mathrm{C}$ in graphite crucible (a) and ejected on the copper rolling wheel (b). The solidified ribbon was $\sim 3 \mathrm{~mm}$ wide and $\sim 50 \mu \mathrm{m}$ thick (c).

Initialy supersaturated Al-Sc-Zr ribbon was produced using quartz crucibles with a $\sim 25 \mathrm{~mm}$ diameter [51]. It was convenient to load and heat materials using quartz crucible when only several grams of ribbon were produced in each run. Since the compaction and extrusion of the melt-spun ribbon requires a much larger amount of ribbon, it was not efficient to use quartz crucibles. With a graphite crucible, a larger amount of materials can be loaded (up to 50 grams). The graphite crucible consists of a removable cap and cylindrical body with a conical tip so that each part can be replaced separately. The shape of the conical tip shortened the distance from ejected the melt to the copper wheel surface allowing more rapid solidification which will be discussed further in Section 2.1.2.2.

Crucible type and location affects the solidification rate which impacts the melt-spun ribbon morphology and microstructure. Critical parameters include ejection pressure, orifice size and height, and copper wheel rotating velocity (Table 2.3).

Table 2.3. Melt spinner parameters and optimized levels for maximum solute solubility

\begin{tabular}{ccc}
\hline Melt spinner variables & Dependents & Settings \\
\hline Ejection pressure & Solidification rate; ribbon thickness & $0.15 \mathrm{psi}$ \\
Orifice diameter & Ribbon width and thickness & $\sim 1 \mathrm{~mm}$ \\
Orifice height (above & Solidification rate (primary); ribbon & $\sim 10 \mathrm{~mm}$ \\
wheel surface) & width/thickness (secondary) & $1500 \mathrm{RPM}$ \\
Wheel rolling rate & Solidification rate & \\
\hline
\end{tabular}

It was found out that the solidification rate increased with ejection pressure within a range. When the ejection pressure exceeds a critical point, the melt bounces off the wheel forming flakes or drops instead remaining in contact with the rotating wheel and forming a ribbon. 
Smaller orifice diameter reduces the amount of melt ejected onto the wheel per unit time, thus increasing the solidification rate and producing a thinner ribbon. On the contrary, the orifice diameter can be too small leading to no ejection. Since the melt was held at $1100^{\circ} \mathrm{C}$ for $1 \mathrm{~min}$ before ejection, it was desirable to finish ejection as quickly as possible to avoid the graphite crucible heating the copper wheel and thus lowering the temperature difference between the melt and wheel. A shorter distance from orifice to the wheel surface helps minimize melt heat loss during ejection, but also can be detrimental with the hot crucible heating the copper wheel.

Increase the wheel velocity could accelerate the solidification rate by producing a thinner ribbon. However, the solidification rate couldn't be increased past a critical value, as there is insufficient heat extraction due to limited contact time between the melt and the wheel. In summary, variables discussed above have a significant impaction on the ribbon solidification rate. The challenge is finding the process conditions that produce the highest ribbon supersaturation.

\subsubsection{Melt-spun ribbon consolidation}

To get the melt-spun ribbon prepared for extrusion, the ribbon was consolidated into an aluminum 6061 can. The design of the can and the consolidation process is described below.

An aluminum $6061 \mathrm{can}(90 \mathrm{~mm}$ OD and $88.4 \mathrm{~mm}$ ID) sealed by an air-tight stainless steel cap was used as a compaction vessel (Figure 2.6(a)). Additionally, a tool steel support (90 mm ID) was designed to prevent the deformation of the 6061 as the wall thickness was too thin to retain its shape during compression (Figure 2.6(b)). 

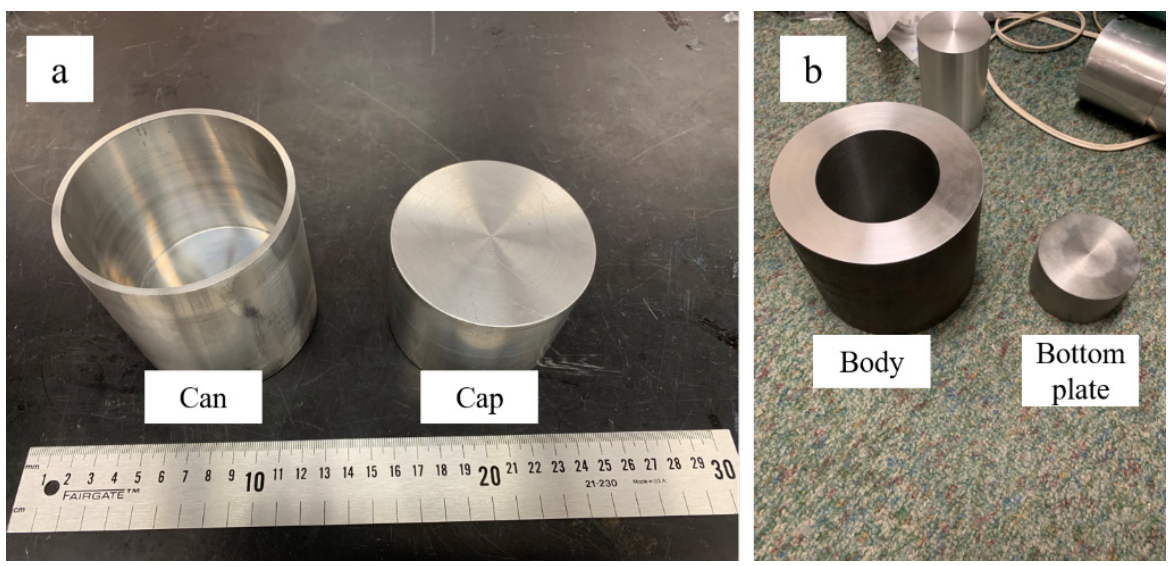

Figure 2.6.The melt-spun ribbon was compacted into the 6061 can and sealed by an airtight stainless steel cap (a). A support tool steel ring and a bottom plate were used to prevent deformation of the 6061 can (b).

To minimize oxidation of the as-produced melt-spun ribbon, the ribbon was compacted using a Carver hydraulic press (10 tons) with $16 \mathrm{MPa}$ pressure while under an argon atmosphere in a glove box (Figure 2.7(a)). Further compaction outside of the glove box was with a Dake press (100 tons) with $160 \mathrm{MPa}$ pressure (Figure 2.7(b)). Any cap extending above the can was cut off using a band saw (Figure 2.7(c)). The resulting ribbon compact density was $\sim 70 \%$ that of the as-cast $\mathrm{Al}-0.06 \mathrm{Sc}-0.06 \mathrm{Zr}$ at $\%$ as determined by the Archimedes method.
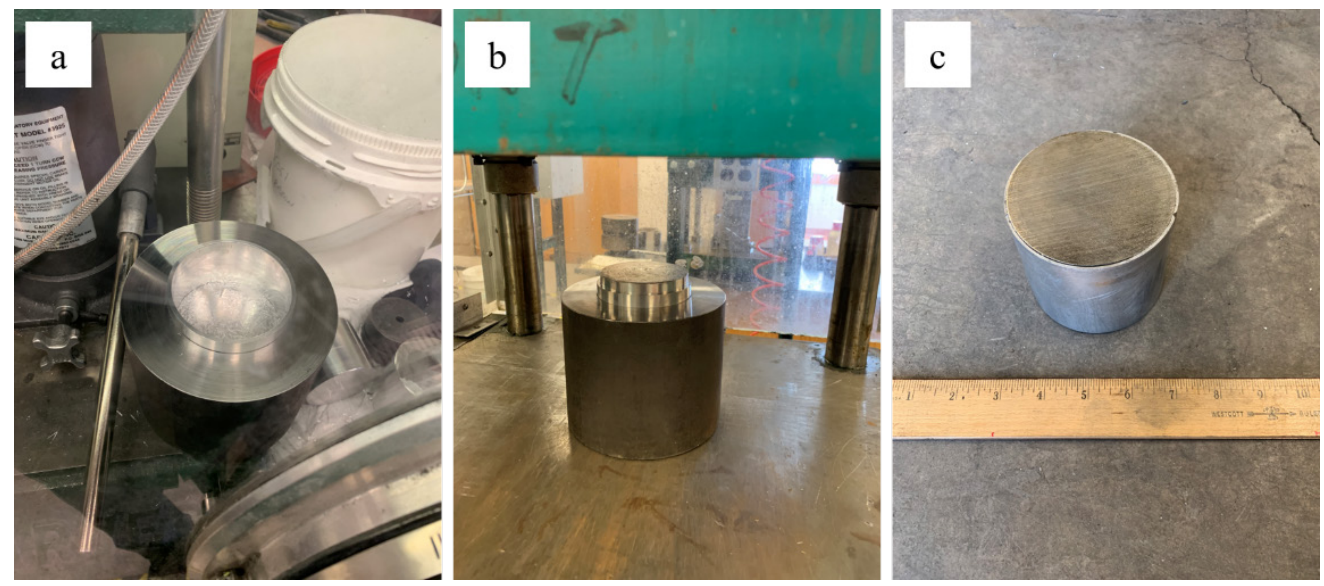

Figure 2.7. The melt-spun ribbon was first compacted using a Carver press in the glove box (a). Then the can was further compacted using a Dake press (b) and excess cap was cut off (c). 


\subsubsection{Ribbon compact extrusion}

Extruded rod was produced through extrusion of ribbon compacted in the $6061 \mathrm{can}$. The chamber and die of the hydraulic extrusion press were preheated at $350^{\circ} \mathrm{C}$ by electric heaters and a furnace respectively. The sealed can was pre-heated at $350^{\circ} \mathrm{C}$ using a fluidized bed (Figure 2.8(a)). The can was partially extruded until the stainless steel cap contacted the extrusion die (Figure 2.8(b)) with $800 \mathrm{MPa}$ of ram pressure.
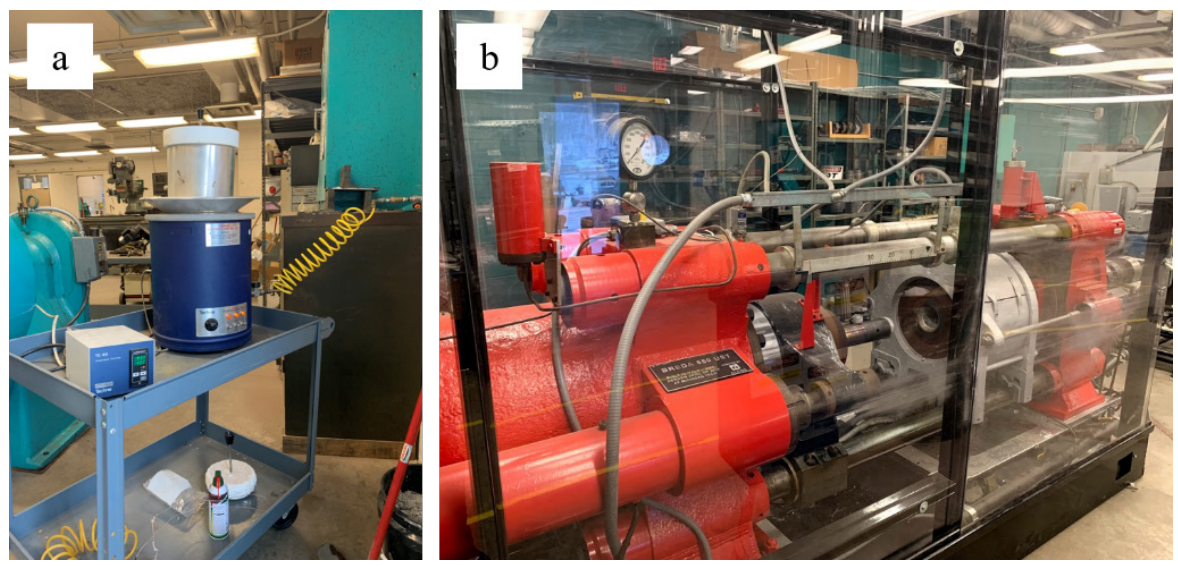

Figure 2.8. The ribbon compact was preheated using a fluidized bed for $5 \mathrm{~h}$ at $350^{\circ} \mathrm{C} \mathrm{(a)}$ and extruded out at the same temperature (b).

The reduction ratio was 49:1 with an exit velocity of $25 \mathrm{~mm} / \mathrm{min}$. The rod was water quenched after extrusion to minimize primary precipitate formation. The measured diameter of the extruded rod was $\sim 12 \mathrm{~mm}$. The image of rod cross-section had a clear boundary between the ribbon and the 6061 aluminum as the two materials didn't mixed during extrudion (Figure 2.9). The final density of the extruded rod was above $98 \%$ that of the as-cast dilute $\mathrm{Al}-0.06 \mathrm{Sc}-0.06 \mathrm{Zr}$ at $\%$ used for comparison. 


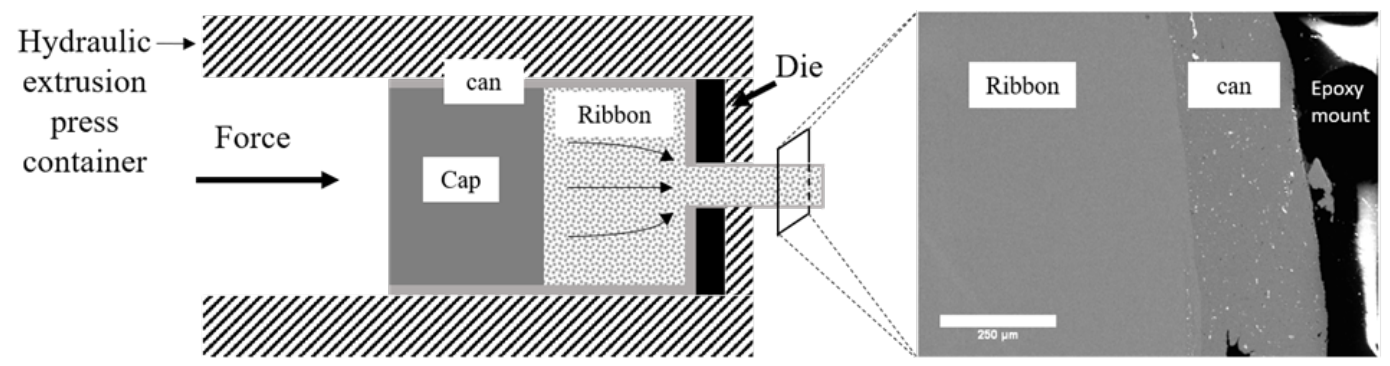

Figure 2.9. Melt-spun ribbon consolidation and extrusion press schematic (left) and typical microstructure (right).

\subsubsection{Heat treatment}

All samples of melt-spun ribbon and extruded rod were peak aged in a two-step heat treatment using a combination of a box furnace and fluidized bed (for quicker heating) (Figure 2.10). The first-step serves to nucleate $\mathrm{Al}_{3} \mathrm{Sc}$ and the second-step promotes the formation of the $\mathrm{Al}_{3} \mathrm{Zr}$ shell [4], [10]. The loose melt-spun ribbon (box furnace) and sealed ribbon compact (fluidized bed) underwent the same initial heat treatment of $350^{\circ} \mathrm{C}$ for $5 \mathrm{~h}$. After the first step, the compacted ribbon was extruded. A second heat treatment was performed with both the melt-spun ribbon and extruded rod held at $400^{\circ} \mathrm{C}$ (box furnace but with aging durations of $1 \mathrm{~h}$ for the melt-spun ribbon and $0.5 \mathrm{~h}$ for the extruded rod due to different peak aging kinetics.

Samples of the melt-spun ribbon and extruded rod were intentionally overaged at $400^{\circ} \mathrm{C}$ for $5 \mathrm{~h}$ to investigate microstructure evolution after peak aging. To study precipitate coarsening in the overaged $\mathrm{Al}-0.4 \mathrm{Sc}-0.4 \mathrm{Zr}$ at $\%$ melt-spun ribbon and extruded rod, all peak-aged samples were overaged at $400^{\circ} \mathrm{C}$ up to $72 \mathrm{~h}$. Samples were taken out from box furnace and water quenched at the after $12 \mathrm{~h}, 24 \mathrm{~h}, 48 \mathrm{~h}$ and $72 \mathrm{~h}$. 


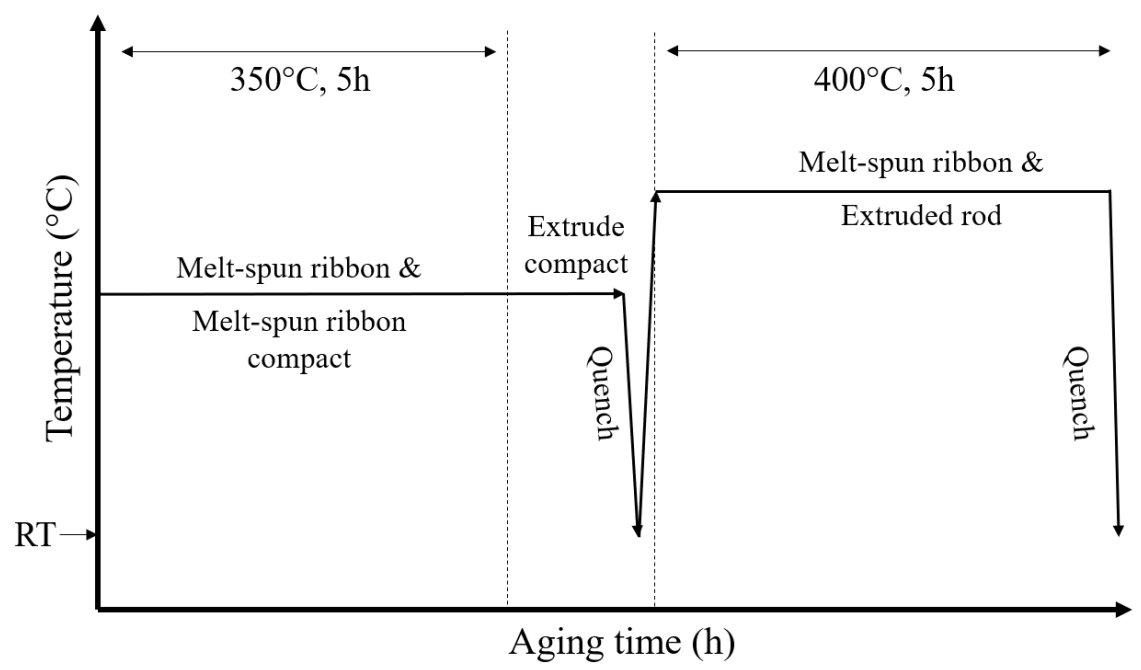

Figure 2.10. The two-step aging heat treatment of the melt-spun ribbon and extruded rod.

Using the same 2-step heat treatment, the hardness of the dilute Al-0.06Sc-0.06Zr at $\%$ alloy reached $\sim 390 \mathrm{MPa}$, which is lower than the peak strength value of $\sim 620 \mathrm{MPa}$ in a previous study [11]. The insignificant strength response of the dilute Al-Sc-Zr alloy has been observed previously and could be due to poor nucleation at $350^{\circ} \mathrm{C}$ and precipitate coarsening at $400^{\circ} \mathrm{C}[10]$. Instead, the dilute $\mathrm{Al}-0.06 \mathrm{Sc}-0.06 \mathrm{Zr}$ at $\%$ alloy was peak-aged at $300^{\circ} \mathrm{C}$ for $15 \mathrm{~h}$.

\subsubsection{Sample preparation}

All specimens for Vickers hardness, nanoindentation and SEM analysis were mounted and polished. The SEM analysis required carbon coating. TEM samples were prepared by a combination of mechanical polishing and electropolishing.

During mounting, the material was positioned at the center of the cupping. The ribbon samples were held on edge with a plastic clip. Quickset epoxy (resin and hardener) was mixed with a ratio of 100:12 and gently poured into the cup. The liquid epoxy worked especially well for clipped ribbon samples as any voids were filled with liquid. The temperature of the epoxy increased slightly $\left(<60^{\circ} \mathrm{C}\right)$ during solidification and it was 
assumed it didn't affect the microstructure. The sample was removed from the mounting cup after $\sim 8$ hours when the epoxy was solid and cool.

\subsubsection{Hardness measurement}

The mounted specimen was first ground using a LECO GR-20 Coarse Grinder with running water. The SIC papers were 400, 600, 800, 1200 grit from coarse to fine respectively. The specimen was ground for $\sim 1 \mathrm{~min}$ at each step with $20 \mathrm{~N}$ load. The ground specimens were polished using a series of diamond paste and finished with a colloidal silica suspension (Table 2.4).

Table 2.4. Fine polishing pads and operations sequence.

\begin{tabular}{cccc}
\hline Sequence & Polishing pad & Suspension & Duration \\
$1^{\text {st }}$ & Allied Final P & Dialube diamond suspensions 6 um & $3 \mathrm{~min}$ \\
$2^{\text {nd }}$ & Allied Final P & Dialube diamond suspensions 3 um & $3 \mathrm{~min}$ \\
$3^{\text {rd }}$ & Allied Final P & Dialube diamond suspensions 1 um & $3 \mathrm{~min}$ \\
$4^{\text {th }}$ & Allied Final B & Colloidal silica suspension 0.04 um & $5 \mathrm{~min}$ \\
\hline
\end{tabular}

Between each step of polishing, the sample was cleaned by ethanol and soap water using a cotton ball and rinsed with water. The final polished sample surface had a mirror finish. The polished samples were capped to protected from dust and scratches.

\subsubsection{Carbon coating}

Before carbon coating, specimens were mounted and polished following the procedures above. Carbon coating provides better electric conductivity and mitigated charging on the surface to improve image quality. Adding carbon tape from the coated surface to the sample holder further improved the image's quality.

\subsubsection{Transmission electron microscopy (TEM)}

Specimens for TEM was prepared by mechanical polishing and electropolishing. First, slices were cut off from bulk materials using wire electrical discharge machining (EDM) to avoid plastic deformation. The Japax LUX3 wire electrical discharge machine was 
used to cut slices from the extruded rod and dilute alloy. The extruded rod was tightly fastened to the plate and cut by with a continuous Bedra Bercocut bronze wire under a distilled water spray. The slices were $0.2 \mathrm{~mm}$ thick without being bent. The wire travel path is defined by G-code input and the travel distance is determined by the material size. Parameters used for the aluminum alloys are listed in Table 2.5.

Table 2.5. EDM settings for sample cutting

\begin{tabular}{cc|cc}
\hline Parameters & values & Parameters & values \\
$\mathrm{T}_{\text {off }}$ & 10 & $\mathrm{~V}_{\mathrm{s}}$ & 4 \\
$\mathrm{~T}_{\text {on }}$ & 4 & $\%$ & 100 \\
$\mathrm{I}_{\mathrm{o}}$ & 3 & Feed & 10 \\
$\mathrm{~V}$ & 4 & Tension & 6 \\
$\mathrm{~F}$ & 0.4 & & \\
\hline
\end{tabular}

Three (3) $\mathrm{mm} \varnothing$ discs were punched from the $0.2 \mathrm{~mm}$ thick slices. The disc samples were mechanically polished to thinner than $0.1 \mathrm{~mm}$ before electropolishing. SIC papers (400, 600,800 and 1200 grit) were used for polishing on both sides of the disc. The sample was cleaned using distilled water and rinsed after each step. The electropolisher consists of three parts: a nitride liquid container, a thinning cell and a Metalthin controller (Figure 2.11). The electrolyte used was a 1:4 mixture of reagent grade nitric acid to reagent grade methanol. The general electropolishing process was summarized below:

- Prepare electrolyte and pour into the tank

- Fill nitride liquid container and start the electrolyte cooling

- Load the sample in the holder when the temperature of electrolyte is below $-40^{\circ} \mathrm{C}$

- Start the electropolishing

- Take sample out and clean using methanol after polishing 


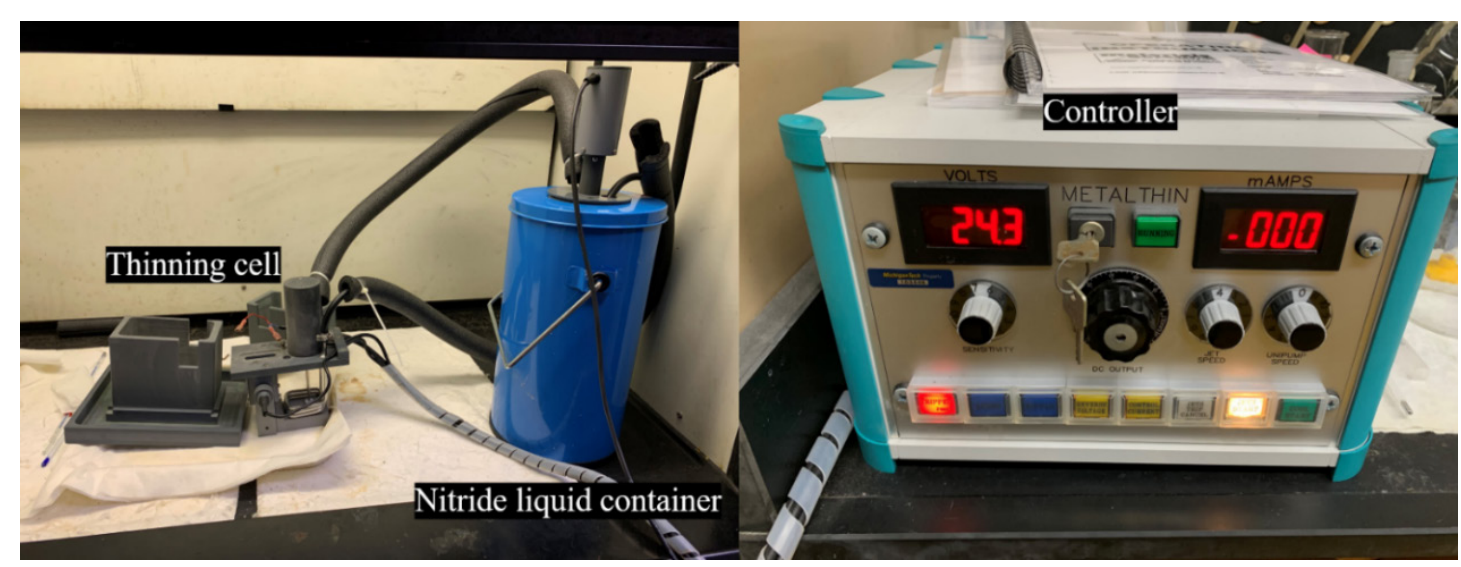

Figure 2.11. Configurations of electropolisher consists of nitride liquid container, thinning cell and Metalthin controller. The nitride liquid container and thinning cell are located under the hood with the Metalthin controller next to the hood.

The temperatures of the electrolyte was maintained within the range of $-60^{\circ} \mathrm{C}$ to $-40^{\circ} \mathrm{C}$ by adjusting the Unipump Speed. An ideal polished specimen has a small hole around the center of the disc with a mirror-like surface for both sides. The electropolishing settings of the alloys in this research are listed in Table 2.6.

Table 2.6. Metalthin controller settings for melt-spun ribbon, extruded rod and dilute

\begin{tabular}{cc}
\multicolumn{2}{c}{ alloy } \\
\hline Settings & Value \\
Voltage (V) & 25 \\
Sensitivity & $\sim 7$ \\
Jet speed & 4 \\
\hline
\end{tabular}

\subsection{Analytical techniques}

The mechanical behavior of dilute Al- $0.06 \mathrm{Sc}-0.06 \mathrm{Zr}$ at $\%$ and supersaturated extruded rod were evaluated by Vickers hardness and tensile, hot compression and creep testing. The mechanical properties of the supersaturated melt-spun ribbon were measured using Vickers hardness and nanoindentation. Primary precipitates were identified using SEM. The grain size, precipitate radius, precipitate number density, dislocation density, precipitate chemical composition and precipitate distribution in the specimen were measured using TEM/STEM. 


\subsubsection{Vickers hardness testing}

The hardness of the melt-spun ribbon and extruded rod were measured in cross-section using a $25 \mathrm{~g}$ load and $15 \mathrm{~s}$ dwell time with 10 measurements per sample.

\subsubsection{Hot hardness testing}

The hardness of the extruded rod and dilute alloy were measured using a Vickers macroindenter (Figure 2.12). A motorized copper plate with two cartridge heaters was heated up to $500^{\circ} \mathrm{C}$. The polished sample was preheated at the desired temperature for 0.5 $\mathrm{h}$ and tested with a $5 \mathrm{~kg}$ load and $5 \mathrm{~s}$ dwell time with 10 measurements per sample.

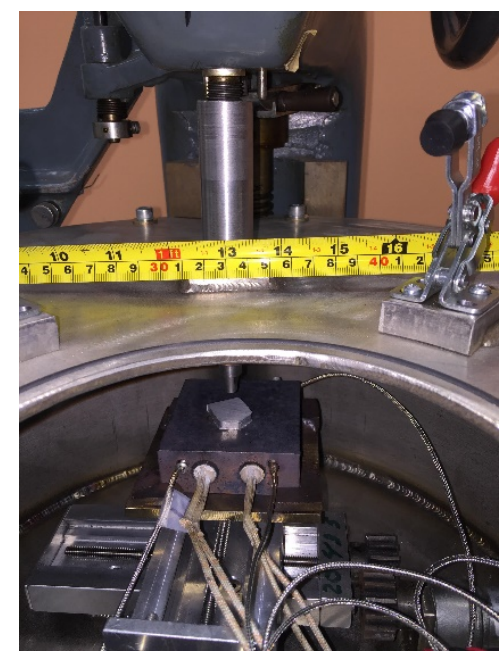

Figure 2.12. Sample preheated on the copper plate with two cartridge heaters.

\subsubsection{Tensile testing}

The tensile strength of the peak-aged extruded rod and dilute alloy were measured at room temperature at a strain rate of $3 \times 10^{-3} \mathrm{~s}^{-1}$. Specimens were machined from the peak-aged extruded rod and VIM cast round tensile bars according to ASTM E8M-04 standard respectively. The gauge length and diameter were $45 \mathrm{~mm}$ and $9 \mathrm{~mm}$ respectively. 


\subsubsection{Hot compression testing}

The compression test is an alternative ultimate strength test method that requires less material than a tensile test. The cylinder sample was machined from the extruded rod and dilute VIM cast with a height:diameter of 2:1. The height was $8 \mathrm{~mm}$ and the diameter was $4 \mathrm{~mm}$. The compression test was done with an MTS instrumented Intron 4206 load frame (Figure 2.13 (a)). The top and bottom platens were heated by a tube furnace (Figure $2.13(b)$ ).

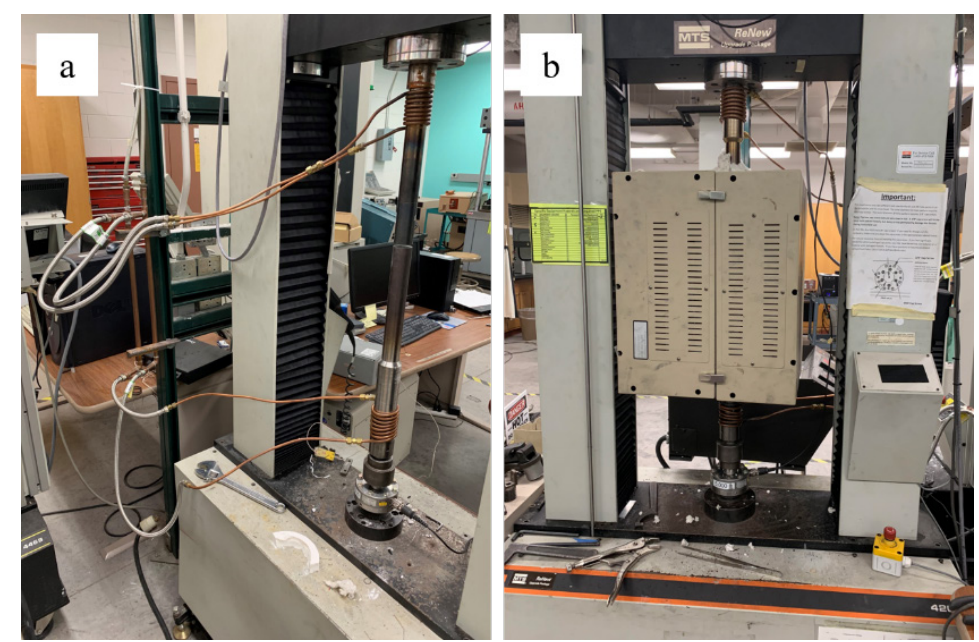

Figure 2.13. Configuration of compression test with compression platens and samples preheated with a tube furnace.

The compression platens were kept in contact during preheating to minimize the temperature difference between them. The temperature of the plate was monitored by a thermocouple attached to the connecting place. The temperature had good agreement with the furnace setting $\left( \pm 1^{\circ} \mathrm{C}\right)$. The compressive strength was measured at a strain rate of $3 \times 10^{-3} \mathrm{~s}^{-1}$. The general testing process was summarized below:

- Set up the load cell (5000 N) and top and bottom platens on the MTS Instron 4206 tester

- Move top and bottom plate into contact

- Preheat plates at the testing temperature for several hours

- Load and preheat the specimen for $40 \mathrm{~min}$ 
- Get specimen and top plate contacted

- Zero the load signal and start the test

\subsubsection{Creep testing}

The load frame and specimen used for the creep test were the same as the compression test specimen (Section 2.2.5) at $300^{\circ} \mathrm{C}, 350^{\circ} \mathrm{C}$ and $400^{\circ} \mathrm{C}$. The testing temperatures and applied load were summarized in Table 2.7. The specimen was preheated for $40 \mathrm{~min}$ at the testing temperature as in the compression test. Different from the compression test using the constant strain rate, the creep test requires a constant load. Thus, the methods used for compression and creep tests were different in TestWorks Elite software.

Table 2.7. Testing temperatures and applied loads for creep test on supersaturated and dilute specimens.

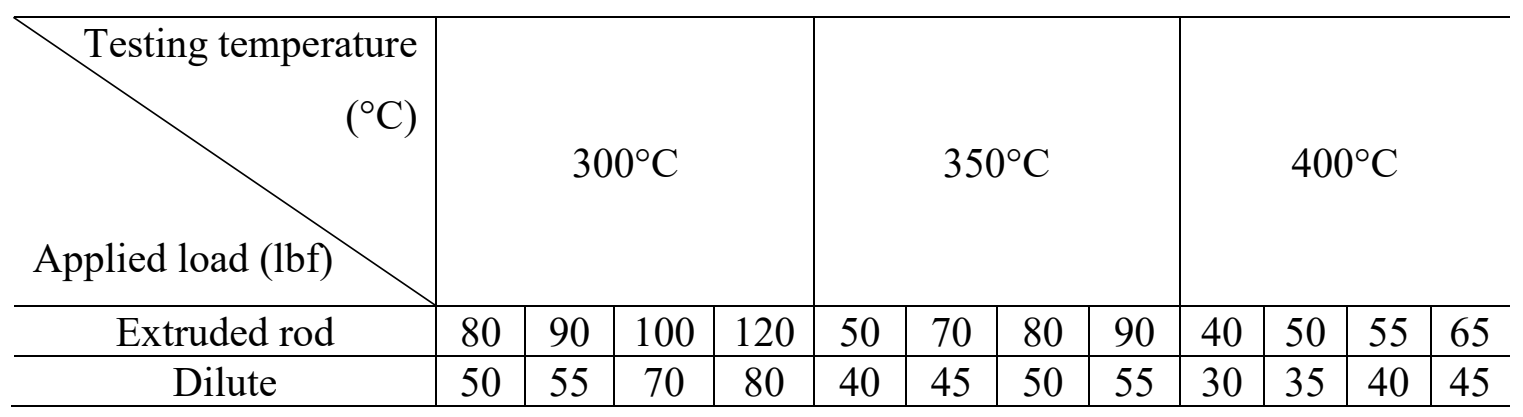

\subsubsection{Scanning electron microscope (SEM) testing}

The specimen preparation procedure for SEM followed the same procedure as for hardness measurement plus carbon coating for the melt-spun ribbon as discussed in section 2.1.6.3. Overall, specimens monitored using SEM in this experiment were polished to $0.04 \mu \mathrm{m}$ colloidal silica suspension.

The primary precipitates in the melt-spun ribbon cross-sections were monitored using secondary electron image (SEI) and backscatter electron image (BEI). In the case of the primary precipitates in this study, they were not difficult to distinguish in the SEI images, but the contrast was more apparent in the BEI images. 


\subsubsection{Transmission electron microscopes (TEM) testing}

Specimen microstructures were investigated using an FEI 200kV Titan Themis Scanning Transmission Electron Microscope (STEM) at Michigan Tech. Specimen preparation procedures for TEM were specified in Section 2.1.6. Compared to the conventional TEM with a parallel electron beam perpendicular to the sample plane, the STEM converges the electron beam into a point on the sample plane. This modification improves the magnification and provides the capability to check the local microstructure at the atomic level.

In characterizing the specimens, the properties quantified in TEM were grain size, dislocation length, precipitate size and number density. The precipitate chemical structure was investigated in STEM. Precipitate volume fractions was calculated based on the monitored area thickness using electron energy loss spectroscopy (EELS).

\section{Chapter 3. Improved strengthening in supersaturated Al-Sc- Zr alloy via melt-spinning and extrusion}

\subsection{Abstract}

A supersaturated ternary alloy with concentration of Al- $0.4 \mathrm{Sc}-0.4 \mathrm{Zr}$ at $\%$ was produced utilizing melt-spinning. The melt-spun ribbon was consolidated and extruded into a rod. A two-step heat treatment was designed to age supersaturated alloys to peak hardness. The melt-spun ribbon and extruded rod were characterized using scanning electron microscopy (SEM), transmission electron microscopy (TEM), microhardness and tensile strength measurements. The ambient microhardness of two-step aged melt-spun ribbon and extruded rod were $1120 \mathrm{MPa}$ and $1180 \mathrm{MPa}$ respectively. The yield and ultimate tensile strength of extruded rod were 300 and $315 \mathrm{MPa}$ with 5.3\% elongation. Larger precipitation volume fractions were found in two-step aged extruded rod than in meltspun ribbon within shorter second-step aging. Strength levels in the melt-spun ribbon and extruded rod agree with order and Orowan strengthening predictions when using TEM measured precipitate radius and volume fractions. 


\subsection{Introduction}

The promising precipitation strengthening in Al-Sc-Zr was revealed in section 1.1. Under equilibrium conditions, $\mathrm{Al}_{3}\left(\mathrm{Sc}_{1-\mathrm{x}} \mathrm{Zr}_{\mathrm{x}}\right)$ volume fractions are limited by low $\mathrm{Sc}$ and $\mathrm{Zr}$ solubility $(0.28 \mathrm{at} \% \mathrm{Sc}$ and $0.033 \mathrm{at} \% \mathrm{Zr}$ in Al alloys for eutectic and peritectic composition respectively) [7], [8], [52], [53]. Additions above these limits will form micrometer sized primary second phase particles [3], [4]. These primary precipitates are not desirable since their hardening efficiency is not good as potent as fine particles dispersoids. The primary particles also provide nucleation sites for $\mathrm{Al}_{3}\left(\mathrm{Sc}_{1-\mathrm{x}} \mathrm{Zr}_{\mathrm{x}}\right)$ lowering the particle density during post solidification aging [3], [54]. Unfortunately, in a conventionally cast Al-Sc-Zr alloy, Sc atoms segregate to the inter dendritic regions while $\mathrm{Zr}$ atoms are concentrated at the dendrite cores [11]. Due to elemental segregation, inhomogeneous precipitation distributions dominate the microstructure and reduce alloy properties.

A rapid solidification method, melt spinning, was found could increase solute concentrations of $\mathrm{Sc}$ and $\mathrm{Zr}$ in $\alpha-\mathrm{Al}$ matrix without primary precipitates formation. The extrusion processing shaped the melt-spun ribbon into bulk and introduced crystalline defects in it. The effects brought by the melt spinning and extrusion were summarized in section 1.3 and 1.4 .

The ambient temperature mechanical properties of a supersaturated Al-Sc-Zr alloy produced via melt spinning are examined in the current work. A two-step heat treatment was applied to age the melt-spun ribbon and extruded rod reach peak value. Both microhardness and tensile strength were measured at ambient temperature and correlated to the microstructural features of both aged melt-spun ribbon and extruded rod. The microstructures were characterized using several techniques including TEM. The experimentally determined mean precipitate radius, precipitate volume fraction, precipitate density, and grain size were then used as inputs in mechanistic property 
models. The results of these models were compared to experimental results and used to highlight potential strengthening mechanisms.

\subsection{Experimental}

Supersaturated and dilute Al-Sc-Zr alloys were investigated. In the supersaturated alloys, the maximum solute concentration was initially unknown. Rapid solidification techniques cannot suppress all primary precipitate formation. To determine the maximum solute content, concentrations of Sc and Zr were increased until the primary phases appeared, then decreased slightly. Parameters of melt spinning were adjusted to optimize the solidification rate including wheel rotating rate and molten ejection pressure. This resulted in a composition of $\mathrm{Al}-0.4 \mathrm{Sc}-0.4 \mathrm{Zr}$ at $\%$. Primary precipitates were monitored on melt-spun ribbon cross-section using SEM. Ribbon consolidation and extrusion were performed after the primary-precipitate-free melt-spun ribbon was produced. Ambient microhardness was measured on both melt-spun ribbon and extruded rod after heat treatment. Tensile strength was measured on peak-aged extruded rod only. After each step in the two-step heat treatment, TEM samples were removed from both the melt-spun ribbon and extruded rod. Conventionally cast Al-0.06Sc-0.06Zr at\% alloy was chosen for strength comparison as this alloy was previously studied for precipitation strengthening under similar heat treatment conditions, which has significant precipitation strengthening response during post solidification aging [11]. In this study, the dilute alloy was vacuum induction melted and cast into a steel candelabra rod mold. Primary precipitation was not observed in Al-0.06Sc-0.06Zr at \% at much slower solidification rates than melt spinning due to the dilute elemental concentrations. The details of the experimental processing were discussed in section 2.1.

A two-step heat treatment was designed for peak hardness in melt-spun ribbon and extruded rod as stated in section 2.1.5. The dilute alloy Al-0.06Sc-0.06Zr at\% was isothermally peak aged from the hardness measurement results. After each treatment step, the sample was water quenched, polished, and microhardness was measured. 
Mechanical properties of melt-spun ribbon, extruded rod and dilute alloy were measured at ambient temperature. Precipitation hardening of melt-spun ribbon and extruded rod were measured using Vickers microhardness on their cross-sections. The tensile strength of the peak-aged extruded rod and dilute alloy were measured as well.

Samples for TEM followed the preparation procedures reviewed in section 2.1.6.4. The microstructure, including the grain size, mean precipitate radius, and precipitate density was characterized using a FEI Titan Themis S-TEM. The precipitation volume fraction was estimated based on the volume of the TEM sample, whose thickness was measured using electron energy loss spectroscopy (EELS).

\subsection{Results}

\subsubsection{Microstructures of Melt-spun Ribbon and Extruded Rod}

Petal-shape primary precipitates were initially observed when solute levels were too high for the melt-spinning solidification rates (Figure 3.1). The morphology of primary precipitate is consistent with $L_{12}$ structure of primary precipitates $A_{3} S c$ and $A_{3} Z r$ formed in dilute and ternary alloys [55]-[57]. Significant initial precipitate segregation was observed on the melt-spun ribbon (a) and extruded rod cross-section (b), which increased local solute concentration and was deleterious to mechanical properties.

The solidification rate was increased by decreasing the copper wheel rotation (1800 RPM to $1500 \mathrm{RPM}$ ) and ejection pressure ( $0.15 \mathrm{psi}$ to $0.13 \mathrm{psi})$, so that most solutes were trapped within $\alpha-\mathrm{Al}$ and very few primary precipitates were observed. The number of primary precipitates was also much smaller in the extruded rods produced from these ribbons. 

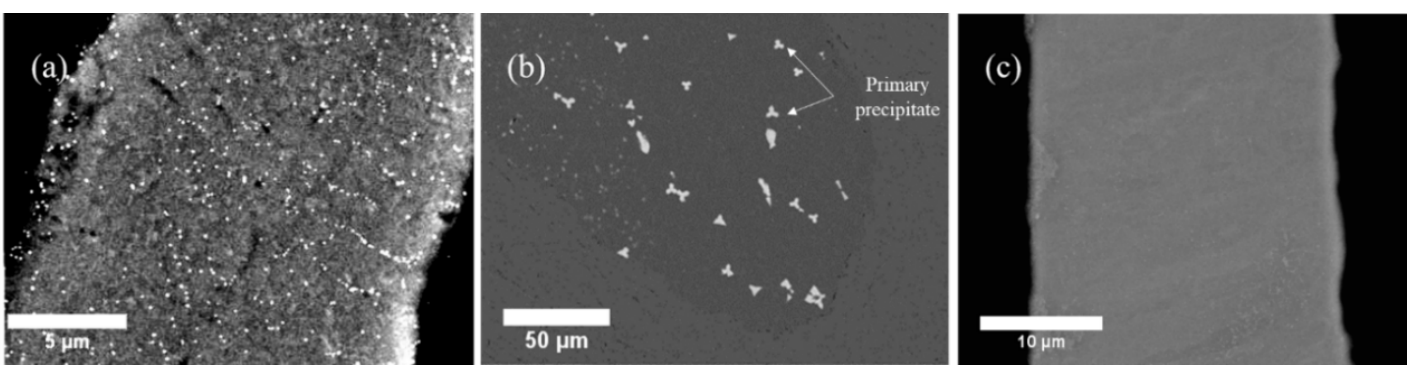

Figure 3.1. SEM micrograph of mechanically polished Al-0.4Sc-0.4Zr at $\%$ melt-spun ribbon (a) and extruded rod cross-sections (b). Petal-shape primary precipitates were observed and mitigated by adjusting ejection pressures and wheel rolling rate (c).

\subsubsection{Vickers Microhardness and Tensile Strength}

The microhardness of the melt-spun ribbon and the extruded rod was measured at the initial, peak aged, and overaged states (Figure 3.2). The hardness of the as-produced extruded rod increased $\sim 80 \mathrm{MPa}$ compared to the first-step aged melt-spun ribbon. The extruded rod was peak-aged to $1180 \pm 20 \mathrm{MPa}$, while the melt-spun ribbon was peak-aged to $1120 \pm 30 \mathrm{MPa}$ at the same temperature. The dilute alloy was peak-aged to $590 \pm 13 \mathrm{MPa}$ at $300^{\circ} \mathrm{C}$ for $15 \mathrm{~h}$. The peak hardness of dilute alloy was slightly smaller than $618 \pm 24$ $\mathrm{MPa}$ found in previous study (isochronally aged from room temperature to $425^{\circ} \mathrm{C}$ in $25^{\circ} \mathrm{C}$ increments for 3 hours per increment) [11]. Compared to the peak hardness of Al$0.06 \mathrm{Sc}-0.06 \mathrm{Zr}$ at $\%$ alloy, the peak hardness of $\mathrm{Al}-0.4 \mathrm{Sc}-0.4 \mathrm{Zr}$ at $\%$ melt-spun ribbon and extruded rod were increased +530 MPa and +590 MPa. The hardness increases in Al$0.4 \mathrm{Sc}-0.4 \mathrm{Zr}$ at $\%$ melt-spun ribbon and extruded rod likely resulted from higher precipitate volume fractions during peak aging. 


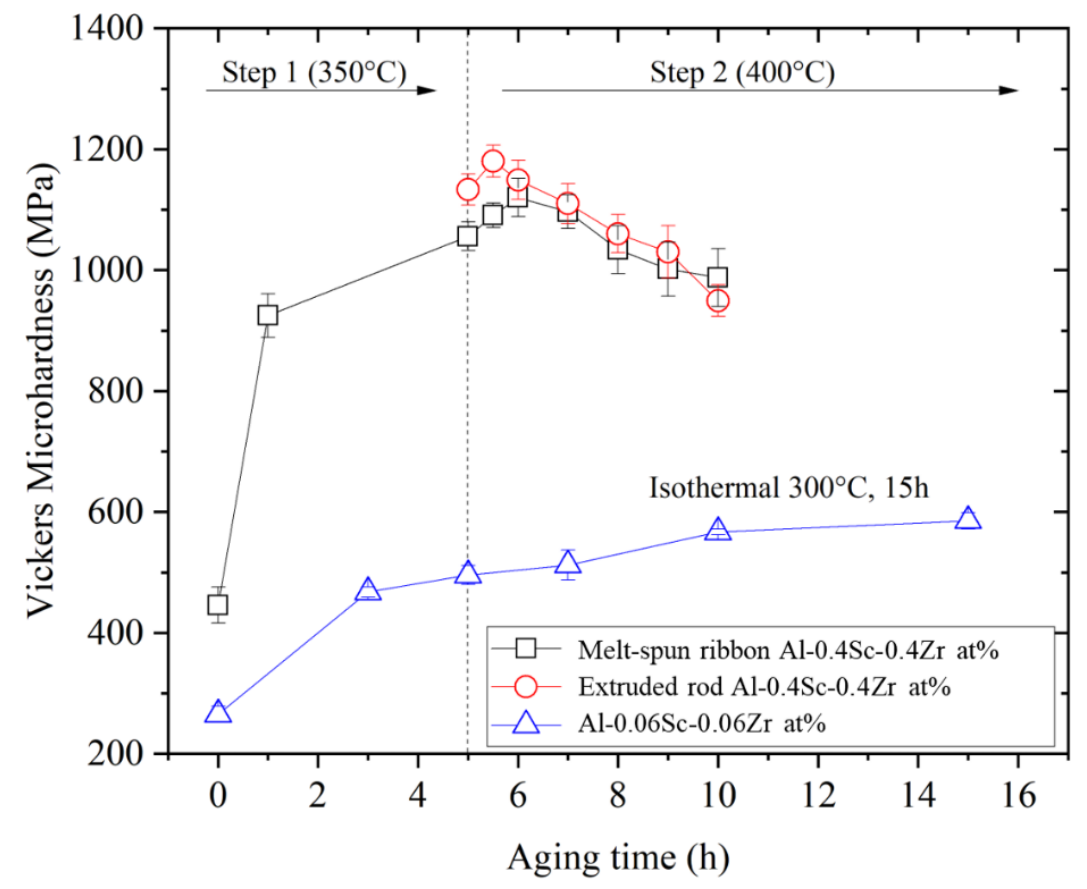

Figure 3.2. Two-step heat treatment $\left(350^{\circ}\right.$, $5 \mathrm{~h}$ and $\left.400^{\circ} \mathrm{C}, 5 \mathrm{~h}\right)$ on $\mathrm{Al}-0.4 \mathrm{Sc}-0.4 \mathrm{Zr}$ at $\%$ melt-spun ribbon, $\mathrm{Al}-0.4 \mathrm{Sc}-0.4 \mathrm{Zr}$ at $\%$ extruded rod and as-cast $\mathrm{Al}-0.06 \mathrm{Sc}-0.06 \mathrm{Zr}$ at $\%$. Ambient temperature Vickers microhardness was measured (error bars are $95 \% \mathrm{CI}$ of the mean).

The yield strength and ultimate tensile strength of peak-aged $\mathrm{Al}-0.06 \mathrm{Sc}-0.06 \mathrm{Zr}$ at $\%$ were $92 \mathrm{MPa}$ and $122 \mathrm{MPa}$ respectively with $20.5 \%$ elongation at room temperature (Figure 3.3). The yield strength and ultimate tensile strength of peak-aged extruded rod were increased to $300 \mathrm{MPa}$ and $315 \mathrm{MPa}$ respectively while elongation decreased to $5.3 \%$. The yield strength and ultimate tensile of the extruded rod showed $208 \mathrm{MPa}$ and $193 \mathrm{MPa}$ strength increase compared to peak-aged $\mathrm{Al}-0.06 \mathrm{Sc}-0.06 \mathrm{Zr}$ at $\%$. Values of yield strength, ultimate tensile strength and elongation were the mean of two tests for each sample. The toughness of the peak-aged extruded rod and $\mathrm{Al}-0.06 \mathrm{Sc}-0.06 \mathrm{Zr}$ at $\%$ was $1500 \mathrm{~J} \cdot \mathrm{m}^{-3}$ and $2000 \mathrm{~J} \cdot \mathrm{m}^{-3}$ respectively estimated from the area under the stress-strain curve in tensile test plot (Figure 3.3) [58]. The smaller toughness was attributed to the porosity and oxide aluminum in the extruded rod through extrusion [59]. 


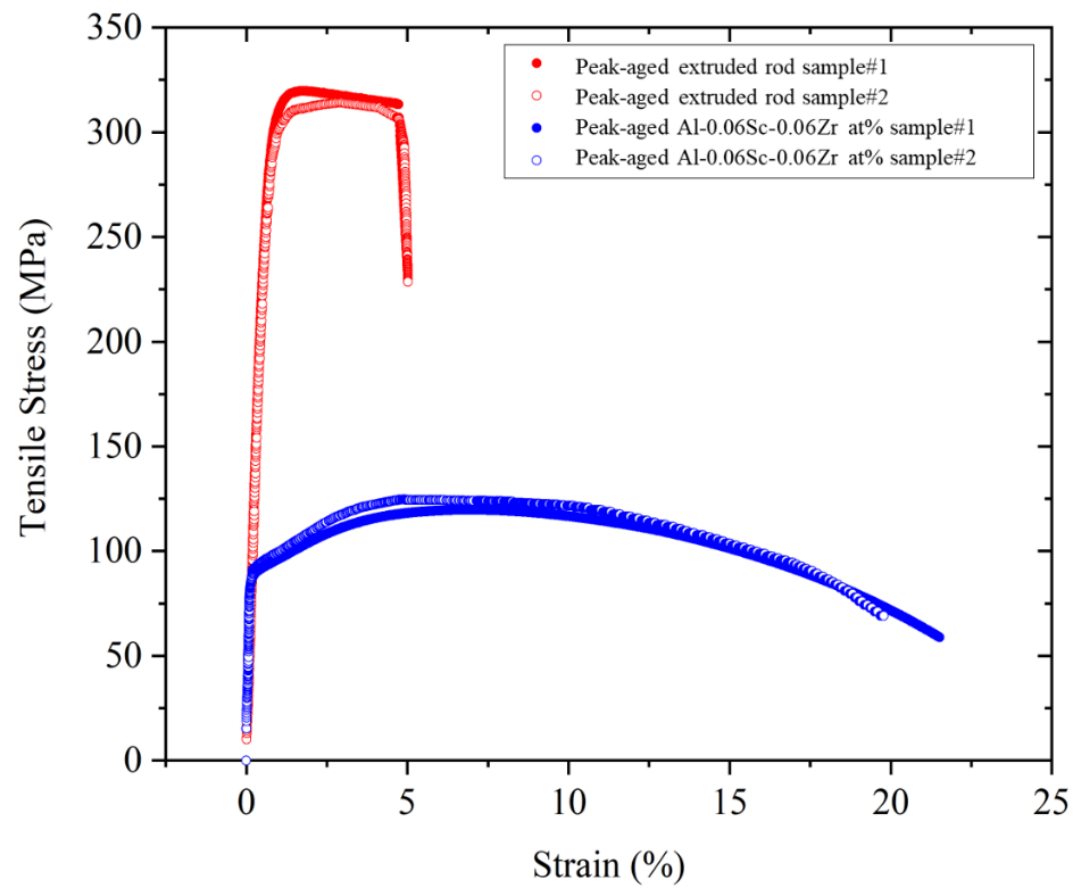

Figure 3.3. Ambient temperature tensile test of peak-aged $\mathrm{Al}-0.06 \mathrm{Sc}-0.06 \mathrm{Zr}$ at $\%\left(300^{\circ} \mathrm{C}\right.$ for $15 \mathrm{~h})$ and peak-aged $\mathrm{Al}-0.4 \mathrm{Sc}-0.4 \mathrm{Zr}$ at $\%$ extruded rod $\left(350^{\circ}\right.$ for $5 \mathrm{~h}$ and $400^{\circ} \mathrm{C}$ for $0.5 \mathrm{~h})$.

\subsubsection{Transmission Electron Microscopy}

Samples were chosen from first-step, peak, and over-aged Al-0.4Sc- $0.4 \mathrm{Zr}$ at $\%$ melt-spun ribbon and extruded rod, and peak-aged Al-0.06Sc-0.06Zr at $\%$. The grain size diameters were measured from bright field TEM images (Figure 3.4). 

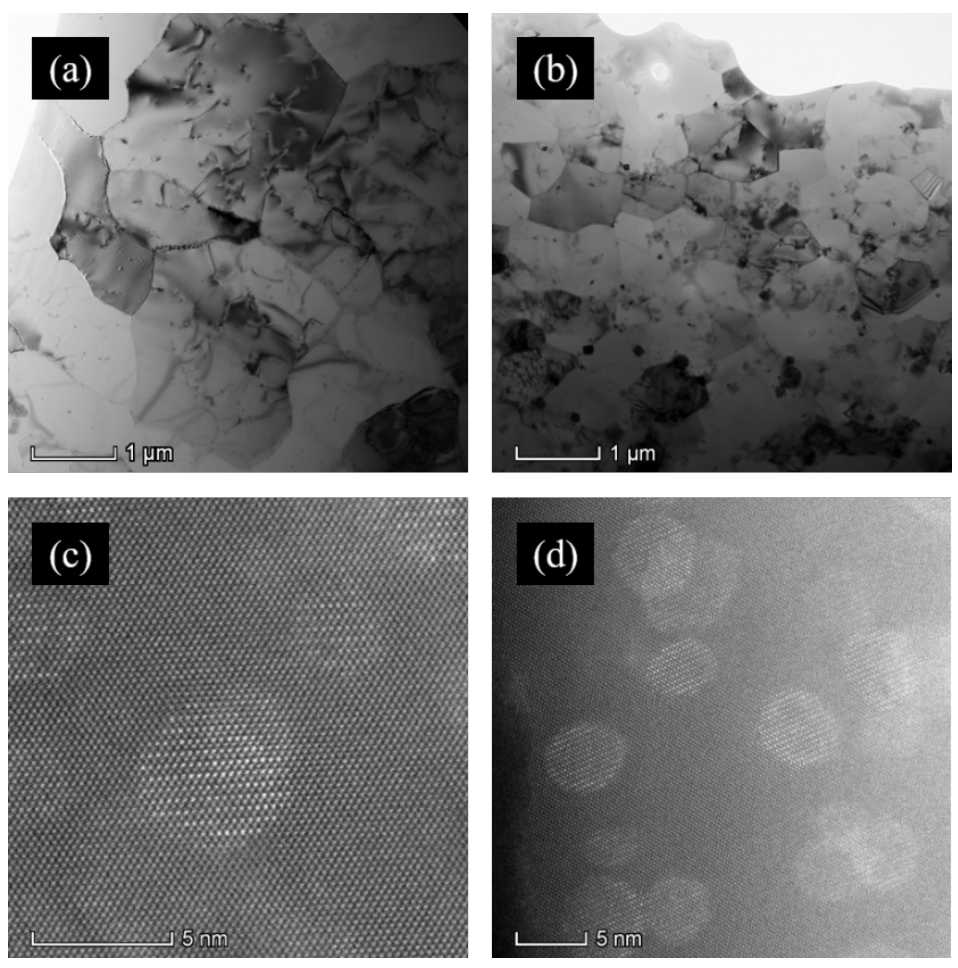

Figure 3.4. Bright-field TEM and STEM images of (a)(c) peak-aged $\mathrm{Al}-0.4 \mathrm{Sc}-0.4 \mathrm{Zr}$ at $\%$ melt-spun ribbon and (b)(d) peak-aged Al-0.4Sc-0.4Zr at\% extruded rod. The grain size of peak-aged $\mathrm{Al}-0.06 \mathrm{Sc}-0.06 \mathrm{Zr}$ at $\%$ was measured using optical microscopy due to its larger size.

As the extruded rod was produced from the melt-spun ribbon after the first aging step, smaller grains were consistently observed in the extruded rod. The mean grain size grew to $\sim 3.1 \mathrm{um}$ in melt-spun ribbon, $\sim 1 \mathrm{um}$ in extruded rod and $\sim 17 \mathrm{um}$ in Al-0.06Sc-0.06Zr at $\%$ after aging (Figure 3.5). The finer structure and larger dislocation densities in extruded rod may also have facilitated atom transport and precipitate nucleation, which further contributed to the higher strength of the extruded rod. 


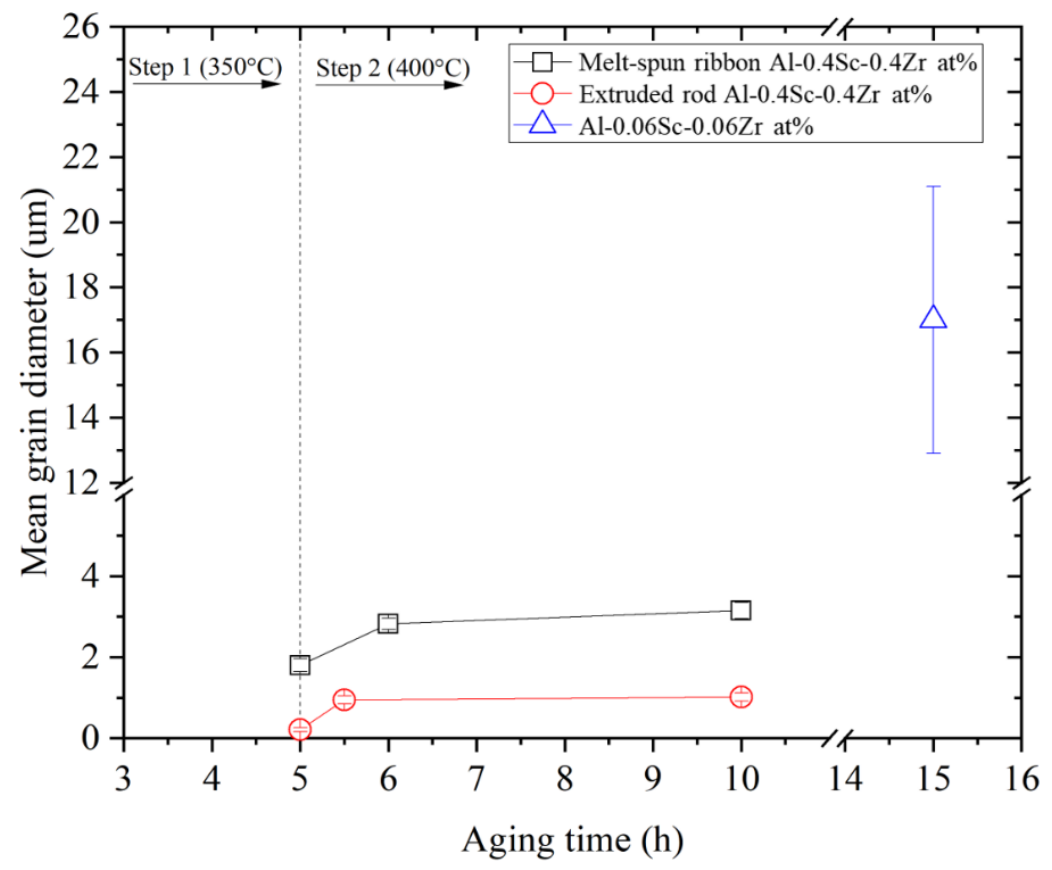

Figure 3.5. Grain size diameters of $\mathrm{Al}-0.4 \mathrm{Sc}-0.4 \mathrm{Zr}$ at $\%$ melt-spun ribbon, extruded rod at first-step, second-step and overaged step; and isothermally peak-aged Al-0.06Sc-0.06Zr at $\%$ at $300^{\circ} \mathrm{C}$ for $15 \mathrm{~h}$.

The mean precipitate radius and precipitate densities of three alloys were measured using HAADF-STEM images consisting of over 300 particles for each sample (Figure 3.6). Precipitate densities were observed in Al-0.4Sc- $0.4 \mathrm{Zr}$ at $\%$ peak-aged melt-spun ribbon and extruded rod up to $5.3 \times 10^{22} \mathrm{ppt} / \mathrm{m}^{3}$ and $7.4 \times 10^{22} \mathrm{ppt} / \mathrm{m}^{3}$ respectively. The mean precipitate radiis grew to $2.75 \pm 0.06 \mathrm{~nm}$ and $3.82 \pm 0.17 \mathrm{~nm}$ in the samples at the corresponding aging conditions. As a comparison, the mean precipitate radius in peakaged Al-0.06Sc- $0.06 \mathrm{Zr}$ at $\%$ was $2.5 \pm 0.4 \mathrm{~nm}$ with precipitate number density of $0.2 \times 10^{22} \mathrm{ppt} / \mathrm{m}^{3}$. The precipitate volume fractions were estimated at $0.47 \pm 0.03 \%$ in peak-aged melt-spun ribbon and $0.6 \pm 0.09 \%$ in extruded rod based on measured mean precipitate sizes and densities. 

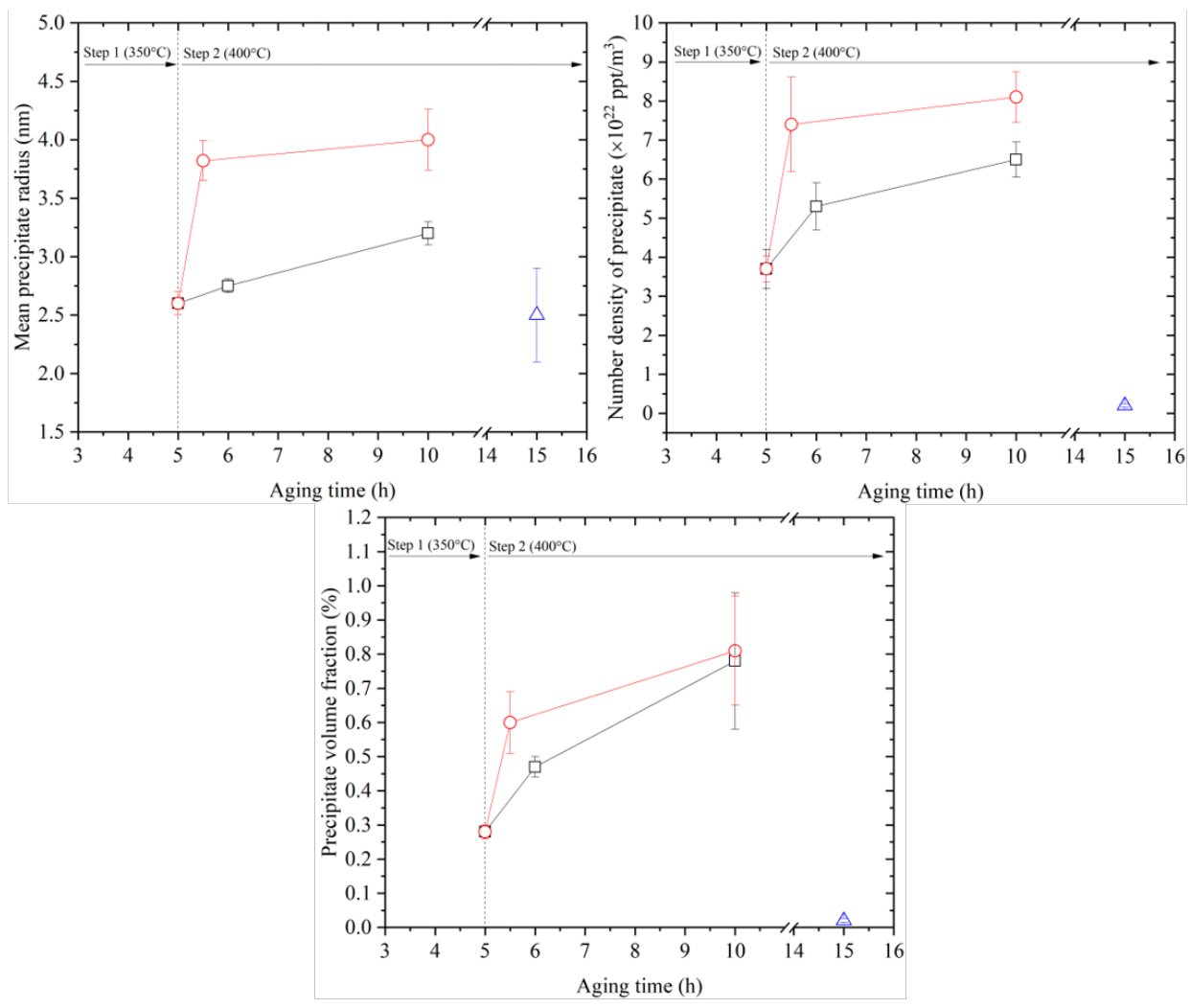

$\square$-Melt-spun ribbon Al-0.4Sc-0.4Zr at $\%-\bigcirc-$ Extruded rod Al-0.4Sc-0.4Zr at $\% \triangle \triangle$ Al-0.06Sc-0.06Zr at $\%$

Figure 3.6. Mean precipitate radius, $\bar{R}$, volume fraction, $\Phi$, and number density of precipitate in $\mathrm{Al}-0.4 \mathrm{Sc}-0.4 \mathrm{Zr}$ at $\%$ melt-spun ribbon and extruded rod with two-step heat treatment; As-cast Al-0.06Sc- $0.06 \mathrm{Zr}$ at $\%$ is isochronally aged at $300^{\circ} \mathrm{C}$ for $15 \mathrm{~h}$.

\subsection{Discussion}

\subsubsection{Microstructures of Melt-spun Ribbon and Extruded Rod}

Grain sizes were reduced in rapidly solidified melt-spun ribbon and further refined in the extruded rod compared to the conventionally cast alloy. After first-step aging, the grain growth in both melt-spun ribbon and extruded rod were restricted by the $\mathrm{Al}_{3}(\mathrm{Sc}, \mathrm{Zr})$ precipitation at $400^{\circ} \mathrm{C}$ up to $5 \mathrm{~h}$. Both Sc and $\mathrm{Zr}$ may act as grain refiners at $400^{\circ} \mathrm{C}$ and this finding supports this behavior [60], [61].

Larger precipitate size and precipitate volume fraction were observed in extruded rod than melt-spun ribbon. Though the precipitate sizes and densities were the same in melt- 
spun ribbon and as-produced extruded rod after first-step heat treatment, more precipitates were nucleated in extruded rod with $\sim 1 \mathrm{~nm}$ larger size after the second heat treatment step. The precipitate sizes and density differences between melt-spun ribbon and extruded rod correlate to the larger strength increases in extruded rod after two-step heat treatment. Compared to the calculated equilibrium precipitate volume fraction $\sim 1.95 \%$ in $\mathrm{Al}-0.4 \mathrm{Sc}-0.4 \mathrm{Zr}$ at $\%$ at $400^{\circ} \mathrm{C}$ [7], [9], the measured precipitate volume fractions of melt-spun ribbon and extruded rod were much smaller than calculated values ( $0.47 \%$ for the melt-spun ribbon and $0.6 \%$ for the extruded rod). In previous studies of dilute $\mathrm{Al}-\mathrm{Sc}-\mathrm{Zr}$ alloys, volume fractions were $0.44 \%$ for $\mathrm{Al}-0.1 \mathrm{Sc}-0.1 \mathrm{Zr}$ at $\%$ isochronally aged to $400^{\circ} \mathrm{C}$ and 0.2 at $\%$ for $\mathrm{Al}-0.09 \mathrm{Sc}-0.03 \mathrm{Zr}$ at $\%$ isothermally aged at $450^{\circ} \mathrm{C}$ for $5 \mathrm{~h}$ [3], [62]. The volume fractions were also smaller than calculated equilibrium volume fractions. To balance the precipitate nucleation and coarsening in supersaturated alloys, the peak aging was shortened as solutes are preferably nucleate on pre-existing particles. With shorten peak aging heat treatment for $\mathrm{Al}-0.4 \mathrm{Sc}-0.4 \mathrm{Zr}$ at $\%$ melt-spun ribbon $\left(350^{\circ} \mathrm{C}\right.$, $5 \mathrm{~h}$ and $\left.400^{\circ} \mathrm{C}, 1 \mathrm{~h}\right)$ and extruded rod $\left(350^{\circ} \mathrm{C}, 5 \mathrm{~h}\right.$ and $\left.400^{\circ} \mathrm{C}, 0.5 \mathrm{~h}\right)$, both samples were considered not reached steady state due to the relative small diffusivities of Sc and $\mathrm{Zr}$. The precipitate volume fractions of melts-pun ribbon and extruded rod were increased to $0.78 \%$ and $0.81 \%$ when overaged for $5 \mathrm{~h}$ at $400^{\circ} \mathrm{C}$ from supersaturation solutions. In addition to the shortened heat treat cycles, the uncertainty in thickness measurement when using TEM-EELS may also have contributed to lower measured volume fractions.

\subsubsection{Precipitate Structure of $\mathrm{Al}_{3}\left(\mathrm{Sc}_{1-\mathrm{x}} \mathrm{Zr}_{\mathrm{x}}\right)$ in Supersaturated Alloys}

The precipitate structure in the melt-spun ribbon and extruded rod after each step heat treatment was analyzed using HAADF-STEM images and energy-dispersive X-ray spectroscopy (EDS) mapping. Distribution of $\mathrm{Sc}$ and $\mathrm{Zr}$ in precipitates in first- and second-step aged ribbon and rod were homogeneous, as verified by EDS line scans across the particles. The core-shell precipitates were observed in both over-aged melt-spun ribbon and extruded $\operatorname{rod}\left(350^{\circ} \mathrm{C}, 5 \mathrm{~h}\right.$ and $400^{\circ} \mathrm{C}$ for $\left.5 \mathrm{~h}\right)$ from the fitted EDS line scan across the precipitate particle (Figure 3.7). The concentration of $\mathrm{Zr}$ was $\sim 7 \mathrm{at} \%$ in the particle periphery region, which is over 3 times larger than the concentration of $\mathrm{Zr}$ in the 
particle center. The EDS mapping of Sc and $\mathrm{Zr}$ in the precipitate further supported the finding that precipitate has a Sc-rich core and Zr-rich shell structure.
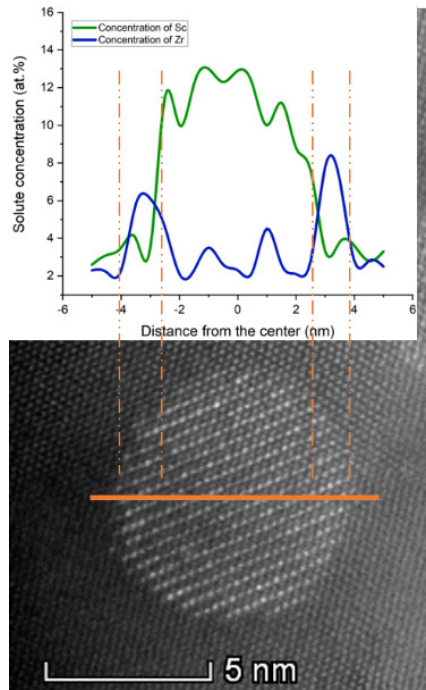

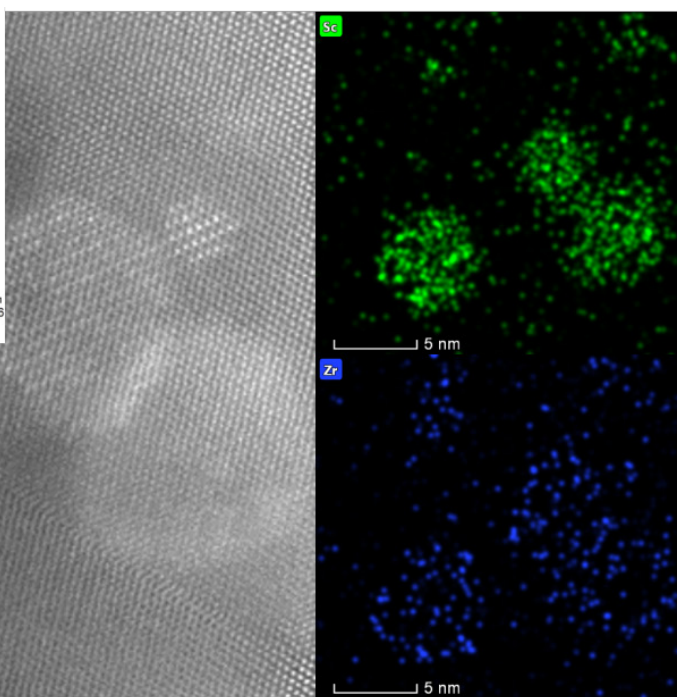

Figure 3.7. HAADF-STEM image of precipitate and EDS maps of Sc and Zr in over-aged melt-spun ribbon $\left(350^{\circ} \mathrm{C}, 5 \mathrm{~h}\right.$ and $\left.400^{\circ} \mathrm{C}, 5 \mathrm{~h}\right)$. The Sc-rich core and $\mathrm{Zr}$-rich shell were verified by EDS mapping. The line scan trend revealed that Sc atomic fraction increases between distances from $-2.7 \mathrm{~nm}$ to $2.7 \mathrm{~nm} ; \mathrm{Zr}$ atomic fraction is increased in ranges of 4.1--2.7 $\mathrm{nm}$ and 2.7-3.8 $\mathrm{nm}$.

The qualitative and quantitative analysis of Sc and $\mathrm{Zr}$ distributions in the precipitate supports the assumption that Sc atoms are concentrated in the central region of the precipitate, $\mathrm{Zr}$ atoms are enriched in the rim region so that precipitate in supersaturated alloy forms core/shell structured precipitates in the dilute alloy [11], [20]. The supersaturated alloy may benefit from the coarsening resistance offered by the $\mathrm{Al}_{3} \mathrm{Zr}$ shell.

\subsubsection{Precipitation Strengthening Prediction in Supersaturated Alloys}

The higher strength increase in the extruded rod versus melt-spun ribbon likely resulted from a combination of larger precipitate volume fraction and Hall-Petch strengthening. According to Equation 1.9, the $\Delta \sigma_{H P}$ microhardness contributions were calculated in the first-step aged, second-step aged and over-aged extruded rod than the same aged melt- 
spun ribbon respectively (using strength conversion of one third the microhardness [63]) (Figure 3.5). Since the measured hardness increased $80 \mathrm{MPa}$ in the first-step aged extrude rod (as-produced) was only attributed to cold work with same precipitate size and volume fraction, the agreement between calculated and measured strength change proves that Hall-Petch strengthening account for the hardness increase after extrusion (Table 3.1). Compared to the measured strength increase, the Hall-Petch strengthening took up $10 \%$ of that, the majority of strengthening increase was attributed to precipitation strengthening in melt-spun ribbon and extruded rod. The calculated Hall-Petch strengthening increase in extruded rod was excluded in precipitation strengthening calculation at each step.

Table 3.1. Calculated Hall-Petch strengthening change in extruded rod

\begin{tabular}{cccc}
\hline & First-step aging & $\begin{array}{c}\text { Second-step aging (peak } \\
\text { aging) }\end{array}$ & Over aging \\
\hline $\begin{array}{c}\text { Grain size in Melt-spun } \\
\text { ribbon (um) }\end{array}$ & $1.8 \pm 0.16$ & $2.82 \pm 0.14$ & $3.15 \pm 0.2$ \\
$\begin{array}{c}\text { Grain size in Extruded } \\
\text { rod (um) }\end{array}$ & $0.21 \pm 0.05$ & $0.95 \pm 0.1$ & $1.02 \pm 0.1$ \\
$\Delta \sigma_{H P}(\mathrm{MPa})$ & $38 \pm 2$ & $41 \pm 3$ & $44 \pm 3$ \\
\hline
\end{tabular}

With the knowledge of mean precipitate radius and volume fraction change in melt-spun ribbon and extruded rod after each step heat treatment, Figure 3.8 compares the coherency and modulus strengthening, order strengthening and Orowan strengthening change as a function of precipitate radius. The strength limits were plotted based on the $95 \%$ confidence interval error of precipitate size and volume fraction. The measured hardness compares to predicted strength value using $\Delta \mathrm{HV} / 3$ conversion. 

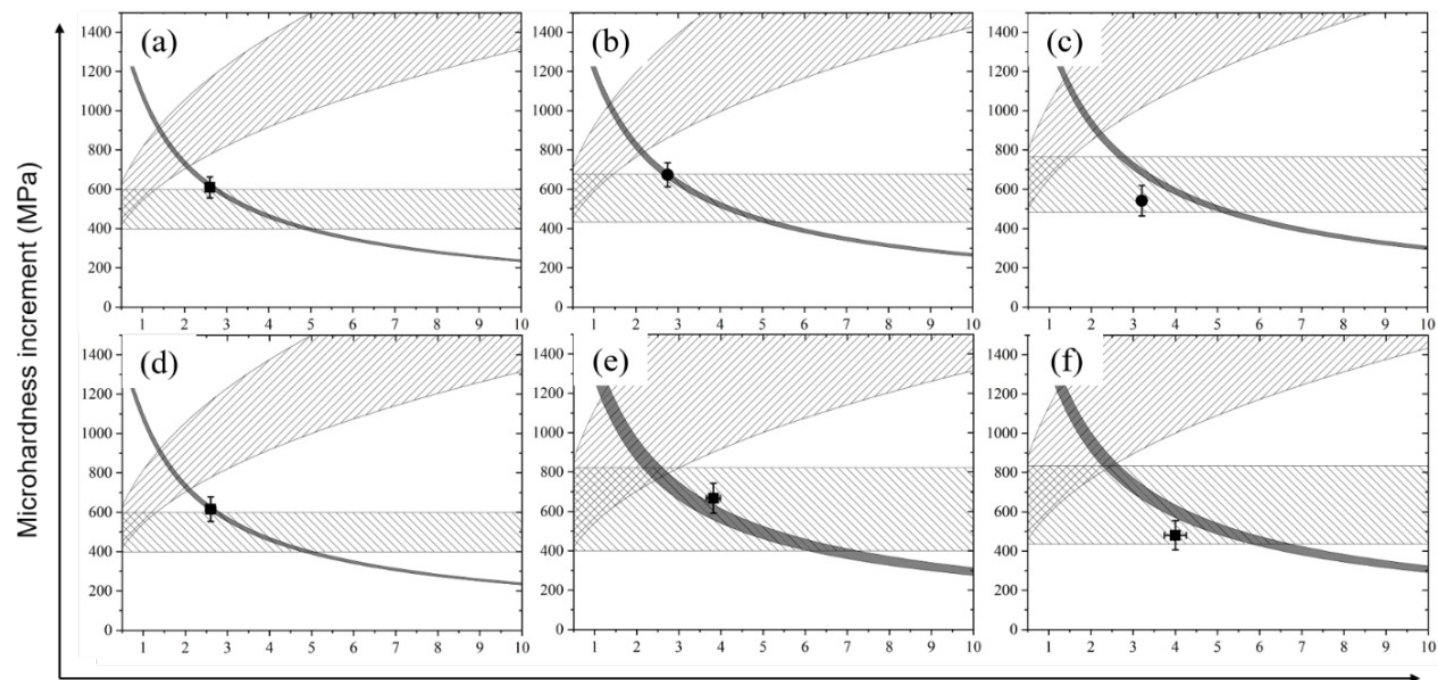

Average precipitate radius $(\mathrm{nm})$

VIIL Coherency+Modulus strengthening $\Delta \sigma_{\text {coh }}+\Delta \sigma_{\text {mod }}$

$\mathbb{M}$ Order strengthening $\Delta \sigma_{\text {ord }}$

Orowan strengthening $\Delta \sigma_{\text {Orowan }}$

- Measured hardness of ribbon

- Measured hardness of rod (Hall-Petch strengthening $\Delta \sigma_{\mathrm{HP}}$ excluded)

Figure 3.8. Calculated coherency and modulus strengthening, order strengthening and

Orowan strengthening change with increasing $\bar{R}$ in (a)-(c) First-step, second-step and over-aged melt-spun ribbon; (d)-(f) First-step (as-produced), second-step and over-aged extruded rod. Calculated Hall-Petch strengthening change was excluded in extruded rod (Table 3.1).

As shown in Figure 3.8, the dominant strengthening changed from order strengthening to Orowan strengthening as the precipitate radius grew into a range of 2-3 nm. All steps showed good quantitative agreement between measured and predicted values, which support the assumption that supersaturated alloys follow the general precipitation strengthening mechanisms. For over-aged melt-spun ribbon (c) and extruded rod (f), the error might be raised from primary precipitates coarsening in over-aged supersaturated alloys which made the measured strength smaller than predicted values. Compared to the strength of the as-produced supersaturated and dilute alloys, the precipitation strength increased over by $600 \mathrm{MPa}$ for peak-aged two supersaturated $\mathrm{Al}-0.4 \mathrm{Sc}-0.4 \mathrm{Zr}$ at $\%$ and over $350 \mathrm{MPa}$ for peak-aged Al-0.06Sc-0.06Zr at $\%$. The precipitation strengthening increase for supersaturated alloys versus the dilute alloy $(\sim 70 \%)$, did not scale directly with increased solute concentration ( $650 \%$, from 0.12 at $\%$ to 0.9 at $\%$ of Sc and $\mathrm{Zr}$ ). From the definition of Orowan strengthening shown in Equation 1.3, the precipitation strength 
increase is directly proportional to precipitate volume fraction and inversely proportional to particle radius. Both precipitate volume fraction and size were larger in both melt-spun ribbon and extruded rod than dilute alloy's (Figure 3.6) leading to some countervailing effects on strength. Less solute than anticipated nucleated precipitates in the supersaturated alloys versus what was expected, therefore the dilute alloy demonstrated a higher hardening efficiency by comparison.

The mechanical properties and microstructure of $\mathrm{Al}-0.4 \mathrm{Sc}-0.4 \mathrm{Zr}$ at $\%$ extruded rod were compared to high $\mathrm{Sc} / \mathrm{Zr}$-content alloys processed by selective laser melting (SLM), which can provide solidification rates above $10^{\wedge} 6 \mathrm{~K} / \mathrm{s}$ (Table 3.2) [64].

Table 3.2. Summary of mechanical properties and microstructures of Al- $0.4 \mathrm{Sc}-0.4 \mathrm{Zr}$ at $\%$ alloy processed by melt-spinning and extrusion; high $\mathrm{Sc} / \mathrm{Zr}$-content alloys processed by selective laser melting.

\begin{tabular}{|c|c|c|c|c|c|c|c|}
\hline $\begin{array}{l}\text { Alloy } \\
(\mathrm{at} \%)\end{array}$ & Processing & $\begin{array}{c}\text { YS } \\
(\mathrm{MPa})\end{array}$ & $\begin{array}{l}\text { UTS } \\
(\mathrm{MPa})\end{array}$ & EL\% & $\begin{array}{l}\text { Grain } \\
\text { size } \\
(\mu \mathrm{m}) \\
\end{array}$ & $\begin{array}{c}\text { Precipitate } \\
\text { Radius } \\
(\mathrm{nm})\end{array}$ & $\begin{array}{c}\text { Referenc } \\
\text { e }\end{array}$ \\
\hline $\begin{array}{c}\mathrm{Al}-0.06 \mathrm{Sc}- \\
0.06 \mathrm{Zr}\end{array}$ & $\begin{array}{l}\text { Conventional } \\
\text { casting }\end{array}$ & 92 & 122 & 20.5 & 17 & 2.5 & - \\
\hline $\begin{array}{c}\mathrm{Al}-0.4 \mathrm{Sc}- \\
0.4 \mathrm{Zr}\end{array}$ & $\begin{array}{c}\text { Melt- } \\
\text { spinning+ } \\
\text { extrusion }\end{array}$ & 300 & 315 & 5.3 & 1 & 3.82 & - \\
\hline $\begin{array}{c}\mathrm{Al}-4.6 \mathrm{Mg}- \\
0.49 \mathrm{Mn}- \\
0.66 \mathrm{Sc}- \\
0.42 \mathrm{Zr}\end{array}$ & $\begin{array}{l}\text { Selective laser } \\
\text { melting }\end{array}$ & 280 & 415 & 15.8 & $0.6-5^{\mathrm{a}}$ & 3.2 & [64] \\
\hline $\begin{array}{c}\mathrm{Al}-4.8 \mathrm{Mg}- \\
0.18 \mathrm{Sc}- \\
0.18 \mathrm{Zr}\end{array}$ & $\begin{array}{l}\text { Selective laser } \\
\text { melting }\end{array}$ & 435 & 478 & 16 & $1.7^{\mathrm{a}}$ & $2.5-4$ & [65] \\
\hline $\begin{array}{c}\mathrm{Al}-3.2 \mathrm{Mg}- \\
0.11 \mathrm{Sc}- \\
0.03 \mathrm{Zr}\end{array}$ & $\begin{array}{l}\text { Selective laser } \\
\text { melting }\end{array}$ & 290 & 373 & 32.5 & $22-30^{\mathrm{b}}$ & $2.5-25$ & [66] \\
\hline
\end{tabular}

${ }^{\mathrm{a}}$ Measured from fine grained area.

${ }^{\mathrm{b}}$ Measured from mean of fine and coarse grained areas. 
Compared to conventional casting which has much smaller cooling rate than $10^{\wedge} 3 \mathrm{k} / \mathrm{s}$, both melt-spinning and selective laser melting could provide rapid solidification rate resulting in finer microstructures and supersaturated solutions. The refined grains and large number of precipitates increase alloys strength and the strengthening is further increase with Mg addition in SLM alloys. The limitations of SLM alloy also comes with its processing such as heat effect, porosity and grain size inhomogeneity. The combination of melt-spinning and extrusion could provide high strength as SLM alloys' with more homogeneous grain distribution.

\subsection{Conclusions}

A supersaturated alloy $\mathrm{Al}-0.4 \mathrm{Sc}-0.4 \mathrm{Zr}$ at $\%$ containing finely dispersed precipitates was produced using melt-spinning and extrusion, mechanical properties were investigated, and microstructures were characterized. Strengthening was found to increase in meltspun ribbon and extruded rod with larger precipitation volume fractions than $\mathrm{Al}-0.06 \mathrm{Sc}-$ $0.06 \mathrm{Zr}$ at $\%$.

This part demonstrates:

- An alloy additions of $0.4 \mathrm{at} \% \mathrm{Sc}$ and $0.4 \mathrm{at} \% \mathrm{Zr}$ were trapped in the $\mathrm{Al}$ matrix by rapid solidification. Both melt-spun ribbon and extruded rod have significant strength increases compared to conventionally cast alloys. The increased strength is mostly driven by increased precipitate phase fractions. The decreased toughness in the extruded rod was brought by the defects during processing.

- The extruded rod strength increased more than the melt-spun ribbon due to the reduced grain size. The calculated Hall-Petch strengthening account for $\sim 10 \%$ the measured hardness increase in extruded rod.

- Strengthening of melt-spun ribbon and extruded rod after each step heat treatment was predicted and verified using order and Orowan strengthening theories based on the measured precipitate size and volume fractions.

- Precipitates consist of Sc-rich core and $\mathrm{Zr}$-rich shell as verified in the over-aged Al- $0.4 \mathrm{Sc}-0.4 \mathrm{Zr}$ at $\%$ melt-spun ribbon and extruded rod. This core-shell precipitate 
structure in the supersaturated alloys is the same as the particle structure in conventionally cast dilute Al-Sc-Zr alloy.

\section{Chapter 4. Coarsening behavior of precipitate $\mathrm{Al}(\mathrm{Sc}, \mathrm{Zr})$ in supersaturated Al-Sc-Zr alloy via melt-spun and extrusion}

\subsection{Abstract}

Supersaturated alloys with a concentration of $\mathrm{Al}-0.4 \mathrm{Sc}-0.4 \mathrm{Zr}$ at $\%$ were melt-spun and extruded. Peak-aged melt-spun ribbon and extruded rod were annealed up to $72 \mathrm{~h}$ at $400^{\circ} \mathrm{C}$ to assess the precipitate coarsening behavior with scanning transmission electron microscopy (STEM). The precipitate size, coherency and distributions were assessed, with more coarsening observed in the extruded melt-spun ribbon. The accelerated effective diffusivity after extrusion was explicitly linked to the initially refined extruded microstructure. Precipitate volume fractions increased in both melt-spun ribbon and extruded rod during annealing. The composition of the precipitate and $\alpha$-Al matrix were measured using energy-dispersive x-ray spectroscopy (EDS), and found to continuously change with annealing. Precipitate size and number density were predicted using Umantsev-Olson-Kuehman-Voorhees (UOKV) model for ternary alloys, and the predictions showed good agreement with experimental results by considering changes in diffusivity and precipitate volume fraction.

\subsection{Introduction}

The benefits of nucleating precipitate $\mathrm{Al}_{3}\left(\mathrm{Sc}_{1-\mathrm{x}} \mathrm{Zr}_{\mathrm{x}}\right)$ in aluminum alloys were reviewed in section 1.1. The improved coarsening resistance is contributed to the smaller diffusivities of $\mathrm{Sc}$ and $\mathrm{Zr}$ compared to some general elements. In addition to the small atomic mobility of $\mathrm{Sc}$ and $\mathrm{Zr}$, these elements are observed to distribute inhomogeneously within the individual precipitates [67], [68], with the interior core of the $\mathrm{Al}_{3}\left(\mathrm{Sc}_{1-\mathrm{x}} \mathrm{Zr}_{\mathrm{x}}\right)$ precipitate being having a higher Sc composition (smaller $x$ ) than the exterior shell. The observation of a Zr-rich shell and Sc-rich core has been rationalized by suggesting the 
initial stage of the precipitation process is dominated by the more rapid Sc diffusion, and as the $\mathrm{Sc}$ becomes depleted in the matrix phase, then the enriched $\mathrm{Zr}$ shell is formed in the later stages of the precipitate growth process [69]. The increased coarsening resistance of $\mathrm{Al}_{3}\left(\mathrm{Sc}_{1-\mathrm{x}} \mathrm{Zr}_{\mathrm{x}}\right)$ precipitates as compared to the $\mathrm{Al}_{3} \mathrm{Sc}$ precipitates in binary $\mathrm{Al}-\mathrm{Sc}$ alloys has been attributed to slower $\mathrm{Zr}$ diffusivity and lower $\mathrm{Al}_{3} \mathrm{Zr}$ lattice mismatch with the $\mathrm{Al}$ matrix [70]-[72], and contributes to increased creep and coarsening resistance during long-term annealing within the range of $300^{\circ} \mathrm{C}$ to $400^{\circ} \mathrm{C}$.

This part aims to investigate and compare the rate-controlling mechanisms for coarsening of $\mathrm{Al}_{3}\left(\mathrm{Sc}_{1-\mathrm{x}} \mathrm{Zr}_{\mathrm{x}}\right)$ in melt-spun ribbon and extruded rod. The precipitate radius, composition, dislocation density, and grain size were measured as specimens were incrementally overaged up to $72 \mathrm{~h}$. Precipitate radius and number density change were analyzed by Equations 1.10-1.12 using the experimentally determined effective diffusivity, precipitate volume fraction, and solute composition. This approach is used to highlight the role of defect density on precipitate coarsening between melt-spun ribbon and the same ribbon extruded into rod.

\subsection{Experimental}

\subsubsection{Sample preparation}

Supersaturated Al-Sc-Zr ribbons were produced by melt spinning and processed into rods by extrusion [73]. The detailed process was illustrated in Chapter 2. The amount of solute in the melt-spun alloys was gradually increased until primary precipitates were detected by SEM, and then solute levels were decreased slightly to identify a composition of 0.4 at $\% \mathrm{Sc}$ and $0.4 \mathrm{at} \% \mathrm{Zr}$ that had maximum supersaturation. The melt-spun ribbon was consolidated into an 6061 aluminum cylinder (90 mm OD and 88.4 ID) under an Ar atmosphere at room temperature using a Carver hydraulic press (16 MPa). Further compaction was completed using a Dake hydraulic press (160 MPa) in air. The consolidated ribbon was preheated is a fluidized bed at $350^{\circ} \mathrm{C}$ for $5 \mathrm{~h}$ and then extruded at $350^{\circ} \mathrm{C}$ in a hydraulic extrusion press ( $800 \mathrm{MPa}$ ) with $49: 1$ ratio and immediately water quenched to limit coarsening and precipitation. The melt-spun ribbon and extruded rod 
compositions were determined by inductively coupled plasma mass spectrometry (ICPMS) (Lehigh Testing Laboratories, DE) as shown in Table 2.1.

\subsubsection{Heat treatment}

Both the melt-spun ribbon and extruded rod were peak aged using a multi-step heat treatment. All melt-spun ribbon, including the feedstock to produce the extruded rod, was first aged at $350^{\circ} \mathrm{C}$ for $5 \mathrm{~h}$. To peak age, a second $400^{\circ} \mathrm{C}$ heat treatment was applied to the melt-spun ribbon for $1 \mathrm{~h}$ and extruded rod for $0.5 \mathrm{~h}$. The shorter peak aging duration for the rod is due to its refined microstructure rod after extrusion [73]. The $350^{\circ} \mathrm{C}$ aging precipitates the $\mathrm{Al}_{3} \mathrm{Sc}$ core, while the $400^{\circ} \mathrm{C}$ aging promotes the formation of $\mathrm{Al}_{3} \mathrm{Zr}$ shell [70], [72].

To characterize the precipitate coarsening behavior and compare with previous research [74], [75], the peak-aged melt-spun ribbon and extruded rod were then annealed at $400^{\circ} \mathrm{C}$ up to $72 \mathrm{~h}$ using an induction furnace. Samples of melt-spun ribbon and extruded rod were removed from furnace and water quenched at steps of $12 \mathrm{~h}, 24 \mathrm{~h}, 48 \mathrm{~h}, 72 \mathrm{~h}$.

\subsubsection{Transmission electron microscopy analysis}

Samples were prepared at each aging step following the electropolishing processing reviewed in section 2.1.6.4. The $\mathrm{Al}_{3}\left(\mathrm{Sc}_{\mathrm{x}} \mathrm{Zr}_{1-\mathrm{x}}\right)$ precipitate morphology with different annealing times was assessed in an FEI Titan Themis S-TEM. Precipitate sizes in brightfield TEM and STEM were measured in ImageJ by counting over 100 precipitates per sample. Precipitate coherency was determined through strain contrast caused by elastic interactions with the adjacent matrix [76], [77]. Volumetric microstructural data including dislocation density, precipitate density, and volume fraction were estimated using sample thicknesses from electron energy loss spectroscopy (EELS). The matrix and precipitate composition was measured by energy-dispersive X-ray spectroscopy (EDS) line scan across 10 precipitates per sample [78]. 


\subsubsection{Effective diffusivity for coarsening acceleration}

The extrusion process increased dislocation density and reduced the grain size and leading to enhanced solute transport that affected microstructural development [79]. Capturing these effects requires employing an effective diffusion coefficient $\left(D_{e f f}\right)$, which in addition to volume diffusion also accounts for atomic diffusion through dislocation cores and grain boundaries. The activation energy is reduced for short circuit pipe diffusion $\left(D_{\text {pipe }}=0.6 D_{\text {bulk }}\right)[33]$ and grain boundary diffusion $\left(D_{g b}=0.5 D_{b u l k}\right)$ [80], [81]. The diffusion coefficient is:

$$
D(T)=D_{0} \exp \left(-\frac{Q}{R T}\right)
$$

Equation 4.1

where $D_{0}$ is the pre-exponential coefficient and $Q$ is the activation energy; $R$ is gas constant and $T$ is the absolute temperature in $\mathrm{K}$. The effective diffusion coefficient $D_{\text {eff }}$ is estimated as [79]:

$$
\begin{array}{cc}
D_{e f f}(T)=(1-f-g) D_{\text {bulk }}(T)+f D_{\text {pipe }}(T)+g D_{g b}(T) & \text { Equation } 4.2 \\
f=\rho \pi r^{2} & \text { Equation 4.3 } \\
g=\frac{\delta}{d} & \text { Equation 4.4 }
\end{array}
$$

where $f$ and $g$ are the area fraction of pipes and grain boundaries, respectively; $\rho$ is the dislocation density, $r$ is the dislocation pipe radius [82], $\delta$ is the grain boundary width with a nominal value of $1 \mathrm{~nm}$, and $d$ is the mean grain diameter. Experimental data gathered in the current study was used to determine effective diffusion relationships that explained the coarsening behavior and alloy properties as a function of processing. Experimental data on defect densities measured in the current study was used to determine effective diffusion coefficients via Equations 4.1-4.4 for use in the coarsening models (Equations 1.10-1.12). 


\subsection{Results}

\subsubsection{Coherency determination of precipitate}

As precipitates grow, the interface with the matrix transitions from coherent to semicoherent and incoherent [76], with precipitates first generating interface dislocations to reduce internal strain. The precipitate coarsening rate in $\mathrm{Al}-\mathrm{Sc}-\mathrm{Zr}$ has been found to increase as the interface changes from coherent $\mathrm{L} 1_{2}$ to incoherent $\mathrm{D0}_{23}$ [14], [75]. This finding is general and not specific to aluminum systems [83], [84]. The precipitate radius started to lose its coherency when the precipitate grew to $\sim 10 \mathrm{~nm}$ in dilute Al-Sc-Zr [75]. The coherency of precipitates was identified using Ashby-Brown strain contrast in the 72h-aged melt-spun ribbon and extruded rod (Figure 4.1) [76]. Only a few incoherent precipitates were observed on dislocations and grain boundaries; thus this paper will focus on coherent precipitate coarsening evolution in both the melt-spun ribbon and extruded rod. Note that incoherent precipitates on crystal defects were quantified for radius measurements.
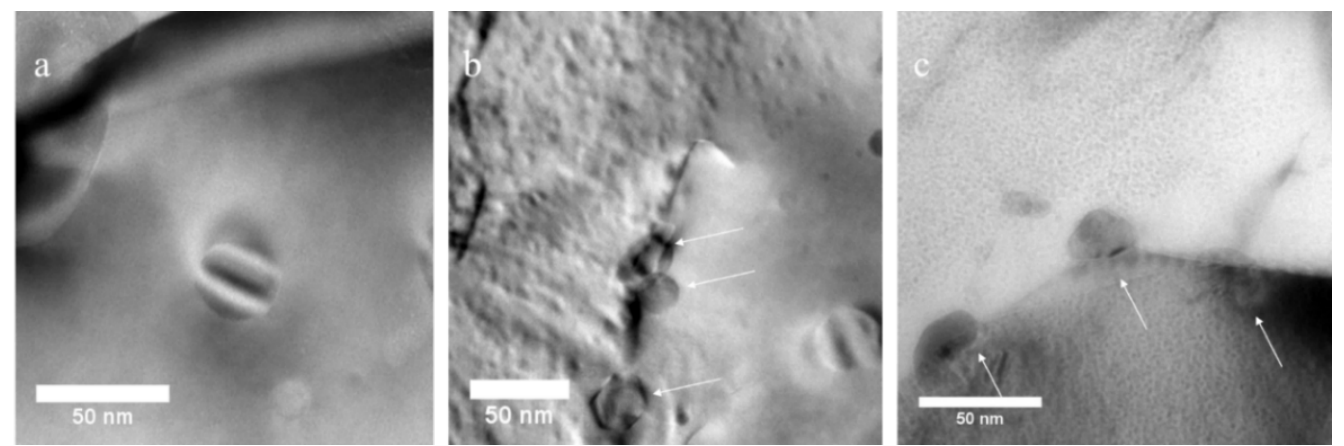

Figure 4.1. Bright-field TEM images of precipitate in the 72h-aged extruded rod. (a) The observed lobes of contrast about the precipitates are consistent with matrix strains of a coherent precipitate [76]. A small number of incoherent precipitates were found at dislocations (b) and grain boundaries (c) (arrows). 


\subsubsection{Time exponents of coarsening}

Precipitate coarsening radii $\langle R(t)\rangle$ and number densities $N(t)$ were plotted on log-log scales as a function of time (Figure 4.2). The slopes yield the reciprocal of the time exponents for precipitate radius and number density changes.
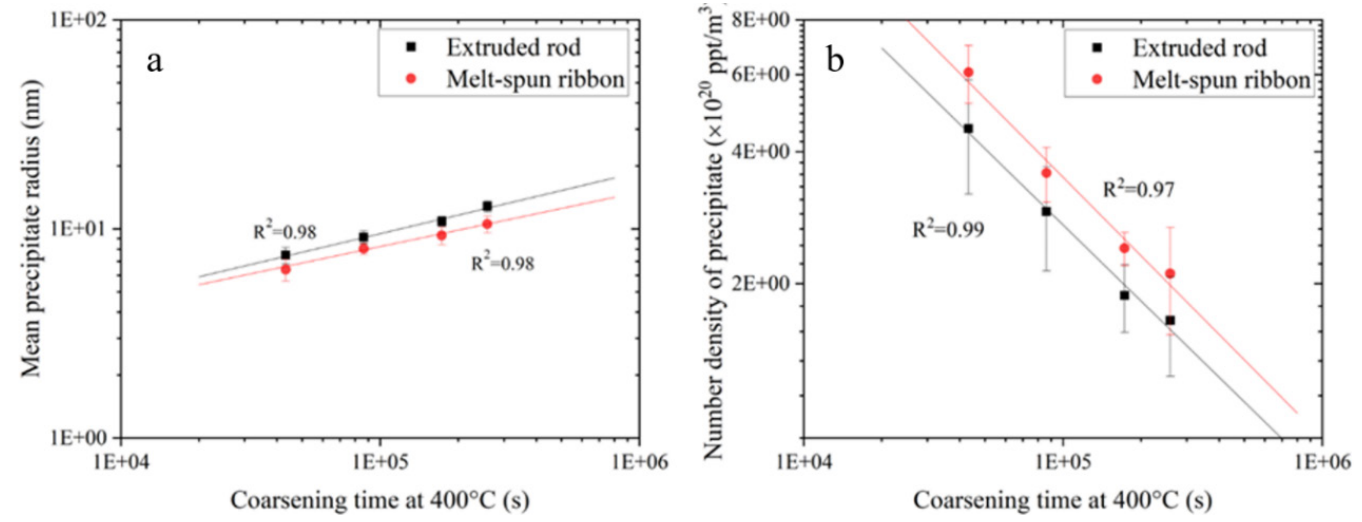

Figure 4.2. Log-log plot of (a) mean precipitate radii and (b) precipitate number density of melt-spun ribbon and extruded rod (error bars are 95\% standard error of the mean).

The time exponents of the precipitate radius function determined as the slopes in Figure 4.2(a) shown in Table 4.1. The time exponents for precipitate radius and number density are 3 and -1 in LSW model respectively. The experimental time exponents for precipitate radius are larger than 3 , for number density are smaller than -1 .

Table 4.1. Time exponents for precipitate radius and number density functions determined by the slopes of the Log-log plots.

\begin{tabular}{c|c|c|c}
\hline & Melt-spun ribbon & Extruded rod & LSW model \\
\hline $\begin{array}{c}\text { Time exponent for } \\
\text { precipitate radius }\end{array}$ & 3.85 & 3.45 & 3 \\
\hline $\begin{array}{c}\text { Time exponent for } \\
\text { precipitate number density }\end{array}$ & -1.73 & -1.67 & -1 \\
\hline
\end{tabular}

\subsubsection{Particle size distributions}

Normalized precipitate size distributions (PSDs) histograms were plotted as a function of normalized precipitate radius $(\mathrm{R} /\langle\mathrm{R}\rangle)$ (Figure 4.3). The PSDs in Figure 4.3 show the 
precipitate size distributions of melt-spun ribbon and extruded rod overaged for $12 \mathrm{~h}, 24 \mathrm{~h}$, $48 \mathrm{~h}$ and $72 \mathrm{~h}$ at $400^{\circ} \mathrm{C}$. The stationary normalized size distribution of $\rho=R /\langle\mathrm{R}\rangle$ was calculated according to the LSW model assuming zero precipitate volume fraction (Equation 4.5)) [47]. The LSW lines in Figure 4.3 represent the stationary distribution function for steady-state precipitate coarsening via bulk diffusion.

$$
f_{L S W}(\rho)=\frac{4}{9} \rho^{2}\left(\frac{3}{3+\rho}\right)^{\frac{7}{3}}\left(\frac{3 / 2}{3 / 2-\rho}\right)^{\frac{11}{3}} \exp \left(-\frac{\rho}{3 / 2-\rho}\right) \quad \text { Equation } 4.5
$$
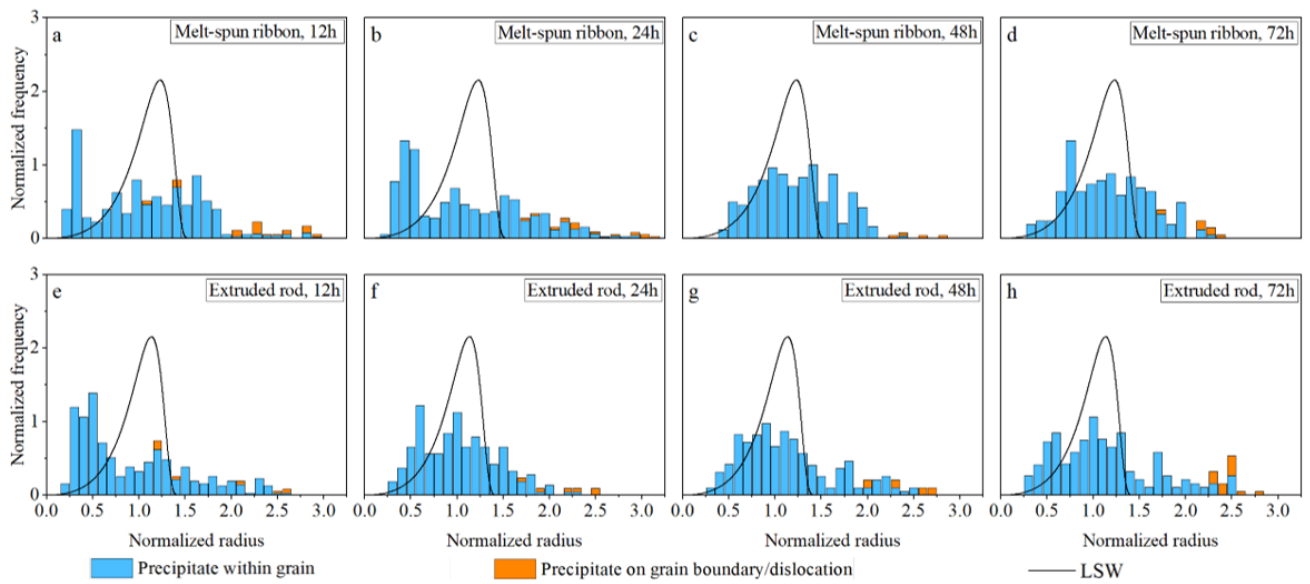

Figure 4.3. Normalized frequency of precipitate size distributions (PSDs) of overaged melt-spun ribbon (a-d) and extruded rod (e-h) for $12 \mathrm{~h}, 24 \mathrm{~h}, 48 \mathrm{~h}, 72 \mathrm{~h}$ at $400^{\circ} \mathrm{C}$. The LSW PSDs (lines) are shown for comparison.

Incoherent precipitates located on grain boundaries/dislocations are noted by different shading (Figure 4.3). Most incoherent precipitates were located within grains, with a small portion of the precipitates were found on dislocations. Precipitates located on crystal defects are preferentially distributed at high normalized radii. Examples of the relatively larger precipitates on dislocations and grain boundaries are shown in the TEM images of the melt-spun ribbon and extruded rods in Figure 4.4. 

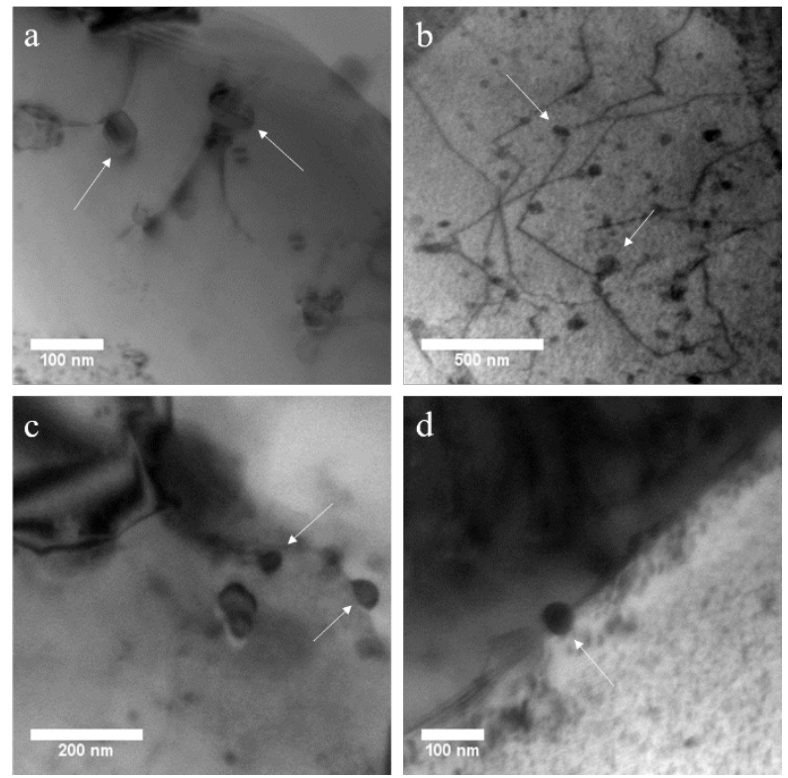

Figure 4.4. TEM images of precipitates locate on (a, b) dislocations and (c, d) grain boundaries in $72 \mathrm{~h}$ overaged $(\mathrm{a}, \mathrm{c})$ melt-spun ribbon and $(\mathrm{b}, \mathrm{d})$ extruded rod. Some incoherent particles are indicated by arrows.

It is apparent that the normalized particle size distributions (PSDs) of annealed melt-spun ribbon and extruded rod are not self-similar and thus are not consistent with the PSD predicted by LSW theory (Figure 4.3). The standard deviation and kurtosis of the normalized precipitate radius in both melt-spun ribbon and extruded rod were calculated at each annealing step as shown in Figure 4.5. Compared to the standard deviation of the normalized radius in the stationary LSW, the standard deviations of melt-spun ribbon and extruded rod were smaller and decreased after annealing. The decreased standard deviations indicated the normalized radius distributions were more concentrated at the average normalized radius $\bar{R} /\langle R\rangle=1$ after been annealed. The larger kurtosis values for melt-spun ribbon and extruded rod than LSW is consistent with the observations that the tails had higher magnitudes and were shifted to large radii [85], [86]. 

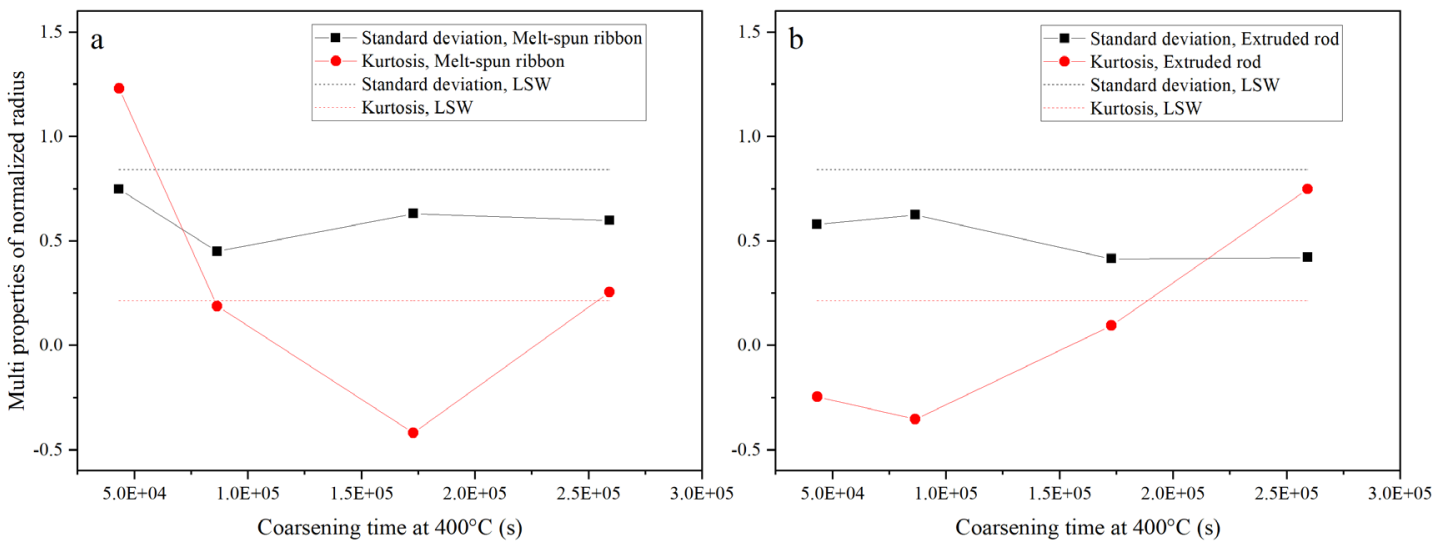

Figure 4.5. The standard deviations and kurtosis of the normalized radius in (a) melt-spun ribbon and (b) extruded rod annealed up to $72 \mathrm{~h}$ at $400^{\circ} \mathrm{C}$. The stationary LSW results are plotted as horizontal lines for comparison.

Compared to the peak normalized frequency, 2.15 , at $1.13\langle R\rangle$ in the stationary LSW plot (Figure 4.3), the PSDs show smaller normalized frequency in the range of 0.9 to 1 , which trend downward as the precipitate volume fraction increases [47], [48], [87]. The normalized precipitate frequency identifies a small number of precipitates located on dislocations and grain boundaries with relatively larger size (Figure 4.3). The portion of precipitates on crystal defects is likely underestimated as a large number of dislocations were recovered during annealing. These observations will be discussed further in Section 4.2 .

\subsubsection{Microstructural evolution}

The grain size of the melt-spun ribbon increased from $\sim 2 \mu \mathrm{m}$ to $\sim 2.5 \mu \mathrm{m}$ when overaged at times from $12 \mathrm{~h}$ to $72 \mathrm{~h}$ (Figure 4.6). The grain size of the extruded rod was reduced during ribbon compaction and extrusion, and then gradually grew during overaging to $\sim 0.9 \mu \mathrm{m}$ at $12 \mathrm{~h}$ and $\sim 1.1 \mathrm{um}$ at $72 \mathrm{~h}$ (Figure 4.6). 


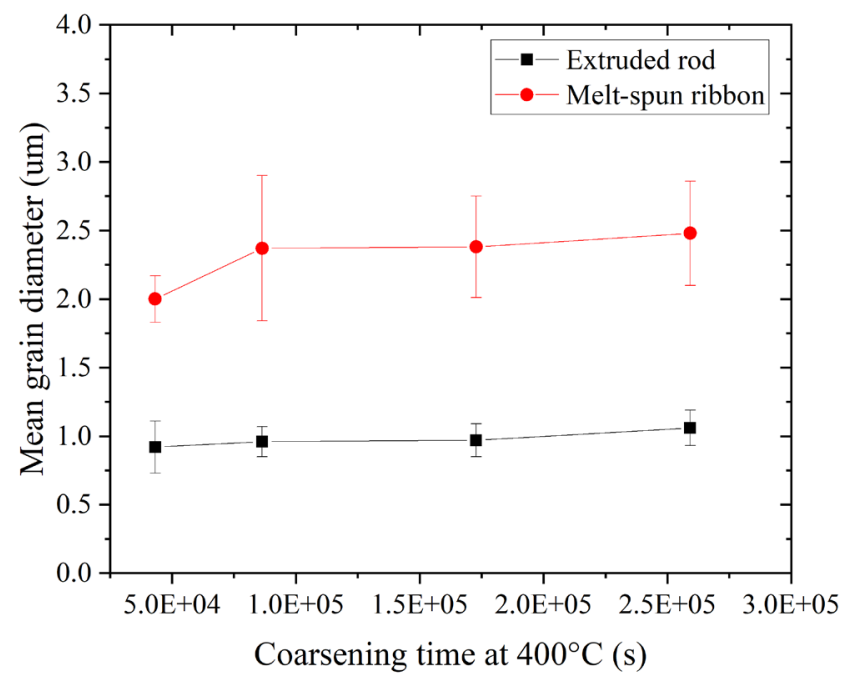

Figure 4.6. Grain diameters of peak-aged $\mathrm{Al}-0.4 \mathrm{Sc}-0.4 \mathrm{Zr}$ at $\%$ melt-spun ribbon and extruded rod annealed up to $72 \mathrm{~h}$ at $400^{\circ} \mathrm{C}$ (error bars are $95 \%$ standard error of the mean).

Dislocation densities were estimated based on dislocation lengths measured in TEM/STEM (Figure 4.7). The thickness of the TEM samples was $\sim 50 \mathrm{~nm}$ as measured by EELS. The dislocation density of melt-spun ribbon decreased from $\sim 8.1 \times 10^{13} \mathrm{~m}^{-2}$ to $\sim 1.6 \times 10^{13} \mathrm{~m}^{-2}$ with annealing from $12 \mathrm{~h}$ to $72 \mathrm{~h}$. As expected, the extruded rod had an increased dislocation density of $\sim 2.0 \times 10^{14} \mathrm{~m}^{-2}$ at low oveaging times, but that decreased to nearly that of the melt spun ribbon after $48 \mathrm{~h}$. Due to the initially reduced grain size and increased dislocation density within the extruded rod versus the melt-spun ribbon, the extruded rod had consistently smaller grain size and higher dislocation densities over all aging times. 


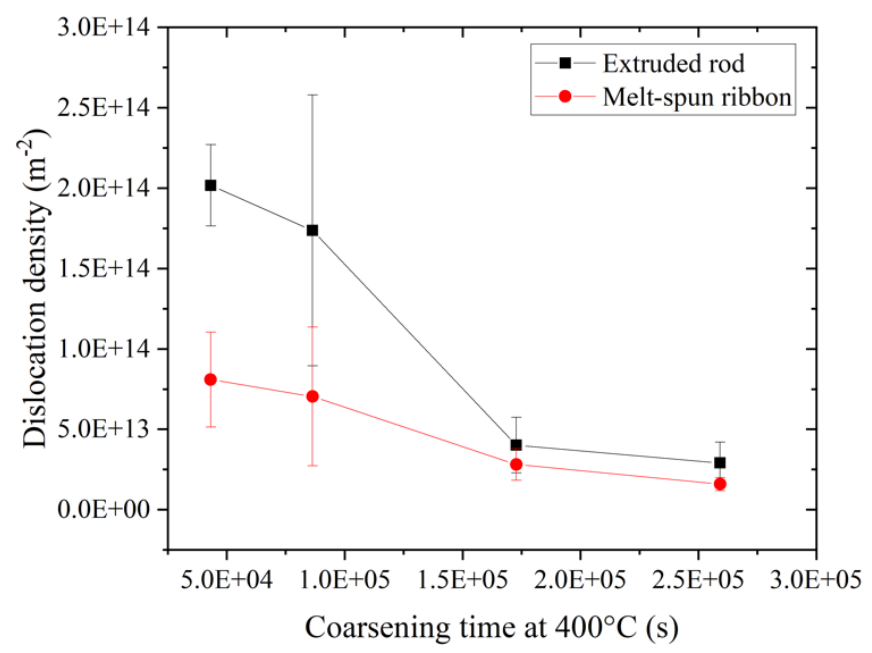

Figure 4.7. Dislocation densities of peak-aged Al-0.4Sc-0.4Zr at $\%$ melt-spun ribbon and extruded rod overaged up to $72 \mathrm{~h}$ at $400^{\circ} \mathrm{C}$ (error bars are $95 \%$ standard error of the mean).

The volume fraction of precipitates in the melt-spun ribbon and extruded rod were estimated based on the precipitate radius and number density changes during annealing (Figure 4.8). The precipitate volume fraction of melt-spun ribbon and extruded rod increased from $0.66 \%$ to $0.88 \%$ and from $0.79 \%$ to $1.2 \%$ respectively after annealing for $12 \mathrm{~h}$ to $72 \mathrm{~h}$ at $400^{\circ} \mathrm{C}$. The observed precipitate volume fractions were smaller than equilibrium precipitate volume fraction estimated from phase diagrams $(\sim 3.2 \%$ for this Al-0.4Sc-0.4Zr at\% alloy) [7], [9]. Smaller precipitate volume fractions than equilibrium predictions were observed in previous studies on Al-Sc-Zr alloys [62], [71], [75]. For example, the precipitate volume fraction of $\mathrm{Al}-0.1 \mathrm{Sc}-0.1 \mathrm{Zr}$ at $\%$ approached $0.44 \%$ after being isochronally aged to $400^{\circ} \mathrm{C}$ (phase diagram is $\sim 0.8 \%$ ) and $\mathrm{Al}-0.09 \mathrm{Sc}-0.03 \mathrm{Zr}$ at $\%$ reached $0.2 \%$ after been isothermally aged at $450^{\circ} \mathrm{C}$ for $5 \mathrm{~h}$ (phase diagram is $\sim 0.48 \%$ ) [62], [71]. Al-Sc-Zr alloys could not reach equilibrium predictions even when annealed for $2412 \mathrm{~h}$ at $375^{\circ} \mathrm{C}$ [75]. This limited solute precipitation may due to the small diffusivities of $\mathrm{Sc}$ and $\mathrm{Zr}$ in $\mathrm{Al}$, and the precipitate volume fraction may increase if aging were continued. The uncertainties in volume fraction calculations are large due to propagation of errors from experimental measurements, particularly the uncertainty in measured TEM sample thickness from EELS. 


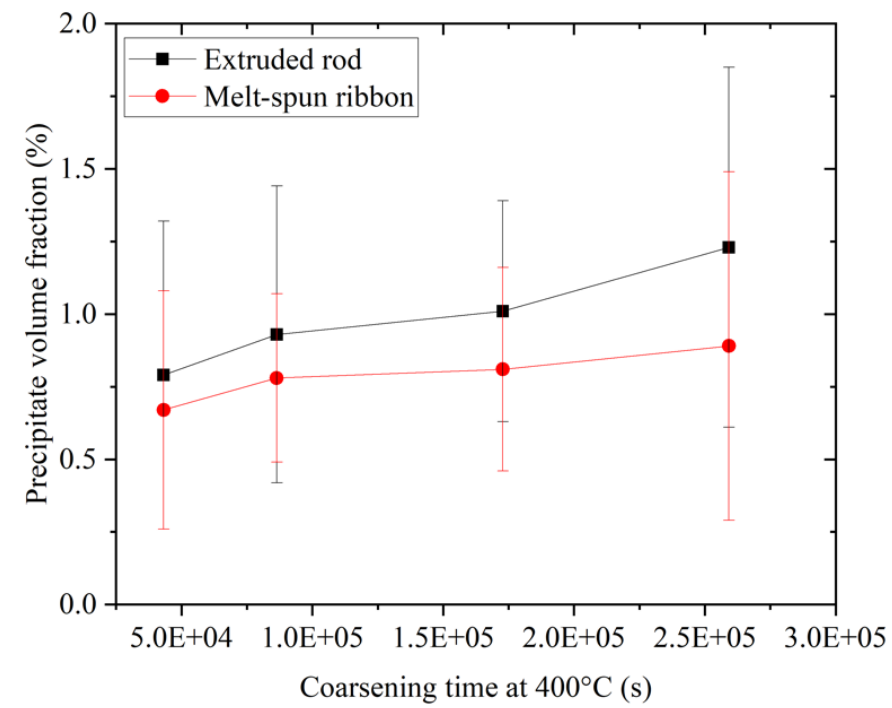

Figure 4.8. Precipitate volume fraction of the peak-aged melt-spun ribbon and extruded rod overaged for $12 \mathrm{~h}, 24 \mathrm{~h}, 48 \mathrm{~h}$ and $72 \mathrm{~h}$ at $400^{\circ} \mathrm{C}$ (error bars are $95 \%$ standard error of the mean).

\subsubsection{Composition change of precipitate}

$\mathrm{Sc}$ and $\mathrm{Zr}$ content in the matrix and precipitates were measured using EDS line scans across the matrix-precipitate interface (Figure 4.9). Precipitate compositions were estimated as the plateaus which typically occurred approximately $1-2 \mathrm{~nm}$ inside the interface. The solute compositions in the matrix were determined in the same range outside the interface.

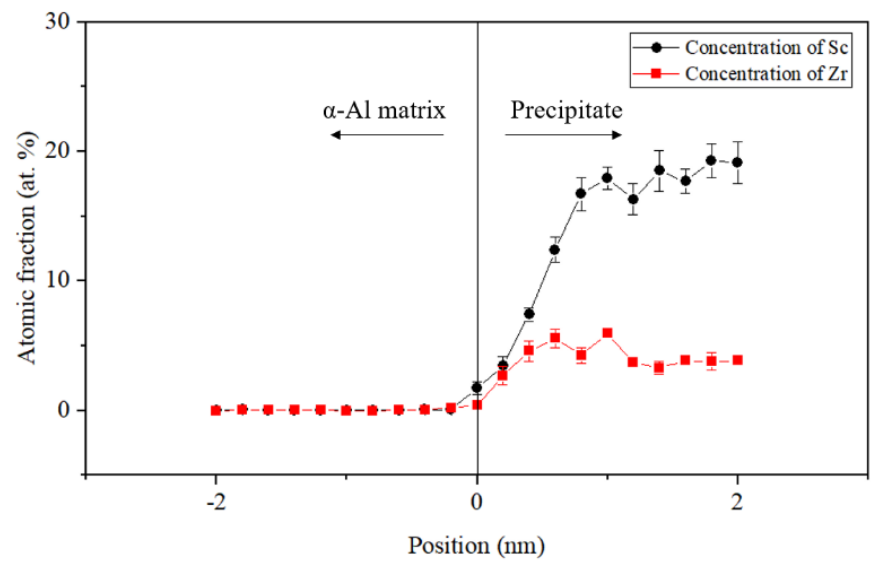


Figure 4.9. Concentrations of $\mathrm{Sc}$ and $\mathrm{Zr}$ change as a function of distance from the interface between the $\alpha$-matrix and an $\mathrm{Al}_{3}\left(\mathrm{Sc}_{1-\mathrm{x}} \mathrm{Zr}_{\mathrm{x}}\right)$ precipitate measured by EDS for an Al-0.4Sc- $0.4 \mathrm{Zr}$ at $\%$ extruded rod aged at $400^{\circ} \mathrm{C}$ for $72 \mathrm{~h}$. Ten precipitates were measured for each sample condition (error bars are 95\% standard error of the mean).

Composition results as measured in Figure 4.9 are compiled in Figure 4.10. As annealing progressed from $12 \mathrm{~h}$ to $72 \mathrm{~h}$ in both the melt-spun ribbon and extruded rod, the atomic fraction of Sc in the precipitates ranged from 18 to $20 \mathrm{at} \%$, while the atomic fraction of $\mathrm{Zr}$ in the precipitates ranged from 2 to $3 \mathrm{at} \%$. The statistical significance of the observed composition variation based on the EDS measurements was analyzed using the Thiel-Sen estimator [88], [89], with at least $>70 \%$ confidence that the $\mathrm{Zr}$ precipitate content increased with aging time, but only a 30\% confidence that the Sc decreased with precipitate aging time (Appendix A). Application of the Thiel-Sen estimator to a previous APT study [90] revealed that the trends identified here are confirmed, but with higher confidence (Appendix A).
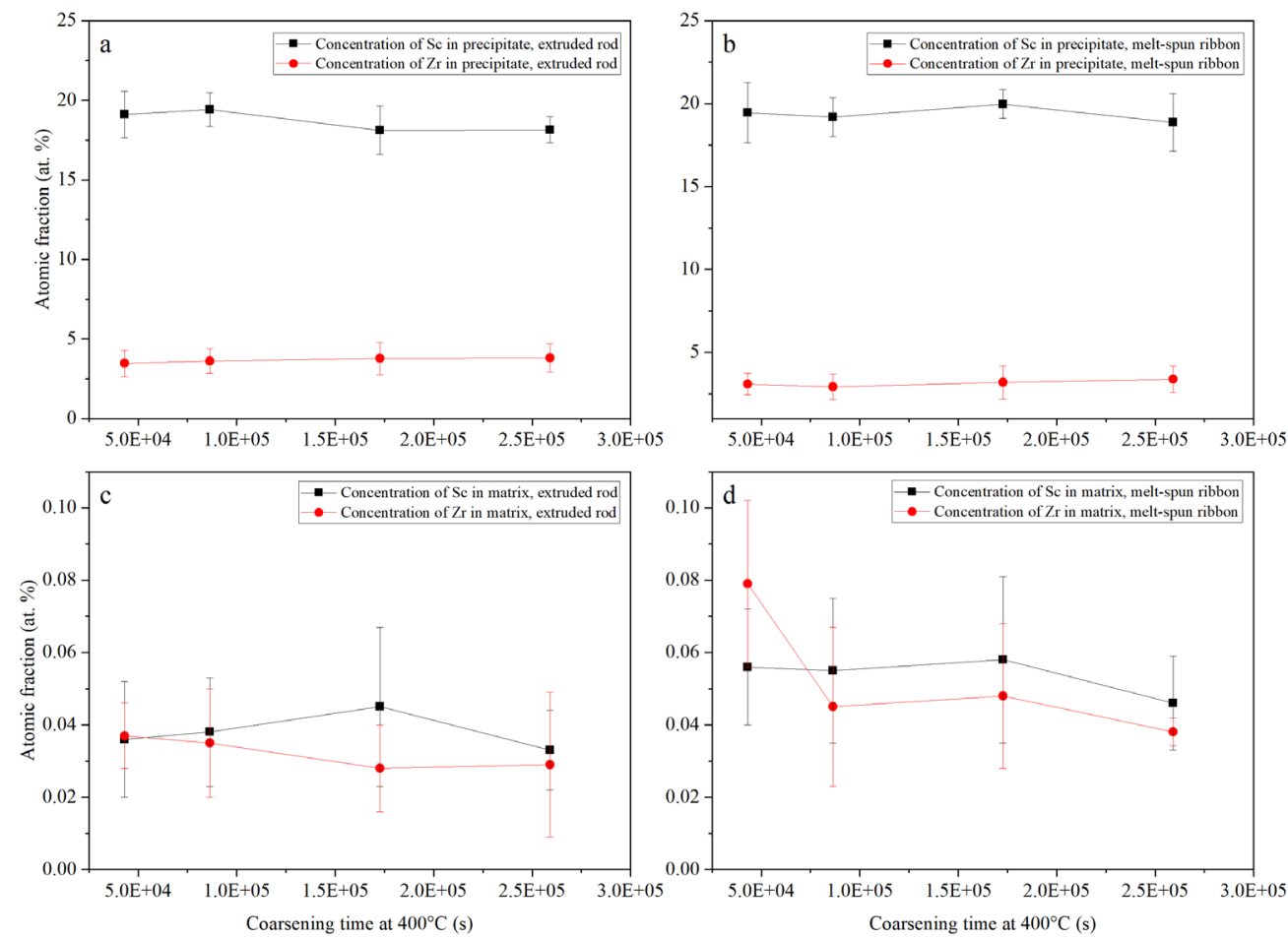
Figure 4.10. Evolution in Sc and Zr concentration in the precipitate and the matrix for melt-spun ribbon and extruded rod annealed up to $72 \mathrm{~h}$ at $400^{\circ} \mathrm{C}$ (error bars are $95 \%$ standard error of the mean).

Solute distribution coefficients were calculated based on measured compositions in the precipitate and matrix (atomic fraction in precipitate/in matrix, Figure 4.11). Distribution coefficients of Sc were ranged from 300 to 550 in both melt-spun ribbon and extruded rod. Distribution coefficients for $\mathrm{Zr}$ were far less than that for Sc ranging from 30 to 150 .

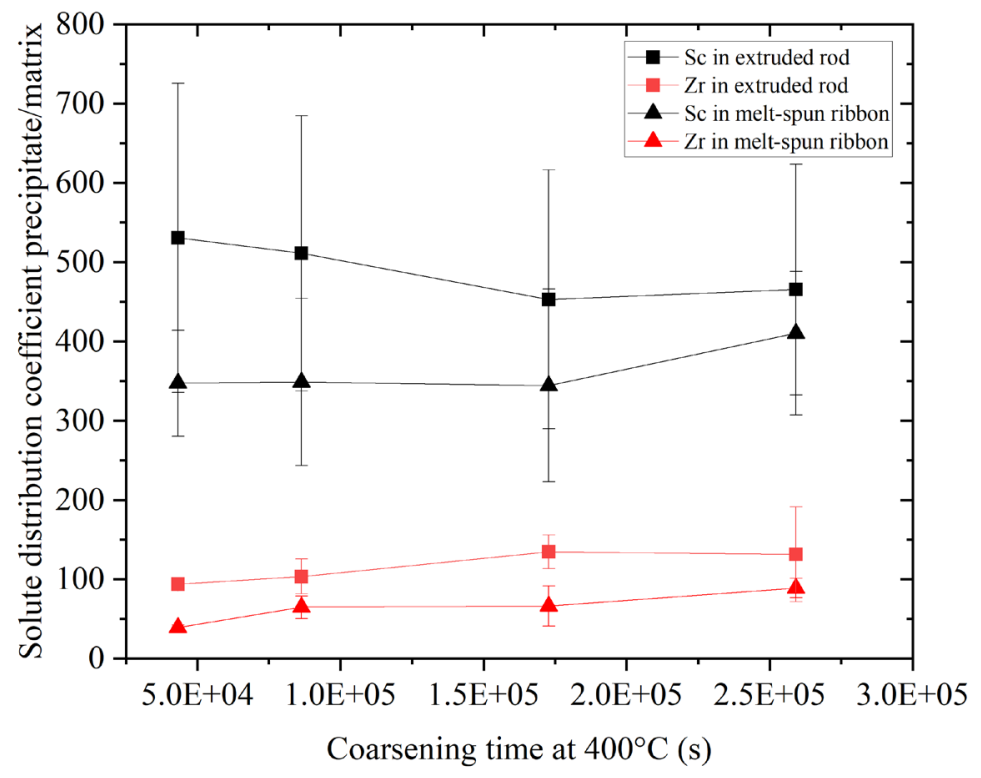

Figure 4.11. Evolution of the solute distribution coefficients (atomic fraction of solute in precipitate/in matrix) at $12 \mathrm{~h}, 24 \mathrm{~h}, 48 \mathrm{~h}$ and $72 \mathrm{~h}$ of annealing at $400^{\circ} \mathrm{C}$ for melt-spun ribbon and extruded rod (error bars are 95\% standard error of the mean).

The core-shell structure of the precipitates was determined from the observation that more $\mathrm{Zr}$ atoms are concentrated in particle periphery $(\sim 0-1 \mathrm{~nm})$ than in the particle center. The concentration of Sc reached a plateau at approximately $1 \mathrm{~nm}$ within the precipitate which is well within the $\mathrm{Zr}$ shell. Solutes changes were slight during aging and their trends were obscured by the measurement error (Figure 4.11). Precipitate composition measurement by APT more clearly reveal a trend of increasing Sc and 
decreasing $\mathrm{Zr}$ during annealing [75]. The APT data shows that Zr solute atoms move into the precipitate during annealing, while the distribution coefficient of Sc decreases as $\mathrm{Zr}$ infiltrates into the precipitate shell.

The solute composition evolution of precipitates in Al-0.09Sc-0.047Zr at $\%$ annealed from $4.5 \mathrm{~h}$ to $2412 \mathrm{~h}$ was studied previously by atom-probe tomography (APT) [90]. The concentrations of $\mathrm{Sc}$ and $\mathrm{Zr}$ in the precipitates were in the range of $27.5 \%-32.5 \%$ and $0.4 \%-1.5 \%$ respectively. The distribution coefficients (atomic fraction in precipitate/matrix) of Sc and Zr ranged from 1000-1500 and 8-32 respectively. Compared to the supersaturated alloys in this investigation, the precipitates in dilute Al-0.009Sc$0.047 \mathrm{Zr}$ at $\%$ alloys contain more $\mathrm{Sc}$ and less $\mathrm{Zr}$. This is likely due to the higher ratio of Sc to $\mathrm{Zr}$ within the Al-0.4Sc-0.4Zr at\% alloy. The higher precipitate solute compositions in the dilute alloys indicate that a larger fraction of the total solute atoms participated in precipitation. The solute composition change trend measured by TEM-EDS in this paper agrees with the results measured by APT on dilute Al-Sc-Zr alloys.

\subsection{Discussion}

\subsubsection{Time exponents of coarsening}

The volume diffusion-controlled LSW theory predicts that the time exponents for precipitate radius evolution $\langle R(t)\rangle^{3}-\langle R(0)\rangle^{3}$ vs $t$ should be 3 . However, the time exponents for the melt-spun ribbon and the extruded rod are larger than 3 (Table 4.1; 3.85 and 3.45 respectively). The Al-0.4Sc-0.4Zr systems studied here have several complicating factors that may affect the time exponent, including time dependent defect density, precipitate composition, and precipitate volume fraction.

These alloys have higher grain boundary area and dislocation densities than traditionally processed materials. The higher matrix defect density is known to increase the effective diffusivity through Equations 4.1-4.4 [91], which increases the coarsening rate. The time dependence of the defect density may be also then affect the time exponent. As confirmed by EDS and previous APT measurements [90], the $\mathrm{Zr}$ composition in the 
precipitate increased with annealing time (Figure 4.10). The $\mathrm{Zr}$ concentration was enriched in the particle periphery or shell region. Thus, the lattice mismatch of precipitate is decreased due to the smaller lattice mismatch of $\mathrm{Al}_{3} \mathrm{Zr}$ versus $\mathrm{Al}_{3} \mathrm{Sc}(1.32 \%$ for $\mathrm{Al}_{3} \mathrm{Sc}, 0.75 \%$ for $\mathrm{Al}_{3} \mathrm{Zr}$ ) [8], [38], [92]. The precipitate interfacial energy is decreased, as this energy is primarily determined by the strain due to precipitates-lattice mismatch [93]. A radius dependent interfacial energy can lead to an increased precipitate coarsening time exponent (Appendix A). This is consistent with other studies in dilute Al-Sc-Zr alloys which have found larger time exponents than 3 [74], [75]. Precipitate volume fraction in supersaturated alloys was found to increase during annealing (Figure 4.8). The diffusion distance of $\mathrm{Zr}$ (x) was $\sim 55 \mathrm{~nm}$ after been overaged for $72 \mathrm{~h}$ using $x=\sqrt{D t}$ at $400^{\circ} \mathrm{C}$ (Table 1.1), the particle spacing was estimated $\sim 450 \mathrm{~nm}$ from the precipitate number density in 72h-overgaed supersaturated alloys $\left(\sim 2 \times 10^{20} \mathrm{ppt} / \mathrm{m}^{3}\right)$. Compared to the calculated equilibrium precipitate volume fraction $\sim 1.95 \%$ in $\mathrm{Al}-0.4 \mathrm{Sc}-0.4 \mathrm{Zr}$ at $\%$ at $400^{\circ} \mathrm{C}$ [7], [9], the measured precipitate volume fractions of melt-spun ribbon and extruded rod were much smaller than calculated values in $72 \mathrm{~h}$-overgaed supersaturated alloys $(0.9 \%$ for the melt-spun ribbon and $1.3 \%$ for the extruded rod). The insufficient diffusion distance of $\mathrm{Zr}$ and nonequilibrium precipitate volume fraction suggested the steady-state have not been reached during annealing as LSW. The transportation of Sc and Zr between precipitates was considered facilitated through nucleating precipitate during overaging.

The LSW coarsening kinetics were modified to account for an increase in particle volume fraction during overaging (Appendix B), and the apparent time exponent for coarsening decreased. Appendix B provides a rationale for the smaller time exponents due to increased particle volume fraction for supersaturated melt-spun ribbon and extruded rod as compared to earlier results in dilute alloys [74], [75].

The time exponents for coarsening observed in this study may be confounded by the conflicting observations that a decreasing defect density and increasing $\mathrm{Zr}$ content can increase the time exponent to 3.3 according to the experimental precipitate composition 
change (Appendix A). A lingering supersaturation can decrease the time exponent to a value smaller than 3 . The remainder of the discussion focuses on the role of defect density in increasing the effective diffusivity during coarsening (Equations 4.1-4.4) and identifies the most influential parameter affecting the coarsening rate.

\subsubsection{Effective diffusivity for coarsening acceleration}

Based on the measured grain size and dislocation density of melt-spun ribbon and extruded rod (Figures 4.6 and 4.7), the effective diffusion coefficient evolution was estimated as a function of annealing time (Equations 4.1 to 4.4) (Figure 4.12).
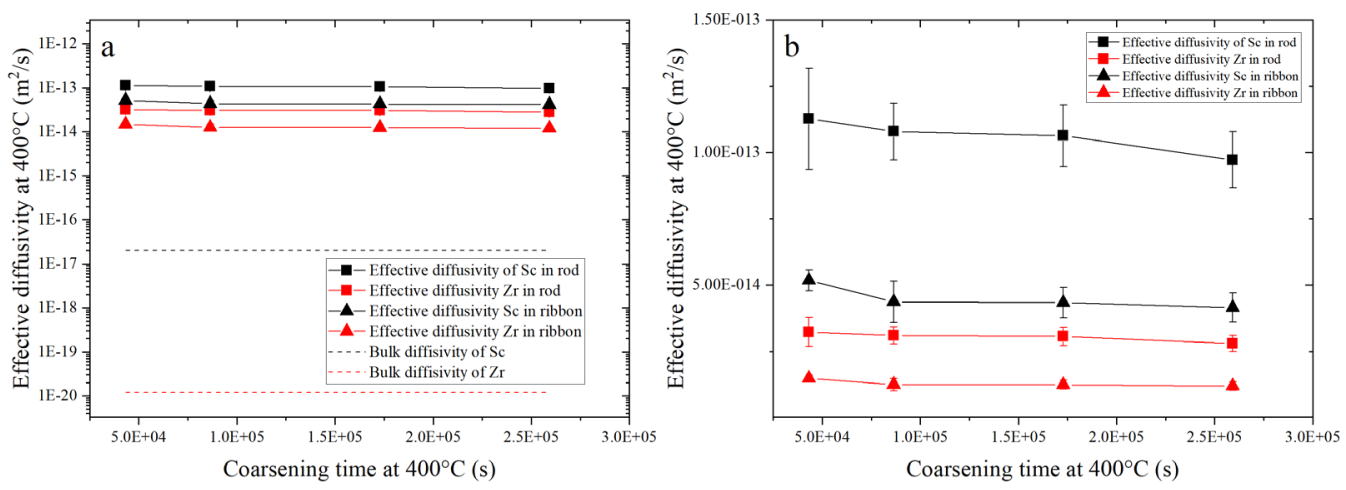

Figure 4.12. Effective diffusivities of solutes in melt-spun ribbon and extruded rod at different annealing steps up to $72 \mathrm{~h}$ at $400^{\circ} \mathrm{C}$. Bulk diffusivities of solutes are imposed for comparison (a) and effective diffusivities are plotted with an expanded scale in (b).

Compared to the bulk diffusivities of both $\mathrm{Sc}$ and $\mathrm{Zr}$ at $400^{\circ} \mathrm{C}$, the calculated effective diffusivities of the solute are elevated by $\sim 10^{3}$ and $\sim 10^{6}$ for Sc and $\mathrm{Zr}$ respectively. The solutes diffusivity increases are attributed to the small grain size produced in the meltspun ribbon due to the rapid solidification. The grains were then further refined during rod extrusion (Figure 4.6). Another contribution to diffusivity increase was due to the numerous dislocations introduced in both materials, but especially in the extruded rod (Figure 4.7). The increased diffusivities aided growth of larger precipitates along grain boundaries and dislocations (Figure 4.3). The diffusion acceleration was thought to play a role in grains even without direct observation as dislocations as recovery occurred during 
annealing. As annealing progressed, the effective diffusivities of solutes in both the meltspun ribbon and extruded rod decreased with grain growth and lower dislocation density.

\subsubsection{Prediction of precipitate radius coarsening evolution}

Knowledge of the solute compositions in the precipitates and matrix, solute distribution coefficients, and effective diffusion coefficients allows for the coarsening rate and precipitate radius to be predicted using the UOKV model for ternary alloys (Equation 1.10). Figure 4.13 shows the UOKV predicted and the experimental coarsening rate at each annealing step in the melt-spun ribbon and extruded rod. In Figure 4.13, the UOKVpredicted coarsening rate are increased $10^{4}-10^{5}$ times using effective diffusivities than using bulk diffusivities at $400^{\circ} \mathrm{C}$.

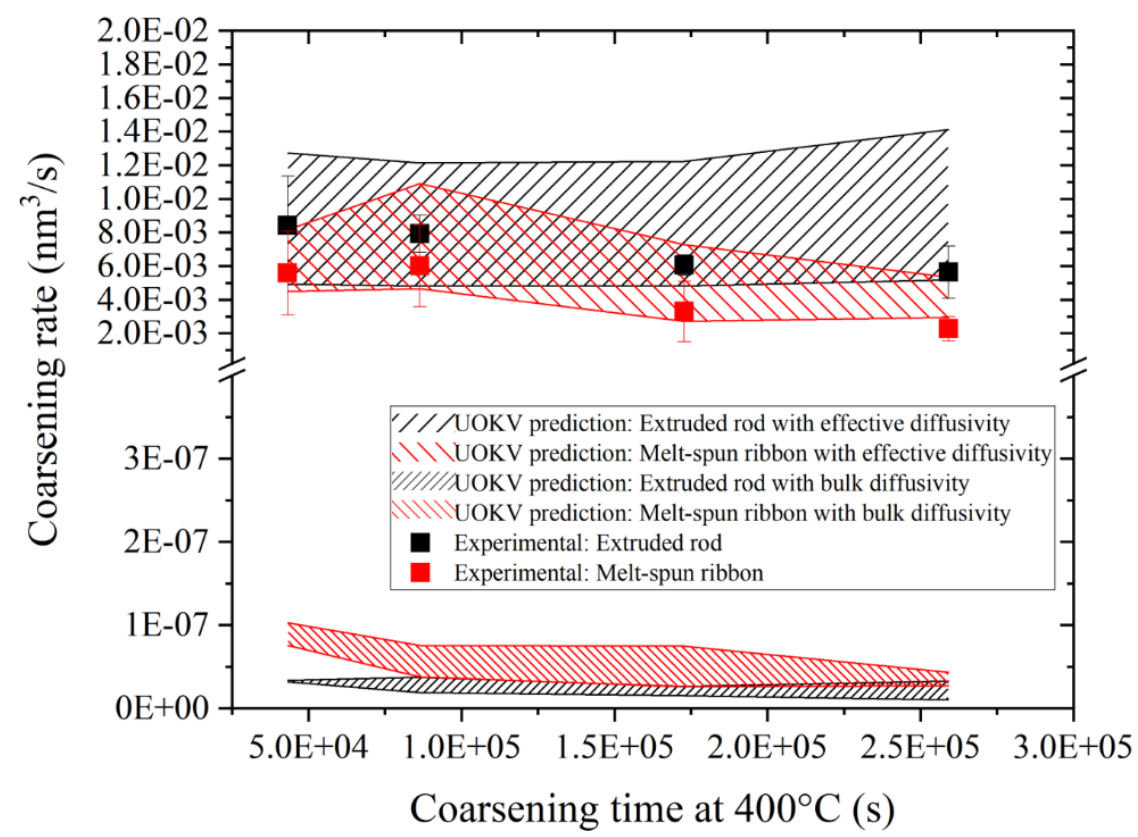

Figure 4.13. Experimental precipitate coarsening rate and UOKV predicted coarsening rate using bulk and effective diffusivities in melt-spun ribbon and extruded rod at different annealing steps up to $72 \mathrm{~h}$ at $400^{\circ} \mathrm{C}$. 
The experimental and UOKV-predicted precipitate coarsening rates at first and last step were summarized in Table 4.2. The experimental precipitate coarsening rates decrease with radius increase during annealing due to the precipitate coarsening rate $\mathrm{dR} / \mathrm{dt}$ being proportional to $1 / R^{2}$ (for time exponent of radius, $n=3$ ). The experimental precipitate coarsening rate of the extruded rod decreased over the entire aging cycle. The precipitate coarsening rate of melt-spun ribbon decreased over the same period. Note that the coarsening rate in the extruded rod is larger than in the melt-spun ribbon at each aging step since the effective solute diffusivities were larger in extruded rod.

When using effective diffusivities in calculations, the UOKV-predicted coarsening rate of the extruded rod decreased from $8.8 \times 10^{-3} \mathrm{~nm}^{3} / \mathrm{s}$ to $8.4 \times 10^{-3} \mathrm{~nm}^{3} / \mathrm{s}$ as samples were aged from $12 \mathrm{~h}$ to $24 \mathrm{~h}$. The extruded rod's coarsening rate then increased over the rest aging cycle. The non-monotonic coarsening rate of the extruded rod was likely introduced due to measurement errors in solute compositions as solute compositions were assumed to monotonically increase (section 3.5). The predicted coarsening rate of meltspun ribbon showed an apparent decreasing trend over the entire aging period.

Table 4.2. Experimental and UOKV predicted coarsening rates change from shortest (12h) to longest (72h) annealing steps.

\begin{tabular}{c|c|c}
\hline Overaging at $400^{\circ} \mathrm{C}$ & & \\
$\begin{array}{l}\text { Precipitate coarsening } \\
\text { rate }\left(\mathrm{nm}^{3} / \mathrm{s}\right)\end{array}$ & $12 \mathrm{~h}$ & $72 \mathrm{~h}$ \\
\hline $\begin{array}{c}\text { Experimental: melt-spun ribbon } \\
\text { Experimental: extruded rod }\end{array}$ & $5.6 \times 10^{-3}$ & $2.2 \times 10^{-3}$ \\
UOKV: melt-spun ribbon & $8.4 \times 10^{-3}$ & $5.8 \times 10^{-3}$ \\
UOKV: extruded rod & $8.4 \times 10^{-3}$ & $4.1 \times 10^{-3}$ \\
\end{tabular}

The UOKV-predicted coarsening rates shows similar trend and order of magnitude agreement with the experimental coarsening rates because the observed reduction in defect densities leads to a time series reduction in effective diffusivity. General 
agreement in coarsening rate with time supports the assertion that diffusivities were increased due to grain boundaries and dislocation core short-circuit diffusion.

Since the UOKV-predicted coarsening rates are consistent with experimental coarsening rates in both melt-spun ribbon and extruded rod during annealing, the precipitate radius change $\langle R(t)\rangle^{3}-\langle R(0)\rangle^{3}$ was calculated based on the model (Figure 4.14). In general, the effective diffusivity produced good agreement with respect to the order of magnitude and trends.
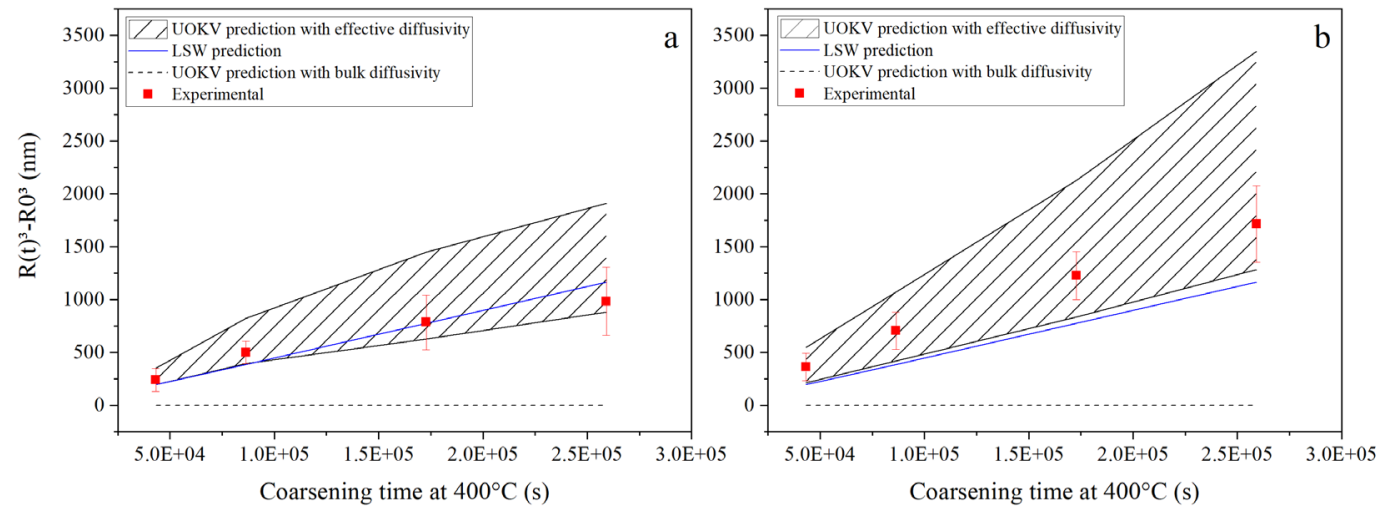

Figure 4.14. The UOKV-predicted and experimentally measured precipitate radius evolution in (a) melt-spun ribbon and (b) extruded rod annealed up to $72 \mathrm{~h}$ at $400^{\circ} \mathrm{C}$. The radius change estimated using general LSW model and UOKV model with bulk diffusivity on ternary alloy were imposed for comparison (error bars are 95\% standard error of the mean).

The radius increase was determined using predicted coarsening rates at steps of $12 \mathrm{~h}, 24 \mathrm{~h}$, $48 \mathrm{~h}$ and $72 \mathrm{~h}$. The experimental and UOKV-predicted precipitate radius at first and last step were summarized in Table 4.3. The comparison of the UOKV model with the experimental results shows an increasing divergence with increased coarsening time although the effect is small. One reason is the time dependent effective diffusivity used in the UOKV model does not increase the predicted time exponent as observed experimentally (Figure 4.2). This further increase in time exponent required by the experimental results could be rationalized on the basis of Appendix A, where an increase 
in time exponent can occur with a monotonic decrease in interfacial energy with average precipitate radius.

The precipitate radius evolution during annealing was predicted using the general LSW model on a ternary alloy for comparison. According to Equation 1.10, the precipitate molar volume, diffusion coefficient and equilibrium solute solubility were estimated based on the atomic fraction ratio of solutes as $\mathrm{Sc}: \mathrm{Zr}$ equals to 1:1. Since solutes continued to precipitate during annealing, the solute concentrations in the matrix declined as measured by EDS and atom-probe tomography [90] and the precipitates grew. The LSW-predicted radius was underestimated due to increasing precipitate volume according to Equation 1.10.

Table 4.3. Experimental and UOKV predicted precipitate radius using effective diffusivities at shortest (12h) to longest (72h) annealing steps.

\begin{tabular}{c|c|c}
\hline Overaging at $400^{\circ} \mathrm{C}$ & & \\
& $12 \mathrm{~h}$ & $72 \mathrm{~h}$ \\
Precipitate radius $\mathrm{R}(\mathrm{t})^{3}-\mathrm{R}(0)^{3}(\mathrm{~nm})$ & & \\
\hline Experimental: melt-spun ribbon & $241 \pm 108$ & $982 \pm 322$ \\
Experimental: extruded rod & $363 \pm 128$ & $1716 \pm 362$ \\
UOKV: melt-spun ribbon & $273 \pm 79$ & $1398 \pm 515$ \\
UOKV: extruded rod & $381 \pm 168$ & 2318 \\
General LSW prediction & 194 & \pm 1032 \\
\hline
\end{tabular}

\subsubsection{Prediction of particle density evolution}

Using Equation 1.12, the number density of precipitates in melt-spun ribbon and extruded rod were calculated and compared to the measured particle number density (Figure 4.15). The volume fraction of precipitate was estimated based on the measured particle size and number density and showed good agreement in magnitude and trends (Figure 4.8). 

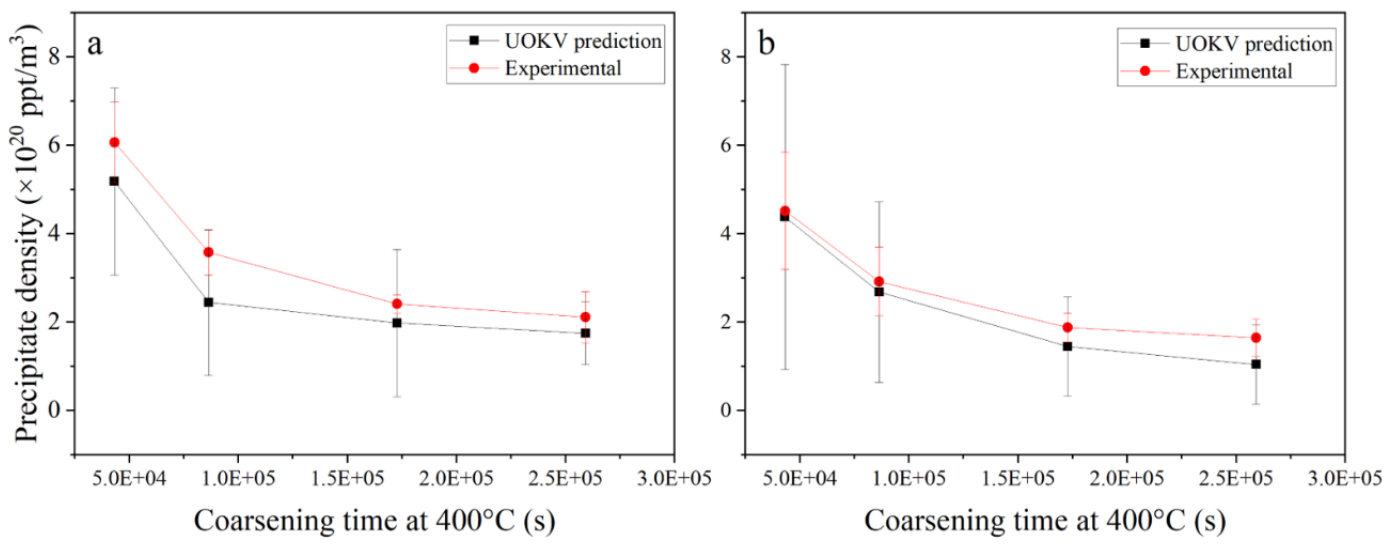

Figure 4.15. The UOKV-predicted and experimentally measured precipitate number density evolution in melt-spun ribbon (a) and extruded rod (b) annealed up to $72 \mathrm{~h}$ at $400^{\circ} \mathrm{C}$ (error bars are $95 \%$ standard error of the mean).

The UOKV-predicted and experimentally measured precipitate number density evolution in melt-spun ribbon and extruded rod were summarized in Table 4.3. For both melt-spun ribbon and extruded rod, the UOKV-predicted precipitate number densities are smaller than experimentally measured values at each corresponding step. Considering the precipitate volume fractions were increased instead of staying constant in the two supersaturated alloys, the particle number densities were overpredicted despite using measured values of solute composition, distribution coefficient, and effective diffusivity changes during annealing. Compared to the precipitate number densities of $5.3 \times 10^{22} \mathrm{ppt} / \mathrm{m}^{3}$ and $7.4 \times 10^{22} \mathrm{ppt} / \mathrm{m}^{3}$ in peak-aged melt-spun ribbon and extruded rod respectively [73], precipitate number densities were significantly decreased after overaging (Figure 4.15). The precipitate number densities in overaged supersaturated alloys decreased to the same magnitude as in overaged dilute alloys [74], [75]. Besides uncertainty in measured sample thickness, this decrease is also attributed to the short particle spacing (solute diffusion distance) due to the larger precipitate volume fractions in supersaturated alloys [24]. 


\subsection{Conclusion}

The coarsening behavior of $\mathrm{Al}_{3}\left(\mathrm{Sc}_{1-\mathrm{x}} \mathrm{Zr}_{\mathrm{x}}\right)$ precipitates was investigated and analyzed in supersaturated Al-Sc-Zr processed by melt-spinning and extrusion. The coherency, size, number density, and composition of the precipitates was assessed as they were coarsened at $400^{\circ} \mathrm{C}$ for up to $72 \mathrm{~h}$. Compared to the UOKV model using volume diffusivities, the coarsening rate was accelerated by increased defect densities which led to increased transport rates. The small divergence of the experimental results with respect to the expected $\langle\mathrm{R}(\mathrm{t})\rangle^{3}-\langle\mathrm{R}(0)\rangle^{3}$ vs $\mathrm{t}$ was rationalized on the basis of a decrease in interfacial energy with increasing precipitate radius caused by $\mathrm{Zr}$ enrichment in the precipitate shell.

This work demonstrates:

- A large number of defects were introduced into both melt-spun ribbon and extruded rod compared to bulk alloys. The coarsening rates in the melt-spun ribbon and extruded rod were accelerated versus the bulk alloys due mainly to the increased defect density. The coarsening rate in the extruded rod was further increased versus melt-spun ribbon due to a microstructure that was further refined by extrusion.

- The coarsening of $\mathrm{Al}_{3}\left(\mathrm{Sc}_{1-\mathrm{x}} \mathrm{Zr}_{\mathrm{x}}\right)$ precipitate didn't reach steady-state as the matrix and precipitate composition was still changing with annealing. The composition of the matrix and precipitates were continually changing with annealing time. The remaining supersaturation may have contributed the accelerated particle growth during annealing.

- Using the UOKV model, predictions of the precipitate size and number density agree with experimental results. Time exponents of radius and number density are strongly influenced by supersaturation and chemical composition. The time exponent was found increased to larger than 3 (3.3) due to the changed chemical composition. 


\section{Chapter 5. High-temperature mechanical properties of supersaturated Al-Sc-Zr alloy via melt-spinning and extrusion}

\subsection{Abstract}

Supersaturated Al-0.4Sc-0.4Zr at $\%$ was processed via melt-spinning and extrusion. The Al-0.4Sc-0.4Zr at $\%$ was peak-aged at $350^{\circ} \mathrm{C}$ for $5 \mathrm{~h}$ and $400^{\circ} \mathrm{C}$ for $0.5 \mathrm{~h}$, while the as-cast Al-0.06Sc- $0.06 \mathrm{Zr}$ at $\%$ was peak-aged isothermally at $300^{\circ} \mathrm{C}$ for $15 \mathrm{~h}$. Macro Vickers hardness, compression strength and creep test were all assess in the temperature range of ambient temperature to $500^{\circ} \mathrm{C}$. Grain size, precipitate size and precipitate volume fraction were quantified in scanning transmission electron microscopy (STEM). A smaller grain size, larger precipitate radius and larger precipitate volume fraction were observed in Al$0.4 \mathrm{Sc}-0.4 \mathrm{Zr}$ at $\%$ as compared to $\mathrm{Al}-0.06 \mathrm{Sc}-0.06 \mathrm{Zr}$ at $\%$. Over the temperature range of $300^{\circ} \mathrm{C}-400^{\circ} \mathrm{C}$, the threshold stress increased from 4-10 MPa in Al-0.06Sc-0.06Zr at $\%$ and 7-14 $\mathrm{MPa}$ in $\mathrm{Al}-0.4 \mathrm{Sc}-0.4 \mathrm{Zr}$ at\%. A larger threshold stress was attributed to the larger precipitate size and volume fraction in $\mathrm{Al}-0.4 \mathrm{Sc}-0.4 \mathrm{Zr}$ at $\%$ than in $\mathrm{Al}-0.06 \mathrm{Sc}-0.06 \mathrm{Zr}$ at $\%$. The mechanism of the dislocation climb was identified by calculating the activation energy, which was consistent with that of self-diffusion.

\subsection{Introduction}

$\mathrm{Al}_{3}\left(\mathrm{Sc}_{1-\mathrm{x}} \mathrm{Zr}_{\mathrm{x}}\right)$ precipitates increase strength and coarsening resistance (see Section 3.2) by (I) grain size refinement [71], (II) coarsening resistance due to Sc and Zr having smaller diffusivities than common aluminum-alloy-additions such as $\mathrm{Cu}, \mathrm{Si}$ and $\mathrm{Mg}$ [15][19]; and (III) a stable "core-shell” structure precipitate with Sc-rich core and Zr-rich shell due to the diffusivity and lattice strain difference between $\mathrm{Sc}$ and $\mathrm{Zr}$ [22], [67]. These last two factors were contributed more significantly at elevated temperatures.

Precipitate strengthening of Sc and $\mathrm{Zr}$ in $\alpha-\mathrm{Al}$ is limited (Section 3.2), as the maximum equilibrium solubilities of solute additions are only 0.28 at $\% \mathrm{Sc}$ and $0.033 \mathrm{at} \% \mathrm{Zr}$ [7], 
[8], [52], [53]. Primary precipitates are observed when excess solute was added [71], [72]. Additionally, solute segregations of Sc (eutectic/interdendritic) and $\mathrm{Zr}$ (peritectic/dendritic) are observed in as-cast Al-Sc-Zr alloys [11]. This leads to the inhomogeneous distributions of the $\mathrm{Al}_{3}\left(\mathrm{Sc}_{1-\mathrm{x}} \mathrm{Zr}_{\mathrm{x}}\right)$ precipitates.

Melt spinning, a rapid solidification technique, was utilized to increase the supersaturated solute concentration in the $\mathrm{Al}$ matrix without primary precipitate formation [73]. Subsequent extrusion of the canned melt-spun ribbon produced a rod with large number dislocations and grain size refinement (Section 3.5.1). These microstructure changes affected the precipitate nucleation and coarsening as discussed in Chapter 3 and Chapter 4. As the temperature increases, the creep mechanism in precipitate-strengthened materials (Section 1.2.2) can transition from dislocation shearing and looping to climb out of the glide plane.

\subsection{Experimental}

\subsubsection{Sample preparation}

The sample preparation procedure for production of supersaturated $\mathrm{Al}-0.4 \mathrm{Sc}-0.4 \mathrm{Zr}$ at $\%$ extruded rods and dilute, as-cast $\mathrm{Al}-0.06 \mathrm{Sc}-0.06 \mathrm{Zr}$ at $\%$ were summarized in Chapter 2. The Al-0.4Sc-0.4Zr at $\%$ rod was peak-aged using a two-step process $\left(350^{\circ} \mathrm{C}\right.$ for $5 \mathrm{~h}$ and $400^{\circ} \mathrm{C}$ for $\left.0.5 \mathrm{~h}\right)$, while the $\mathrm{Al}-0.06 \mathrm{Sc}-0.06 \mathrm{Zr}$ at $\%$ was isothermally aged $\left(300^{\circ} \mathrm{C}\right.$ for $\left.15 \mathrm{~h}\right)$.

\subsubsection{Hot Macro Vickers, compression, and creep testing}

Macro hot hardness, hot compression and creep tests were done on the peak-aged Al$0.4 \mathrm{Sc}-0.4 \mathrm{Zr}$ at $\%$ and $\mathrm{Al}-0.06 \mathrm{Sc}-0.06 \mathrm{Zr}$ at $\%$ rods (Table 5.1 ). The operations and settings were summarized in section 2.2.2, 2.2.4 and 2.2.5 respectively.

Table 5.1. Temperature range and testing numbers of Macro hot hardness, hot compression and creep tests on supersaturated and dilute alloys.

\begin{tabular}{c|c|c}
\hline Testing methods & Testing temperature steps $\left({ }^{\circ} \mathrm{C}\right)$ & $\begin{array}{c}\text { Testing numbers at } \\
\text { each step }\end{array}$ \\
\hline
\end{tabular}




\begin{tabular}{c|c|c}
\hline Hot Macro Vickers & $25,200,300,400,500$ & 10 \\
\hline Hot compression & $25,200,300,400,500$ & 2 \\
\hline Creep & $300,350,400$ & 4 \\
\hline
\end{tabular}

\subsubsection{Transmission electron microscopy analysis}

Grain size, precipitate size and precipitate number density in the as-prepared, peak-aged and crept $\mathrm{Al}-0.4 \mathrm{Sc}-0.4 \mathrm{Zr}$ at $\%$ and $\mathrm{Al}-0.06 \mathrm{Sc}-0.06 \mathrm{Zr}$ at $\%$ were assessed in bright-field TEM and STEM using an FEI Titan Themis S-TEM. The specimen preparation procedures of TEM were summarized in section 2.1.9. Precipitate radius was measured with ImageJ for over 100 precipitate for each sample. The precipitate volume fractions were estimated according to the measured precipitate radius and number density, with TEM foil thickness measured using electron energy loss spectroscopy (EELS).

\subsection{Results}

\subsubsection{Compression properties up to $500^{\circ} \mathrm{C}$}

The ultimate compressive strength of the peak-aged Al-0.4Sc-0.4Zr at $\%$ and Al-0.06Sc$0.06 \mathrm{Zr}$ at $\%$ specimens were measured from room temperature to $500^{\circ} \mathrm{C}$ every $100^{\circ} \mathrm{C}$ (Figure 5.1). The ultimate compressive strength showed the largest difference between Al-0.4Sc-0.4Zr at $\%$ and Al-0.06Sc-0.06Zr at $\%$ at ambient temperature with $300 \pm 20 \mathrm{MPa}$ versus $90 \pm 10 \mathrm{MPa}$ respectively. As the test temperature increased, the ultimate compressive strength difference between the alloys decreased until the difference became negligible at temperatures above $300^{\circ} \mathrm{C}$. The hot macro Vickers hardness tests were done and converted into strength using a $\Delta \mathrm{HV} / 3$ conversion at ambient temperature [63]. The hot macro Vickers hardness showed consistent strength loss to hot compression strength over the same temperature range. 


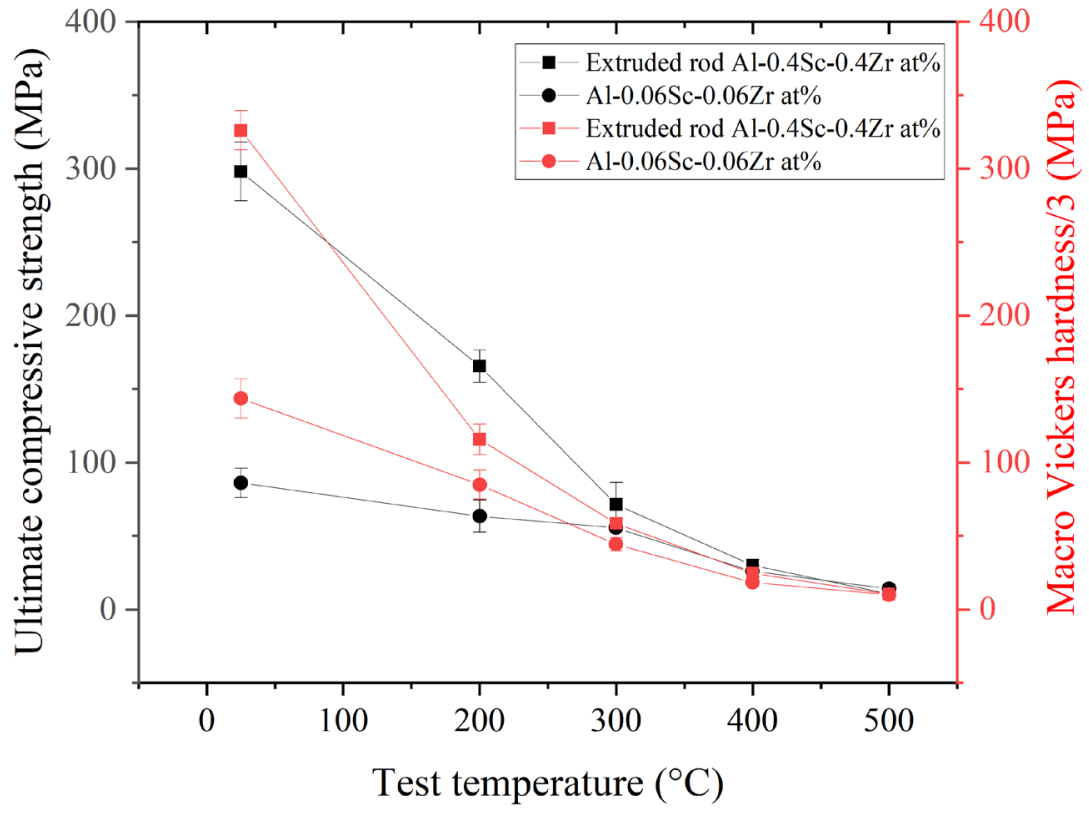

Figure 5.1. Ultimate compressive strengthen of peak-aged Al-0.4Sc-0.4Zr at $\%$ and Al$0.06 \mathrm{Sc}-0.06 \mathrm{Zr}$ at $\%$ from room temperature to $500^{\circ} \mathrm{C}$ (left scale). Also plotted is the hot macro hardness/3 for comparison (right scale) (Error bars are 95\% standard error of the mean.)

\subsubsection{Creep properties at $300^{\circ} \mathrm{C}$ to $400^{\circ} \mathrm{C}$}

The creep properties at steady-state strain rate versus applied stress in peak-aged A1$0.4 \mathrm{Sc}-0.4 \mathrm{Zr}$ at $\%$ and $\mathrm{Al}-0.06 \mathrm{Sc}-0.06 \mathrm{Zr}$ at $\%$ were investigated at $300^{\circ} \mathrm{C}, 350^{\circ} \mathrm{C}$ and $400^{\circ} \mathrm{C}$ (Figure 5.2). At each temperature step, Al-0.4Sc-0.4Zr at\% required larger applied stress than the $\mathrm{Al}-0.06 \mathrm{Sc}-0.06 \mathrm{Zr}$ at $\%$ to produce a similar steady-state strain rate indicating the larger creep resistance in the supersaturated alloy. The creep resistance consistently decreased with temperature increase for both alloys as thermally activated diffusion processes were more active [94]. 


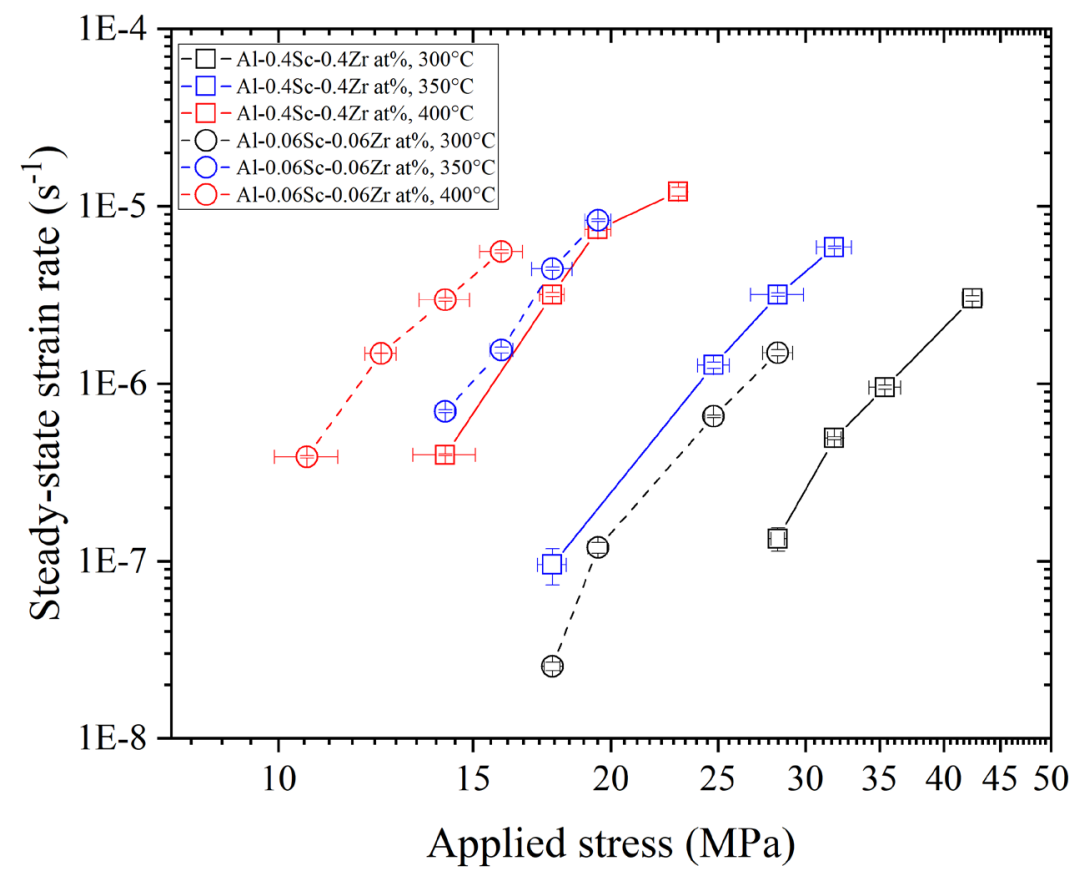

Figure 5.2. Steady-state strain rate versus applied stress for peak-aged $\mathrm{Al}-0.4 \mathrm{Sc}-0.4 \mathrm{Zr}$ at $\%$ and $\mathrm{Al}-0.06 \mathrm{Sc}-0.06 \mathrm{Zr}$ at $\%$ at $300^{\circ} \mathrm{C}, 350^{\circ} \mathrm{C}$ and $400^{\circ} \mathrm{C}$ (error bars are $95 \%$ standard error of the mean).

The stress exponents were determined from the slope of a double logarithmic plot at each temperature. The stress exponents were in the range of $6-11$ for $\mathrm{Al}-0.4 \mathrm{Sc}-0.4 \mathrm{Zr}$ at $\%$ and 5-17 for Al-0.06Sc-0.06Zr at\% (Table 5.2). The experimental stress exponents are much larger than the stress exponent for annealed $\mathrm{Al} \mathrm{n}=4.4$ [28], indicating the existence of the threshold stress $\sigma_{t h}$. A threshold stress is the minimum applied stress required for the dislocation climb [95]. This modifies the power law relation as discussed in Section 1.2.2. The value of $\sigma_{t h}$ was obtained from the x-axis intercept in the linear plot of $\dot{\varepsilon}^{1 / n}$ vs $\sigma$ using $\mathrm{n}=4.4$ at each temperature step (Figure 5.3 and Table 5.2) [28]. 

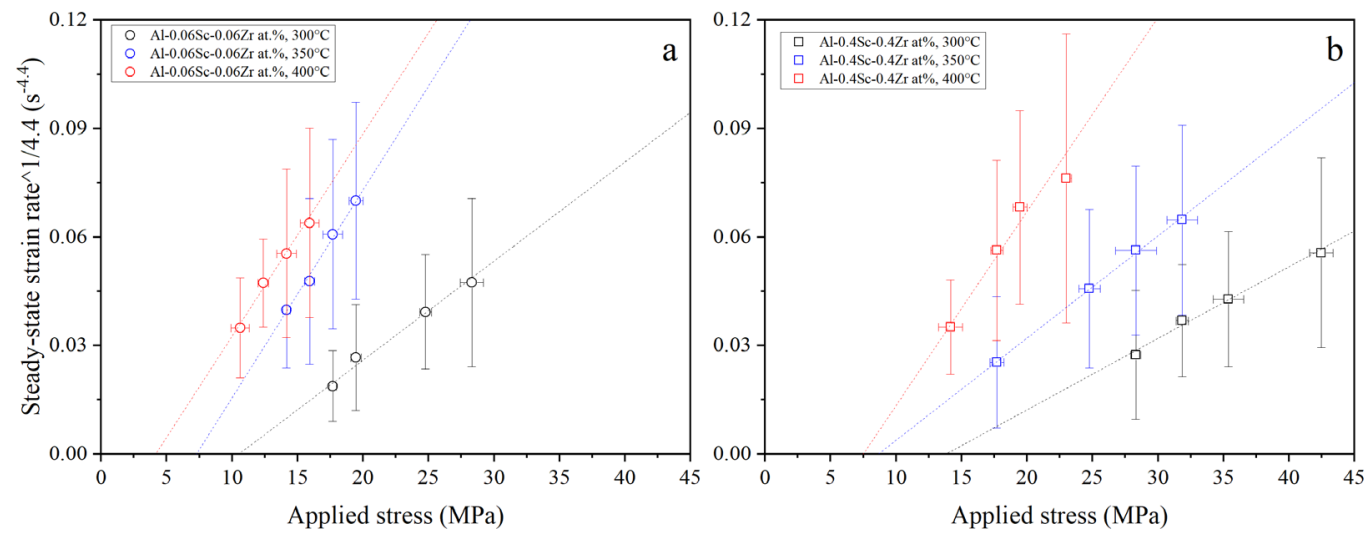

Figure 5.3. Linear plot of $\dot{\varepsilon}^{1 / 4.4}$ vs $\sigma$ for Al-0.4Sc-0.4Zr at $\%$ and Al-0.06Sc- $0.06 \mathrm{Zr}$ at $\%$ at $300^{\circ} \mathrm{C}, 350^{\circ} \mathrm{C}$ and $400^{\circ} \mathrm{C}$. The values of $\sigma_{t h}$ was obtained from the x-axis intercept (error bars are $95 \%$ standard error of the mean).

Table 5.2. Threshold stress and stress exponents for Al-0.4Sc-0.4Zr at $\%$ and $\mathrm{Al}-0.06 \mathrm{Sc}-$ $0.06 \mathrm{Zr}$ at $\%$ at $300^{\circ} \mathrm{C}, 350^{\circ} \mathrm{C}$ and $400^{\circ} \mathrm{C}$

\begin{tabular}{c|c|c|c|c|c|c}
\hline & \multicolumn{2}{|c|}{$300^{\circ} \mathrm{C}$} & \multicolumn{2}{c|}{$350^{\circ} \mathrm{C}$} & \multicolumn{2}{c}{$400^{\circ} \mathrm{C}$} \\
\hline & $\begin{array}{c}\text { Threshold } \\
\text { stress }\end{array}$ & $\begin{array}{c}\text { Stress } \\
\text { exponent }\end{array}$ & $\begin{array}{c}\text { Threshold } \\
\text { stress }\end{array}$ & $\begin{array}{c}\text { Stress } \\
\text { exponent }\end{array}$ & $\begin{array}{c}\text { Threshold } \\
\text { stress }\end{array}$ & $\begin{array}{c}\text { Stress } \\
\text { expone } \\
\text { nt }\end{array}$ \\
\hline $\begin{array}{c}\text { Al-0.4Sc- } \\
0.4 Z r \text { at\% }\end{array}$ & $13.6 \pm 1.5$ & $11.8 \pm 1.7$ & $8.6 \pm 0.8$ & $12.8 \pm 2.6$ & $7.5 \pm 0.7$ & $11 \pm 5.5$ \\
\hline $\begin{array}{c}\text { Al-0.06Sc- } \\
0.06 Z r \text { at\% }\end{array}$ & $10.5 \pm 0.5$ & $8 \pm 2.1$ & $7.5 \pm 1$ & $8.3 \pm 1.3$ & $4.3 \pm 0.4$ & $8 \pm 0.9$ \\
\hline
\end{tabular}

A larger threshold stress was found in the Al-0.4Sc-0.4Zr at\% (7.5 MPa, 8.6 MPa and 13.6 MPa) than in Al-0.06Sc-0.06Zr at\% (4.3 MPa, 7.5 MPa and 10.5 MPa) at each temperature.

\subsubsection{Transmission Electron Microscopy}

Grain size and precipitate radii in the Al-0.4Sc-0.4Zr at $\%$ and $\mathrm{Al}-0.06 \mathrm{Sc}-0.06 \mathrm{Zr}$ at $\%$ alloys were measured from TEM/STEM images in as-prepared and crept specimens (Figure 5.4). The mean grain size increased slightly in both Al-Sc-Zr alloys as $\mathrm{Al}_{3}\left(\mathrm{Sc}_{1-\mathrm{x}} \mathrm{Zr}_{\mathrm{x}}\right)(0.95 \mu \mathrm{m}$ to $1.5 \mu \mathrm{m}$ in $\mathrm{Al}-0.4 \mathrm{Sc}-0.4 \mathrm{Zr}$ at $\%$ and $17 \mu \mathrm{m}$ to $20.3 \mu \mathrm{m}$ in Al$0.06 \mathrm{Sc}-0.06 \mathrm{Zr}$ at $\%$ respectively) as precipitates restricted grain growth [96]. Precipitate 
radii changed significantly in crept specimens for both $\mathrm{Al}-0.06 \mathrm{Sc}-0.06 \mathrm{Zr}$ at $\%$ and $\mathrm{Al}-$ $0.4 \mathrm{Sc}-0.4 \mathrm{Zr}$ at $\%$. The largest precipitate grew from $3.8 \mathrm{~nm}$ to $8.3 \mathrm{~nm}$ in Al-0.4Sc-0.4Zr at $\%$, and from $2.8 \mathrm{~nm}$ to $5.1 \mathrm{~nm}$ in $\mathrm{Al}-0.06 \mathrm{Sc}-0.06 \mathrm{Zr}$ at $\%$ after creep at $400^{\circ} \mathrm{C}$.
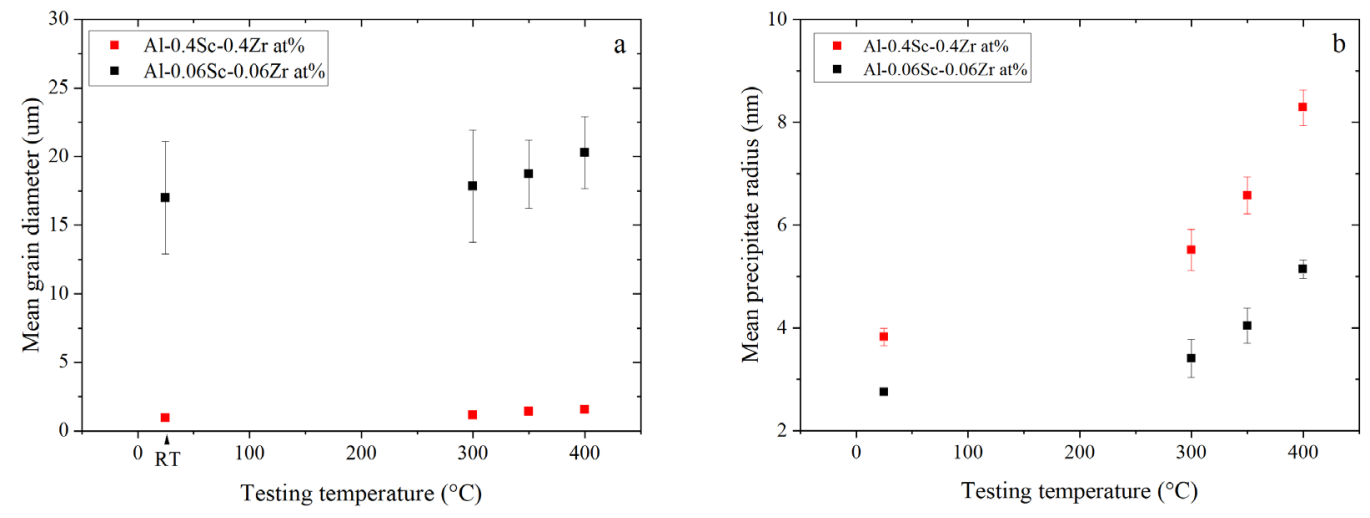

Figure 5.4. Measured grain size (a) and precipitate radii (b) were measured from TEM/STEM images after creep at $300^{\circ} \mathrm{C}, 350^{\circ} \mathrm{C}$ and $400^{\circ} \mathrm{C}$. Measured grain size and precipitate radii in the as-prepared alloys were imposed for comparison. (Error bars are $95 \%$ standard error of the mean.)

The precipitate number density was measured from TEM/STEM images in the asprepared and crept condition (Figure 5.5(a, b)). The precipitate volume fractions were calculated using the measured precipitate radius and number density (Figure 5.5(c, d)). 

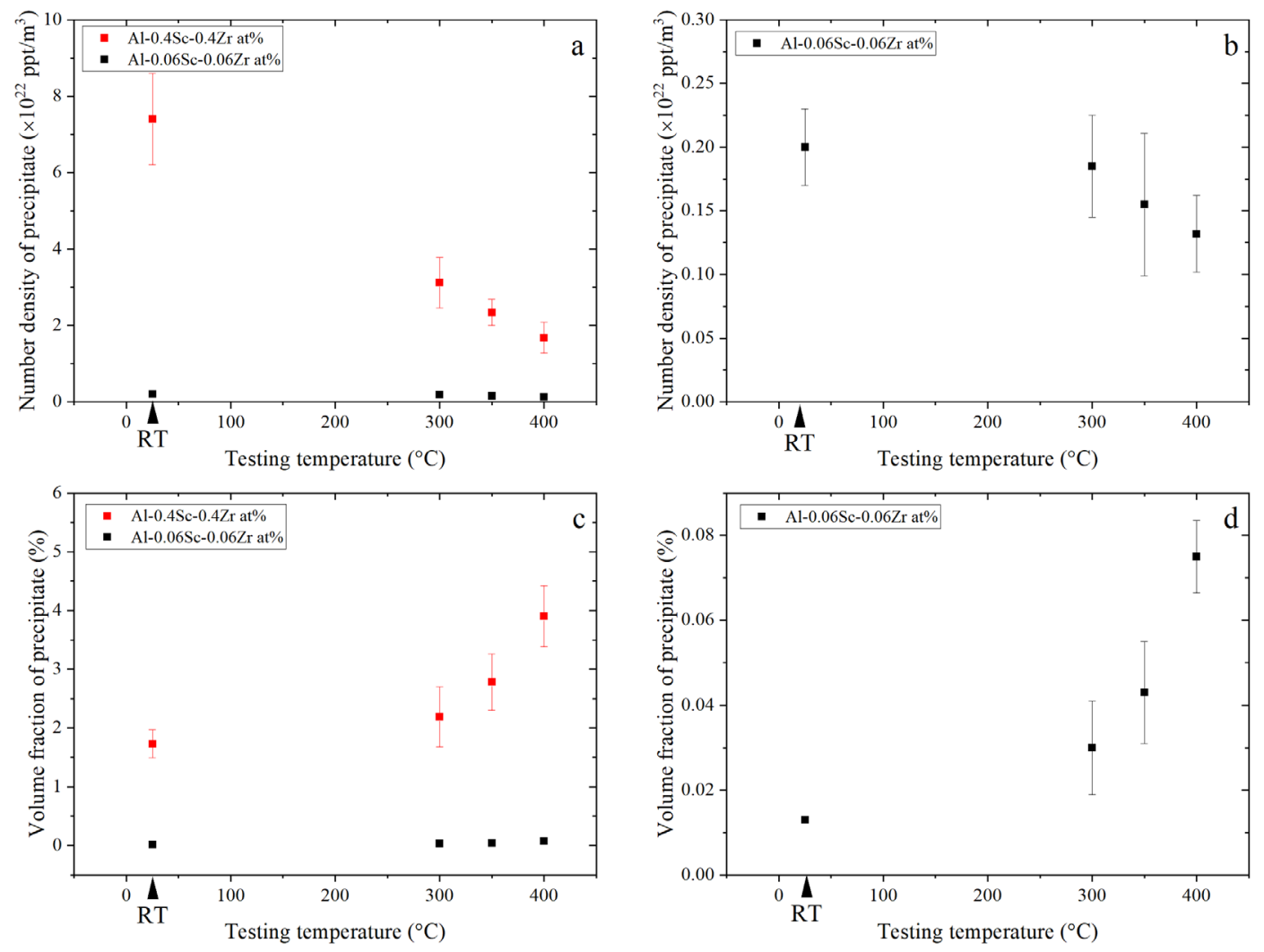

Figure 5.5. Measured precipitate number densities $(\mathrm{a}, \mathrm{b})$ and calculated volume fractions (c, d) in $\mathrm{Al}-0.5 \mathrm{Sc}-0.4 \mathrm{Zr}$ at $\%$ and $\mathrm{Al}-0.06 \mathrm{Sc}-0.06 \mathrm{Zr}$ at $\%$ in the as-prepared and after creep at $300^{\circ} \mathrm{C}, 350^{\circ} \mathrm{C}$ and $400^{\circ} \mathrm{C}$. (b) and (d) are enlarged plots showing the change in Al$0.06 \mathrm{Sc}-0.06 \mathrm{Zr}$ at $\%$ precipitate density. (Error bars are $95 \%$ standard error of the mean.)

The volume fraction of precipitates increased in both alloys after the creep test at each temperature step. The creep mechanisms affected by the precipitate radius and volume fraction increase will be discussed with respect to the activation energy for dislocation climb. 


\subsection{Discussion}

\subsubsection{Compression properties up to $500^{\circ} \mathrm{C}$}

As shown in Figure 5.1, the strength difference improvement of Al- $0.4 \mathrm{Sc}-0.4 \mathrm{Zr}$ at $\%$ over Al-0.06Sc-0.06Zr at $\%$ became insignificant at temperature above $300^{\circ} \mathrm{C}$.

At room temperature, the dominant strengthening mechanism was the Orowan strengthening in both $\mathrm{Al}-0.4 \mathrm{Sc}-0.4 \mathrm{Zr}$ at $\%$ and $\mathrm{Al}-0.06 \mathrm{Sc}-0.06 \mathrm{Zr}$ at $\%$ at ambient temperature (Chapter 3). Assuming the Orowan strengthening remained the dominant strengthening mechanism at $300^{\circ} \mathrm{C}$, the Orowan strengthening in $\mathrm{Al}-0.4 \mathrm{Sc}-0.4 \mathrm{Zr}$ at $\%$ and Al-0.06Sc-0.06Zr at\% was calculated using Equation 1.3 (Table 5.3). The decrease in the temperature-dependent shear modulus for $\mathrm{Al}$ was applied with a rate of $d G / d T=$ $-13.6 \mathrm{MPa} / \mathrm{K}[28]$.

Table 5.3. The calculated Orowan strength of Al-0.4Sc-0.4Zr at $\%$ and $\mathrm{Al}-0.06 \mathrm{Sc}-0.06 \mathrm{Zr}$ at $\%$ at ambient and $300^{\circ} \mathrm{C}$.

\begin{tabular}{c|c|c|c|c}
\hline \multirow{2}{*}{} & \multicolumn{2}{|c|}{$\begin{array}{c}\text { Ultimate compression } \\
\text { strength (MPa) }\end{array}$} & \multicolumn{2}{c}{$\begin{array}{c}\text { Orowan strengthening } \\
\text { prediction }(\mathrm{MPa})\end{array}$} \\
\cline { 2 - 5 } & Al-0.4Sc- & Al-0.06Sc- & Al-0.4Sc- & Al-0.06Sc- \\
& $0.4 \mathrm{Zr}$ at $\%$ & $0.06 \mathrm{Zr}$ at $\%$ & $0.4 \mathrm{Zr}$ at $\%$ & $0.06 \mathrm{Zr}$ at $\%$ \\
\hline $25^{\circ} \mathrm{C}$ & $298 \pm 20$ & $86 \pm 10$ & $200 \pm 12$ & $70 \pm 7$ \\
\hline $300^{\circ} \mathrm{C}$ & $71 \pm 15$ & $55 \pm 1$ & $166 \pm 11$ & $58 \pm 6$ \\
\hline$\%$ loss & $76 \%$ & $36 \%$ & $17 \%$ & $17 \%$ \\
\hline
\end{tabular}

Compared to the predicted Orowan strength, the measured strength had a larger decrease at $300^{\circ} \mathrm{C}$ for both $\mathrm{Al}-0.4 \mathrm{Sc}-0.4 \mathrm{Zr}$ at $\%$ and $\mathrm{Al}-0.06 \mathrm{Sc}-0.06 \mathrm{Zr}$ at $\%$. Thus, the Orowan strengthening at elevated temperatures is no longer the active strengthening mechanism.

\subsubsection{Creep properties at $300^{\circ} \mathrm{C}-400^{\circ} \mathrm{C}$}

The creep resistance was higher in $\mathrm{Al}-0.4 \mathrm{Sc}-0.4 \mathrm{Zr}$ at $\%$ than $\mathrm{Al}-0.06 \mathrm{Sc}-0.06 \mathrm{Zr}$ at $\%$ in part due to the larger threshold stress at each temperature (Table 5.2), though the threshold stress increase was not influential when the Orowan mechanism was active at ambient temperature (200 MPa for Al-0.4Sc-0.4Zr at\% vs. $70 \mathrm{MPa}$ for $\mathrm{Al}-0.06 \mathrm{Sc}-0.06 \mathrm{Zr}$ at $\%$ ). 
The presence of the threshold stress in the precipitate-strengthened alloys could be attributed to several possible mechanisms, which include (I) precipitate shearing; (II) dislocation looping around precipitates; (III) dislocation climb over precipitates; and (IV) attraction force between precipitates and dislocations on the departure side. The last mechanism is not active for coherent precipitate and will be excluded from this analysis. The strengthening mechanisms of shearing and looping at elevated temperatures are similar to what they are at ambient temperature and reviewed in section 1.2.1 except the temperature-dependent shear modulus was applied in the calculations. The shearing and looping mechanisms were excluded since their calculated values were several times larger than the experimental threshold stress (Table 5.2). Thus, the mechanism of dislocation movement is considered as climbing over precipitate. The larger threshold stress in supersaturated alloy was thought to be associated to the larger dislocation line increase due to the larger precipitate radii and precipitate volume fractions in Al-0.4Sc$0.4 \mathrm{Zr}$ at $\%$ than in $\mathrm{Al}-0.06 \mathrm{Sc}-0.06 \mathrm{Zr}$ at\% [97].

The activation energy for creep in Al-0.4Sc-0.4Zr at\% and Al-0.06Sc-0.06Zr at $\%$ helped to identify the dominant creep mechanism using an Arrhenius plot of $\ln (\dot{\varepsilon})$ vs $1 / T$. Stress values chosen at each temperature step are shown in Table 5.4.

Table 5.4. Chosen applied stress and corresponding strain rate of $\mathrm{Al}-0.4 \mathrm{Sc}-0.4 \mathrm{Zr}$ at $\%$ and Al-0.06Sc- $0.06 \mathrm{Zr}$ at $\%$ at $300^{\circ} \mathrm{C}, 350^{\circ} \mathrm{C}$ and $400^{\circ} \mathrm{C}$.

\begin{tabular}{|c|c|c|c|c|}
\hline & $1 / \mathrm{T}\left({ }^{\circ} \mathrm{C}^{-1}\right)$ & $1 / 400$ & $1 / 350$ & $1 / 300$ \\
\hline \multirow[b]{2}{*}{$\begin{array}{l}\mathrm{Al}-0.4 \mathrm{Sc}- \\
0.4 \mathrm{Zr} \text { at } \%\end{array}$} & Stress (MPa) & 23 & 28 & 28 \\
\hline & $\begin{array}{c}\text { Strain rate }\left(\mathrm{s}^{-}\right. \\
1)\end{array}$ & $\begin{array}{l}1.2 \\
\pm 0.1 \times 10^{-5}\end{array}$ & $3.2 \pm 0.1 \times 10^{-6}$ & $\begin{array}{l}1.3 \\
\pm 0.2 \times 10^{-7}\end{array}$ \\
\hline \multirow{2}{*}{$\begin{array}{c}\mathrm{Al}-0.06 \mathrm{Sc}- \\
0.06 \mathrm{Zr} \\
\mathrm{at} \%\end{array}$} & Stress $(\mathrm{MPa})$ & 14 & 14 & 18 \\
\hline & $\begin{array}{c}\text { Strain rate }\left(\mathrm{s}^{-}\right. \\
1)\end{array}$ & $\begin{array}{l}3.0 \\
\pm 0.1 \times 10^{-6}\end{array}$ & $7.0 \pm 0.1 \times 10^{-7}$ & $\begin{array}{l}2.5 \\
\pm 0.1 \times 10^{-8}\end{array}$ \\
\hline
\end{tabular}

The activation energies were determined as the slope of the fitted lines (Figure 5.6). 


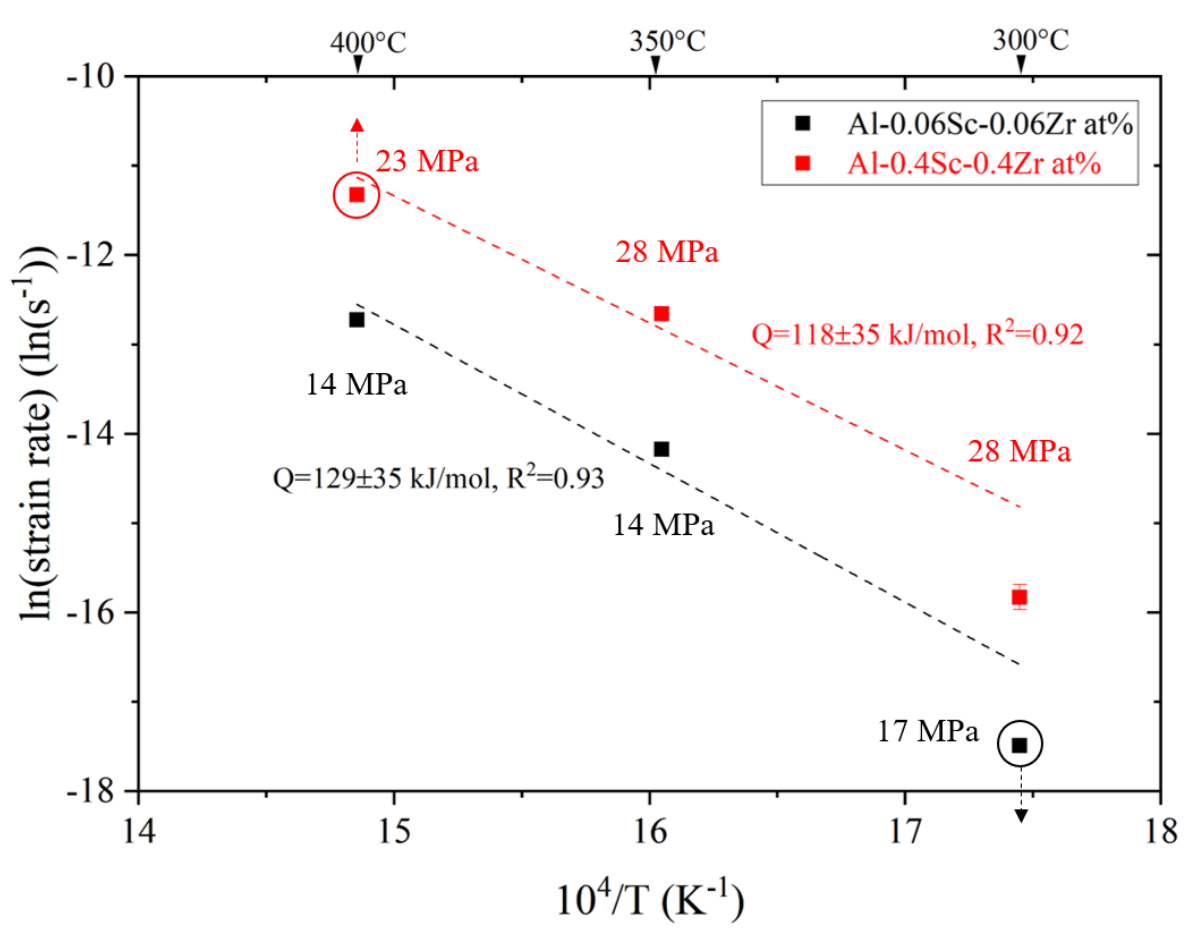

Figure 5.6. Arrhenius plot of the steady-state creep strain rate vs inverse temperature at $300^{\circ} \mathrm{C}, 350^{\circ} \mathrm{C}$ and $400^{\circ} \mathrm{C}$. Strain rate for Al-0.4Sc- $0.4 \mathrm{Zr}$ at $\%$ at $400^{\circ} \mathrm{C}$ and $\mathrm{Al}-0.06 \mathrm{Sc}-$ $0.06 \mathrm{Zr}$ at $\%$ at $300^{\circ} \mathrm{C}$ were tested using inconstant applied stress. The arrows stand for the trend of strain rate if constant stress applied.

The activation energy was $120 \pm 35 \mathrm{~kJ} / \mathrm{mol}$ for the Al- $0.4 \mathrm{Sc}-0.4 \mathrm{Zr}$ at $\%$ and was $130 \pm 35$ $\mathrm{kJ} / \mathrm{mol}$ for Al-0.06Sc- $0.06 \mathrm{Zr}$ at $\%$ respectively. If dislocation climb is the dominant creep mechanism, the activation energy should be equal to the bulk activation energy for diffusion in $\mathrm{Al}(132 \mathrm{~kJ} / \mathrm{mol})$ as it is matrix-diffusion mediated [28]. The calculated activation energies for $\mathrm{Al}-0.4 \mathrm{Sc}-0.4 \mathrm{Zr}$ at $\%$ and $\mathrm{Al}-0.06 \mathrm{Sc}-0.06 \mathrm{Zr}$ at $\%$ were within the range of the activation energy for bulk diffusion, which supports the interpretation that dislocation climb is the dominant creep mechanism in both Al-0.4Sc-0.4Zr at $\%$ and Al$0.06 \mathrm{Sc}-0.06 \mathrm{Zr}$ at $\%$. As activation energy required to be calculated at constant stress for all temperature steps in each alloy, the uncertainty in the calculated activation energies raised from the inconstant applied stress (Table 5.4). Smaller stress was applied on Al$0.4 \mathrm{Sc}-0.4 \mathrm{Zr}$ at $\%$ at $400^{\circ} \mathrm{C}$ and larger stress on $\mathrm{Al}-0.06 \mathrm{Sc}-0.06 \mathrm{Zr}$ at $\%$ at $300^{\circ} \mathrm{C}$. This led to the strain rate was underestimated for $\mathrm{Al}-0.4 \mathrm{Sc}-0.4 \mathrm{Zr}$ at $\%$ at $400^{\circ} \mathrm{C}$ and overestimated 
for Al-0.06Sc-0.06Zr at $\%$ at $300^{\circ} \mathrm{C}$ indicated by arrows in Figure 5.6. The fitted slopes are expected to increase if consistent stress was applied in each alloy. The calculated activation energies would increase to become closer or beyond the bulk activation energy for diffusion in $\mathrm{Al}(132 \mathrm{~kJ} / \mathrm{mol})$.

\subsection{Conclusions}

The mechanical properties of the supersaturated A1-0.4Sc-0.4Zr at $\%$ and dilute Al$0.06 \mathrm{Sc}-0.06 \mathrm{Zr}$ at $\%$ were investigated with hot macro Vickers hardness, compression and creep testing. A threshold creep stress was found for both alloys. The creep mechanisms in the supersaturated $\mathrm{Al}-0.4 \mathrm{Sc}-0.4 \mathrm{Zr}$ at $\%$ and dilute $\mathrm{Al}-0.06 \mathrm{Sc}-0.06$ at $\%$ were identified and discussed.

This work demonstrates:

- The macro Vickers hardness and compression strength of Al-0.4Sc-0.4Zr at $\%$ and Al-0.06Sc-0.06Zr at\% indicated significant strength loss more than predicted by the Orowan strength loss above $300^{\circ} \mathrm{C}$. It corresponds to a change in dislocation movement from looping to climbing.

- Dislocation climb was considered as the dominant creep mechanism in Al-0.4Sc$0.4 \mathrm{Zr}$ at $\%$ and $\mathrm{Al}-0.06 \mathrm{Sc}-0.06 \mathrm{Zr}$ at $\%$ according to the analysis of the experimental strength for them. The existence of the dislocation climb mechanism was studied by the activation energies of creep in Al-0.4Sc- $0.4 \mathrm{Zr}$ at $\%$ and $\mathrm{Al}-$ $0.06 \mathrm{Sc}-0.06 \mathrm{Zr}$ at $\%$.

- Threshold stress was increased in Al-0.4Sc-0.4Zr at \% than Al-0.06Sc-0.06Zr at $\%$ with larger precipitate radius and volume fraction as the larger number of vacancies are required for dislocation lines increase. 


\section{Chapter 6. Nanoindentation study on supersaturated Al-Sc- Zr via melt-spinning and extrusion}

\subsection{Abstract and Introduction}

\subsubsection{Abstract}

Microhardness and elastic modulus of supersaturated $\mathrm{Al}-0.4 \mathrm{Sc}-0.4 \mathrm{Zr}$ at $\%$ melt-spun ribbon and extruded rod were assessed using two nanoindentation testing methods. For high-speed testing on ribbon and rod, the hardness was $1.41 \pm 0.01 \mathrm{GPa}$ for ribbon and $1.39 \pm 0.04 \mathrm{GPa}$ for rod. The elastic modulus showed a large difference between them $(68.1 \pm 0.4 \mathrm{GPa}$ for ribbon and $80.5 \pm 1.7 \mathrm{GPa}$ for rod). More mechanical properties of the melt-spun ribbon include hardness and modulus were investigated using depth-dependent continuous stiffness measurements (CSM). The hardness of $\sim 1.46 \mathrm{GPa}$ was consistent with the hardness measured with high-speed testing. The hardness was calculated from the displacement and load plot. The modulus was determined as $\sim 73 \mathrm{GPa}$ at a displacement of $1000 \mathrm{~nm}$, while the effect of the plasticity and strain rate were not fully explained.

\subsubsection{Introduction}

The strength and coarsening resistance increase in the supersaturated $\mathrm{Al}-0.4 \mathrm{Sc}-0.4 \mathrm{Zr}$ at $\%$ were studied in the previous sections. Comprehensive testing methods were applied to the extruded rod to study its mechanical properties including microhardness, tensile/compressive strength and threshold stress in creep. However, given the geometry of the melt-spun ribbon, it was only characterized by Vickers microhardness in crosssection with a 0.25 newtons load and $15 \mathrm{~s}$ dwell. Two factors were considered to affect test accuracy when measuring the ribbon's hardness using the Vickers test. First, limited by the thickness in the cross-section of the melt-spun ribbon ( $\sim 30 \mathrm{um})$, the maximum load for the Vickers method was 0.25 newtons. As the hardness value can be a function of testing load, load dependencies can be seen at small loads [98]. Secondly, indentations located at the center of melt-spun ribbon cross-section had a $\sim 20$ um diagonal length $d$. The distance from the indent to the specimen edge is $<10 \mu \mathrm{m}$ which is much smaller than 
the suggested minimum distance for the Vickers test of $2.5 d$ according to ISO 6507. In that way, edge effects might affect the test results.

Nanoindentation test is a promising technique for strength measurement in materials with small volumes. Different from traditional hardness tests (both macro and micro), which require newtons of pressure, nanoindentation uses loads within the micro newton range. With instrumented indentation methods, the applied load can be recorded as a function of the indenter penetration depth. This load and indenter depth can be plotted into a load vs displacement curve to determine mechanical properties such as Young's modulus in addition to hardness. Since the nanoindentation test uses a small load and indenter (Berkovich), the indentation areas are only a few square micrometers or even nanometers. The geometry and area of the indents are usually investigated using high-resolution imaging techniques instead of optical microscopy.

In this study, the microhardness and elastic modulus of the $\mathrm{Al}-0.4 \mathrm{Sc}-0.4 \mathrm{Zr}$ at $\%$ melt-spun ribbon and extruded rod were assessed using nanoindentation at ambient temperature. The area and geometry of indents were characterized using ESEM. The measured hardness was compared to theoretical strength, and measurement uncertainty was discussed.

\subsection{Experimental}

\subsubsection{Sample preparation}

The supersaturated $\mathrm{Al}-0.4 \mathrm{Sc}-0.4 \mathrm{Zr}$ at $\%$ was produced using melt-spinning and extrusion as discussed in Section 3.3. No primary precipitates were observed on the as-produced melt-spun ribbon cross-section monitored using SEM. The ribbon and rod were peak aged using a two-step heat treatment as discussed in Section 2.1.5.

\subsubsection{Sample mounting}

Specimen mounting of extruded rod followed the general mounting procedure as mentioned in Section 2.1.6.1. The melt-spun ribbon was mounted vertically with the 
support of two pieces of 6061, which was cut at the center of a 6061-cylinder using EDM. The stacks were tightened by copper tape at the outside of the 6061 cylinder (Figure 6.1).
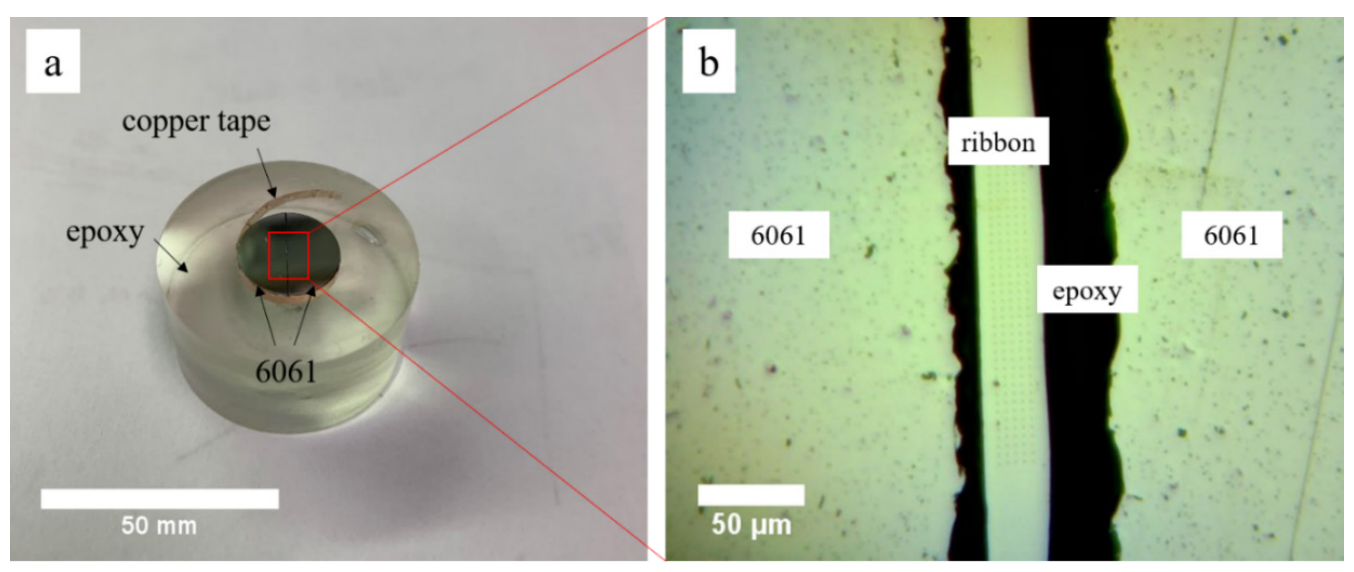

Figure 6.1. Al-0.4Sc-0.4Zr at\% melt-spun ribbon was mounted with the support of two 6061 pieces and fastened by copper tape (a). Enlarged plot of mounted melt-spun ribbon supported by two 6061 pieces (b).

\subsubsection{Sample polishing}

Given the small size of the indentation (usually $<10 \mu \mathrm{m}$ ) and low testing load $(<1 \mathrm{~N})$, the thickness of the deformed layer on the specimen surface can have a significant impact on the test results. Specimen preparation for nanoindentation testing is more critical than for hardness and SEM as discussed in section 2.1.6.1.

The melt-spun ribbon was mounted with the support of two 6061 half-rod pieces. The top

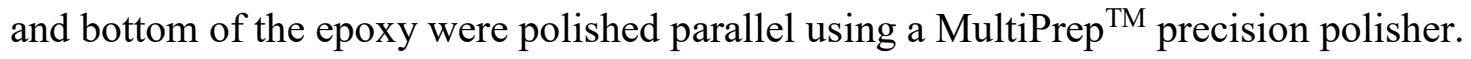
The parallel-surface specimen was loaded in the 400-grams holder and fastened by screws on the holder's side (Figure 6.2(a)). The loaded specimen was ground and polished following the sequence in Table 2.4. Finally, the specimen was polished using a vibratory polisher for at least 6 hours using 0.04 um colloidal silica suspension and nylon polishing cloth (Figure 6.2(b)). 

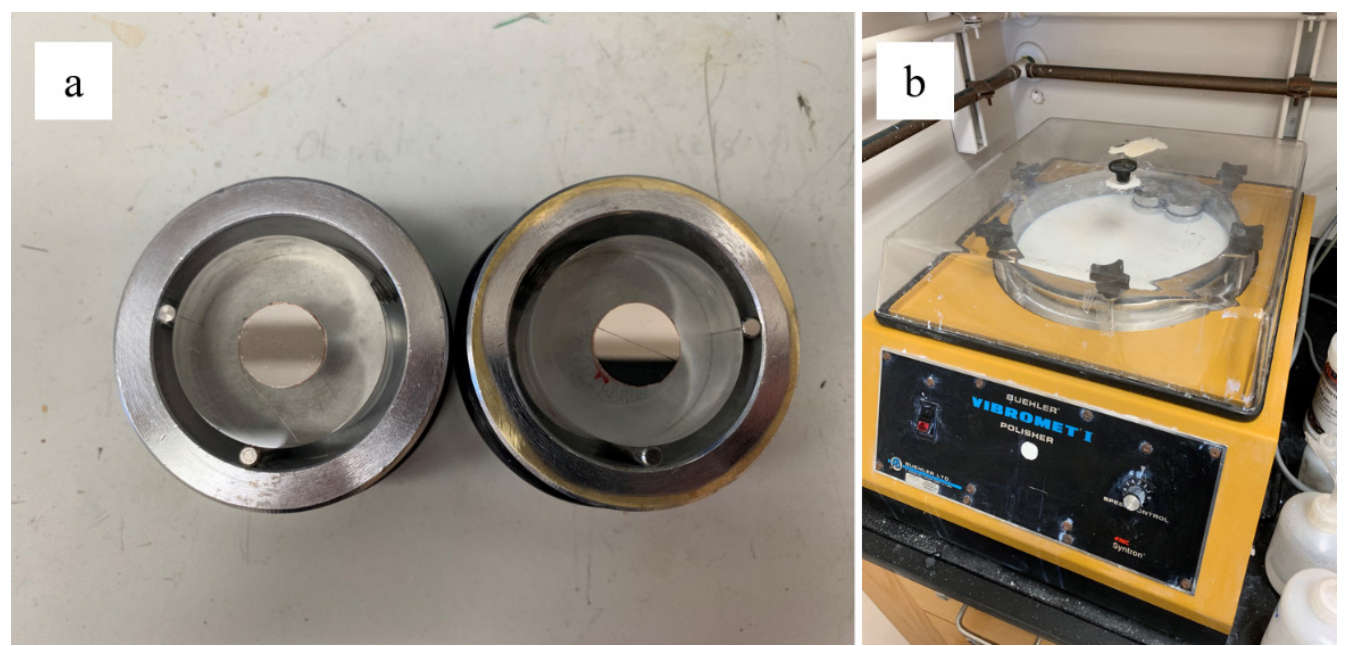

Figure 6.2. The mounted specimen in the holder (a) and vibratory polishing is the final step for nanoindentation sample preparation (b).

\subsubsection{Nanoindentation testing}

Nanoindentation tests on $\mathrm{Al}-0.4 \mathrm{Sc}-0.4 \mathrm{Zr}$ at $\%$ melt-spun ribbon was performed using an iMicro nanoindenter (Figure 6.3).

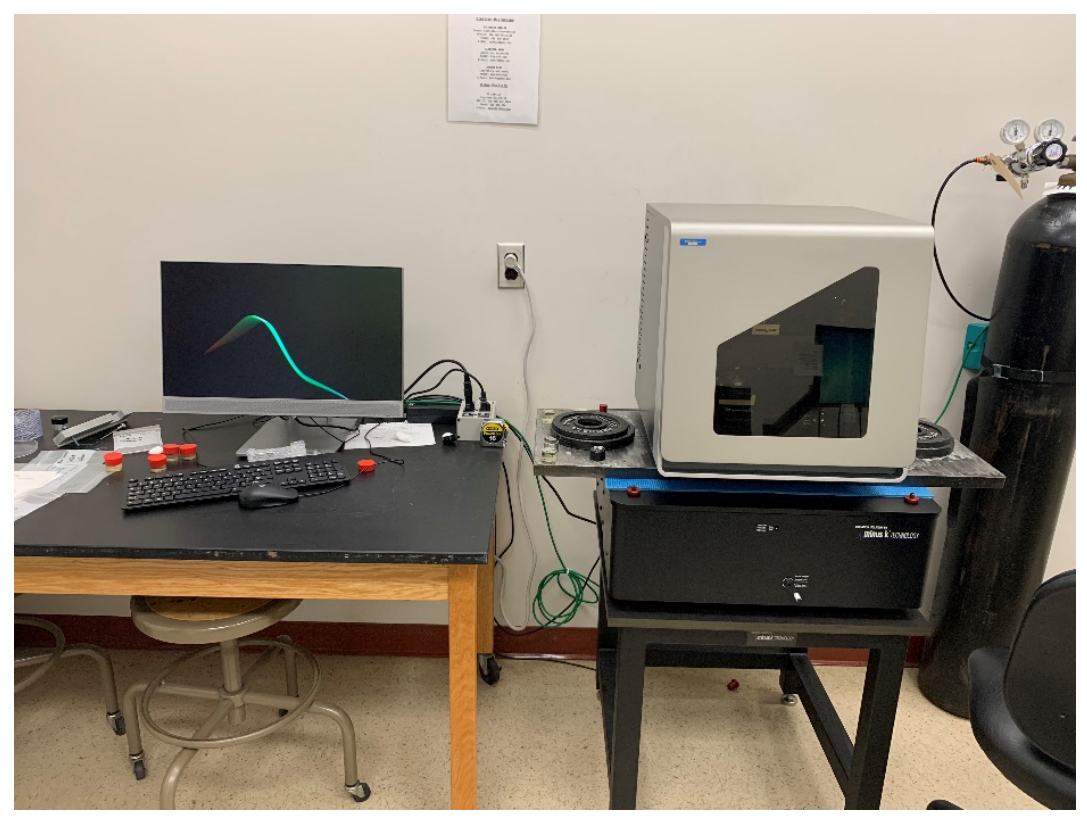

Figure 6.3. iMicro nanoindenter equipment. 
Two testing methods were used in this study: high-speed measurement and continuous stiffness measurement (CSM). The hardness and elastic modulus of the specimen were obtained from a large number of indents using high-speed measurement. The cumulative results of the measurement reveal consistent hardness and modulus across the measured areas.

Continuous stiffness measurement is a dynamic method that records the load change with a sinusoidal load profile is applied as the indenter penetrates $1 \mu \mathrm{m}$ into the sample per ASTM E2546 (ISO 14577). The hardness $H$ is determined by the maximum test load $P_{\text {max }}$ and projected contact area $A$ as:

$$
H=\frac{P_{\max }}{A}
$$

For high-speed measurement, three sets of $10 \times 10$ indentations were made on extruded rod cross-section in different regions, and $4 \times 50$ indenters were made on the melt-spun ribbon cross-section respectively. For continuous stiffness measurement (CSM), 10 indentations were made at the center of the melt-spun ribbon cross-section. All indenter displacements are $1000 \mathrm{~nm}(1 \mu \mathrm{m})$ for both melt-spun ribbon and extruded rod.

\subsection{Results and Discussions}

High-speed tests were applied on the Al-0.4Sc-0.4Zr at\% melt-spun ribbon and extruded rod with a displacement of $1000 \mathrm{~nm}$ into the specimen surface. The hardness and elastic modulus were obtained from the measurements (Figure 6.4). 

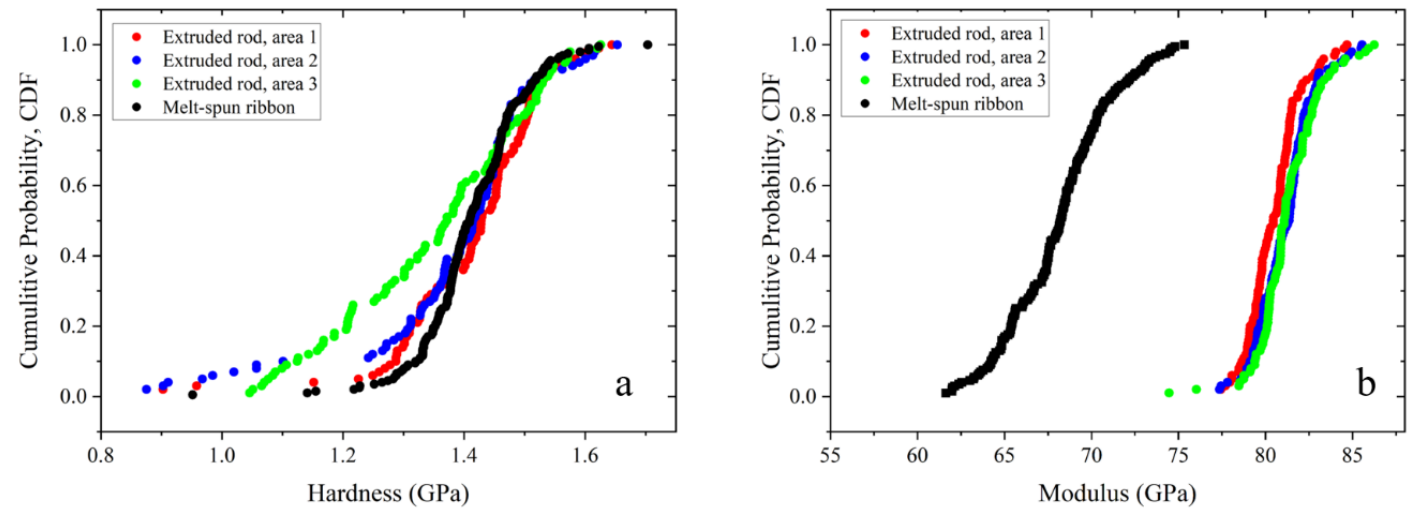

Figure 6.4. Cumulative plots of hardness (a) and modulus (b) of the peak-aged Al-0.4Sc$0.4 \mathrm{Zr}$ at $\%$ melt-spun ribbon and extruded rod measure using the high-speed measurement.

The cumulative plots of hardness and modulus showed the difference between Al-0.4Sc$0.4 \mathrm{Zr}$ at $\%$ melt-spun ribbon and extruded rod. The average of hardness and modulus listed in Table 6.1.

Table 6.1. The mean hardness and modulus of the peak-aged Al-0.4Sc-0.4Zr at $\%$ meltspun ribbon and extruded rod measured using high-speed measurement.

\begin{tabular}{c|c|c}
\hline & Hardness $(\mathrm{GPa})$ & $\begin{array}{c}\text { Elastic modulus } \\
(\mathrm{GPa})\end{array}$ \\
\hline $\begin{array}{c}\text { Al-0.4Sc-0.4Zr at\% melt-spun } \\
\text { ribbon }\end{array}$ & $1.41 \pm 0.01$ & $68.1 \pm 0.4$ \\
\hline Al-0.4Sc-0.4Zr at\% extruded rod & $1.39 \pm 0.04$ & $80.5 \pm 1.7$ \\
\hline
\end{tabular}

The hardness of the melt-spun ribbon $(1.41 \pm 0.01 \mathrm{GPa})$ was found close to extruded rod's $(1.39 \pm 0.04 \mathrm{GPa})$. This finding is consistent to the Vickers hardness test results in Section 3.4, which found slightly smaller Vickers hardness in the melt-spun ribbon (1120 \pm 30 $\mathrm{MPa})$ than in extruded rod $(1180 \pm 20 \mathrm{MPa})$ which are consistent with the calculated Orowan strengthening using the measured precipitate radius and volume fractions. The elastic modulus was higher in the extruded rod $(80.5 \pm 1.7 \mathrm{GPa})$ compared to the elastic modulus of the melt-spun ribbon $(68.1 \pm 0.4 \mathrm{GPa})$. The difference in the elastic modulus between the melt-spun ribbon and extruded rod was most likely due to the different 
elemental compositions between them after been peak-aged since the elastic modulus is the intrinsic properties of the materials and doesn't affected by the microstructure change [44]. The oxide aluminum (from the melt-spun ribbon surface) and internal defects in the extruded rod might affect the experimental elastic modulus for the extruded rod.

High-speed measurements quickly reveal the hardness and modulus of materials from a large number of indentations. Hardness and elastic modulus test results could be affected by several factors such as indenter size and sample surface roughness [99]. The Berkovich indenter has a 7:1 width to height ratio [100]. Limited by the width of the melt-spun ribbon cross-section $(\sim 30 \mu \mathrm{m})$, the maximum displacement was of $1 \mu \mathrm{m}$ ensured $>2 \mathrm{~d}$ distance from indenter to specimen edge. In that way, the hardness test results could be affected by specimen surface roughness due to the small load of $<30 \mu \mathrm{N}$.

Hardness and elastic modulus of $\mathrm{Al}-0.4 \mathrm{Sc}-0.4 \mathrm{Zr}$ at $\%$ melt-spun ribbon were measured as a function of depth using the continuous stiffness measurement (CSM) (Figure 6.5). Tests were held at depth of $180 \mathrm{~nm}$ and $1060 \mathrm{~nm}$ using the continuous stiffness measurement for comparison.
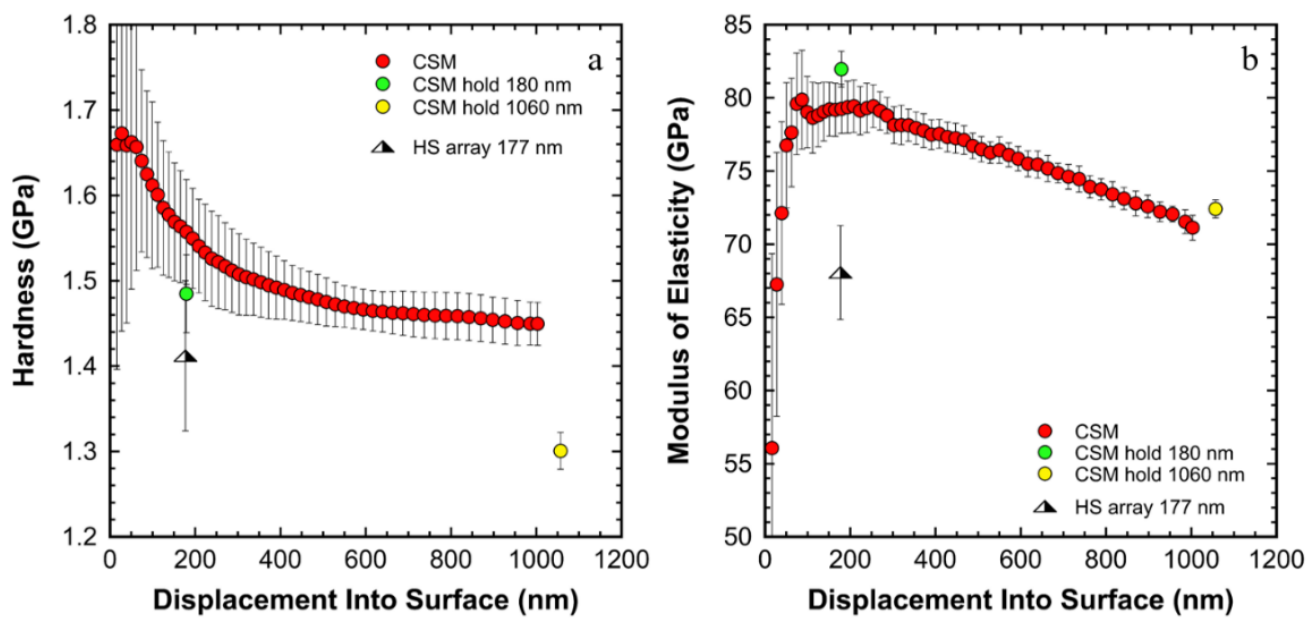

Figure 6.5. Hardness (a) and elastic modulus (b) of Al- $0.4 \mathrm{Sc}-0.4 \mathrm{Zr}$ at $\%$ melt-spun ribbon as a function of depth to $1000 \mathrm{~nm}$ using continuous stiffness measurement (CSM). 
Indenter was held at depths of $180 \mathrm{~nm}$ and $1060 \mathrm{~nm}$ using CSM. A $177 \mathrm{~nm}$ deep Highspeed testing points was imposed for comparison.

As shown in Figure 6.5, the hardness of the melt-spun ribbon kept decreased with indenter penetration and stabilized at $\sim 1.46 \mathrm{GPa}$ at depths larger than $400 \mathrm{~nm}$ (Figure 6.5 (a)). The elastic modulus continuously decreased with depths above $100 \mathrm{~nm}$. The elastic modulus dropped to $73 \mathrm{GPa}$ at the displacement of $1000 \mathrm{~nm}$ (Figure 6.5(b)). The measured hardness and elastic modulus using continuous stiffness measurement were larger than the measured values using the high-speed at the same depth of $177 \mathrm{~nm}$. The difference was possibly due to the plasticity effect brought by sample preparation and indenter size [99]. With constant load hold at depth of $180 \mathrm{~nm}$ and $1060 \mathrm{~nm}$, the harmonic amplitude of the oscillations was decreased so minimized the affection of load thus providing more accurate test results using hold-CSM. With the support of hold-CSM at steps of $180 \mathrm{~nm}$ and $1060 \mathrm{~nm}$, the elastic modulus was believed decreased as a function of depth (Figure 6.5(b)). The decrease in the elastic modulus was possibly attributed to the strain rate and physical gradient of chemical composition as a function of depth [101].

The projected contact area of indent was measured using ESEM after the continuous stiffness measurement (CSM). The theoretical contact area $A$ is a function of the indenter displacement $h$ for Berkovich tip defined as [102]:

$$
A=24.56 h^{2} \quad \text { Equation } 6.2
$$

The measured projected contact area, $22.4 \pm 0.3 \mu \mathrm{m}^{2}$, was $<10 \%$ smaller than the theoretical contact area, $24.56 \mu^{2}$, at the displacement of $1 \mu \mathrm{m}$. Thus, the predicted hardness of the melt-spun ribbon was $\sim 1.5 \mathrm{GPa}$ according to Equation 6.1 with the knowledge of the projected contact area and maximum load (Table 6.2). Minor pile up on the edge of the indent was observed around the indentation and contact boundary (Figure 6.6) due to the plasticity of the material [103]. The bend boundary led larger contact area 
than actual contact area, which likely result in the overestimation of the hardness prediction and elastic modulus [104], [105].

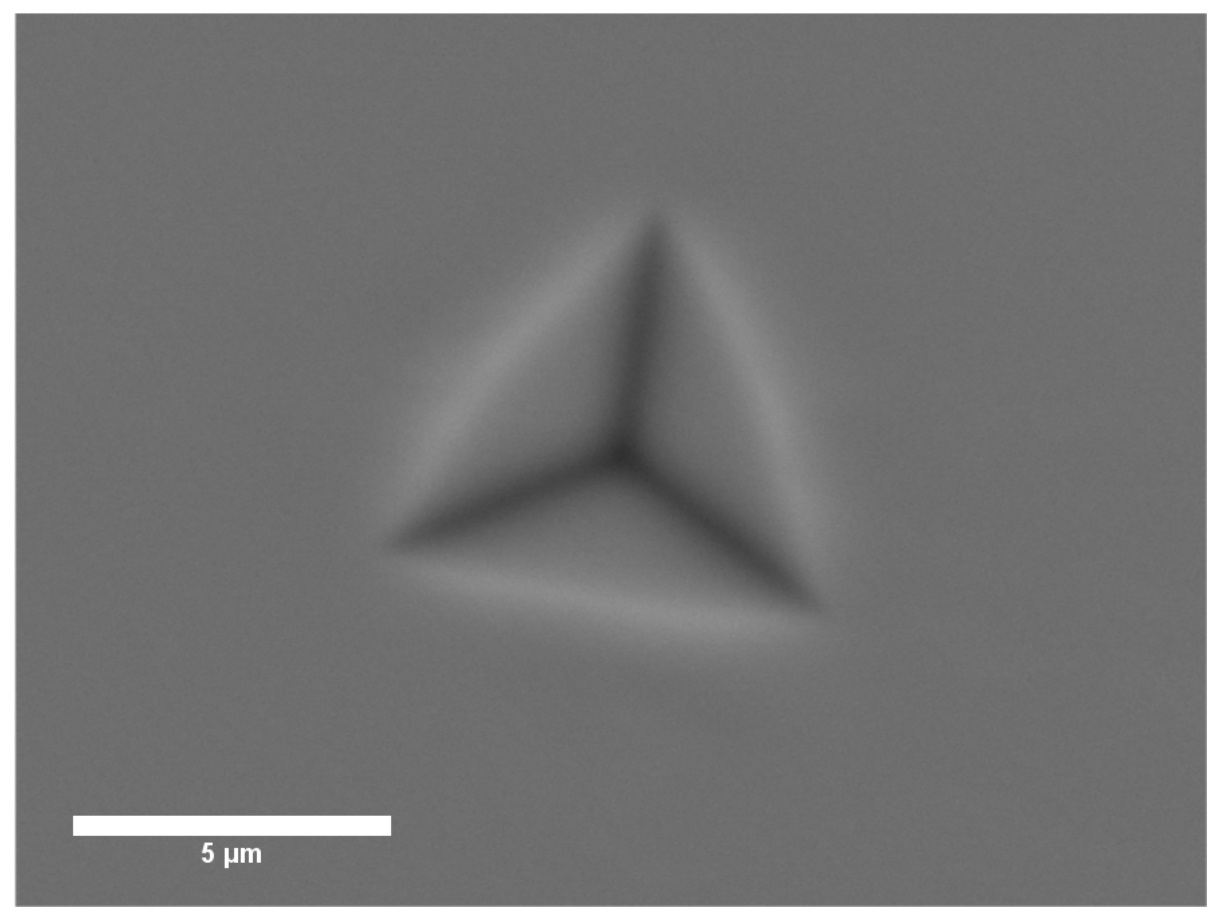

Figure 6.6. BES image of the indentation made using continuous stiffness measurement.

Pile-up was observed around the indentation and contact boundary.

Table 6.2. The experimental and predicted hardness the peak-aged Al-0.4Sc-0.4Zr at $\%$ melt-spun ribbon measured using continuous stiffness measurement at $1000 \mu \mathrm{m}$ depth.

\begin{tabular}{c|c|c}
\hline & Experimental & Prediction \\
\hline Hardness $(\mathrm{GPa})$ & 1.46 & 1.5 \\
\hline
\end{tabular}

This work still has unanswered questions that need to be investigated such as the effect of strain rate, the effect of the polishing deformation layer on the specimen surface and the plasticity effect in the CSM on the melt-spun ribbon. The mechanical properties may change along the thickness of the cross-section and could help reveal changes in the solidification rates as a function of distance from the $\mathrm{Cu}$ wheel. This could be supported by microstructure investigation of the melt-spun ribbon and extruded rod. 


\subsection{Conclusions}

Hardness and elastic modulus of the Al-0.4Sc-0.4Zr at $\%$ melt-spun ribbon and extruded rod were measured using high-speed measurements. The properties of the melt-spun ribbon were also measured using depth-dependent continuous stiffness measurements. The hardness of the melt-spun ribbon was predicted according to applied load and indentation area. The understanding of the difference between the measured and predicted required for a more comprehensive study of the two alloys.

\section{Chapter 7. General summary}

Supersaturated Al-Sc-Zr bulk materials were synthesized by melt-spinning ribbon that was consolidated into rods via extrusion. The mechanical properties of these supersaturated alloys were characterized at ambient and elevated temperatures. The increase in precipitate volume fraction as size resulting from the increased supersaturation was accessed with respect to strengthening behavior (precipitation strengthening and threshold stress) and coarsening resistance (Figure 7.1).

Compared to the dilute alloy, the supersaturated alloys showed a larger strength at ambient temperature and a higher threshold stress at elevated temperature. The strength increase was attributed to larger precipitate size and higher number density in supersaturated alloys leading to greater Orowan strengthening. The microstructure investigation revealed that the supersaturated alloys contain smaller grain and higher dislocation densities than the dilute alloys, which increased the precipitation kinetics leading to greater nucleation and coarsening. The dislocation climb was believed as the dominant creep mechanism whose movement was determined by the self-diffusion through lattice.

In the supersaturated alloys, precipitate coarsening rate was accelerated than the dilute alloy. The acceleration in coarsening rate was attributed to the atomic transportation through dislocation lines played an important role during overaging due to the small grain 
and large dislocation density. The increased precipitate volume fraction accelerated the coarsening rate as well, while the changed chemical composition was found retarded the coarsening rate.

In summary, the supersaturated alloys showed larger strength at ambient and elevated temperature due to the increased precipitate volume fraction. The increased precipitate size was detrimental to Orowan strength increase, while turned out beneficial for threshold stress at elevated temperature. Solute diffusion mechanisms were different in precipitate coarsening and dislocation climbing due to the microstructure characters. 

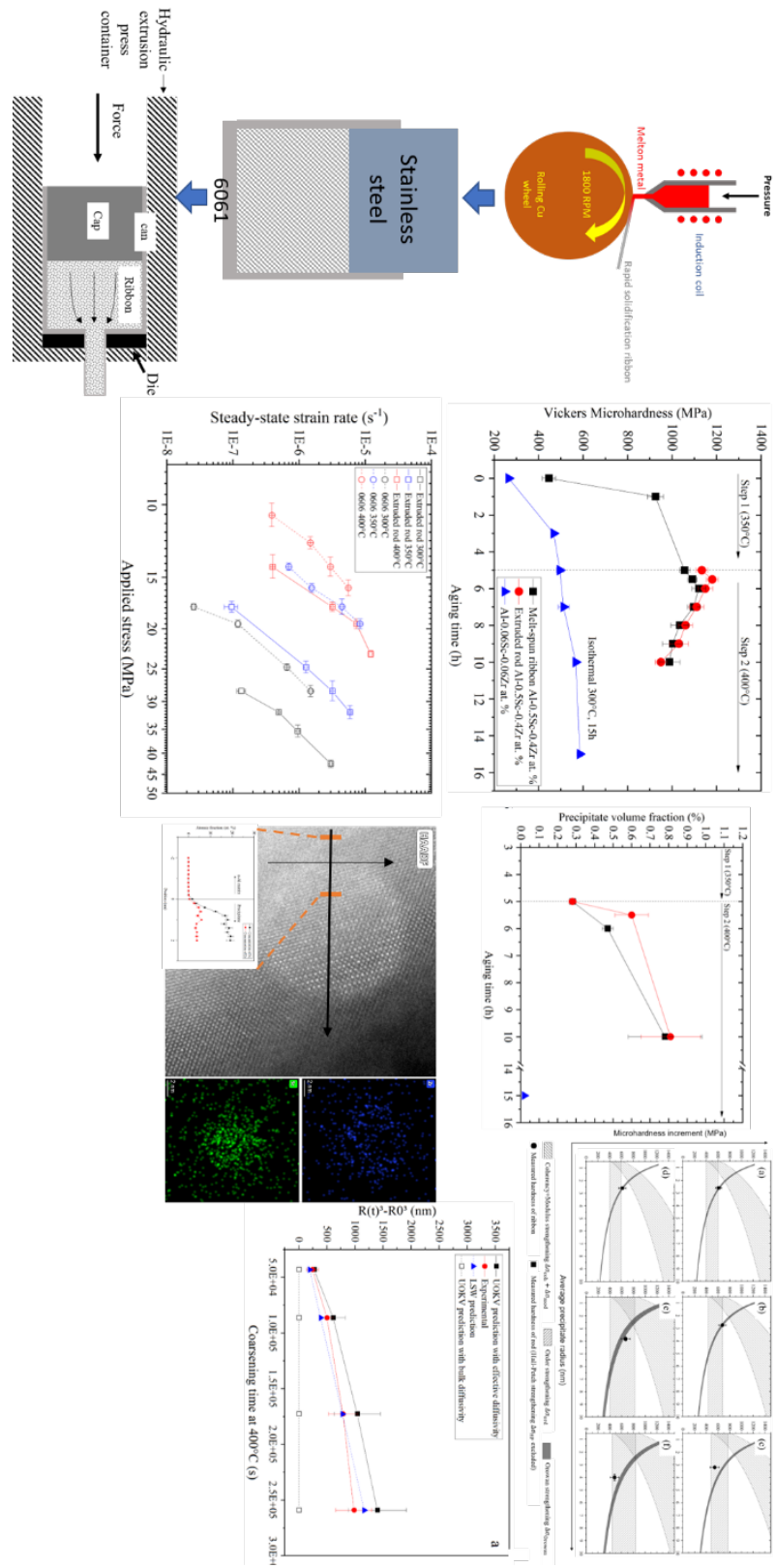

Figure 7.1. Representative figures of the comprehensive study of the processingstructure-properties relationships of supersaturated Al-Sc-Zr (using some of the previous figures in the dissertation). 


\section{Reference}

[1] K. Knipling, D. Dunand, and D. Seidman, "Criteria for developing castable, creepresistant aluminum-based alloys - A review," Zeitschrift für Metallkunde, vol. 97, pp. 246-265, Mar. 2006, doi: 10.3139/146.101249.

[2] E. Clouet and M. Nastar, "Monte Carlo Study of the Precipitation Kinetics of Al3zr in Al-Zr," Complex Inorganic Solids, Springer, Boston, MA, pp. 215-239, Sep. 2005, doi: https://doi.org/10.1007/0-387-25953-8_17.

[3] K. E. Knipling, R. A. Karnesky, C. P. Lee, D. C. Dunand, and D. N. Seidman, "Precipitation evolution in $\mathrm{Al}-0.1 \mathrm{Sc}, \mathrm{Al}-0.1 \mathrm{Zr}$ and $\mathrm{Al}-0.1 \mathrm{Sc}-0.1 \mathrm{Zr}$ (at.\%) alloys during isochronal aging," Acta Materialia, vol. 58, no. 15, pp. 5184-5195, Sep. 2010, doi: 10.1016/j.actamat.2010.05.054.

[4] E. A. Marquis and D. N. Seidman, "Nanoscale structural evolution of Al3Sc precipitates in Al(Sc) alloys," Acta Materialia, vol. 49, no. 11, pp. 1909-1919, Jun. 2001, doi: 10.1016/S1359-6454(01)00116-1.

[5] D. N. Seidman, E. A. Marquis, and D. C. Dunand, "Precipitation strengthening at ambient and elevated temperatures of heat-treatable $\mathrm{Al}(\mathrm{Sc})$ alloys," Acta Materialia, vol. 50, no. 16, pp. 4021-4035, Sep. 2002, doi: 10.1016/S1359-6454(02)00201-X.

[6] G. M. Novotny and A. J. Ardell, "Precipitation of Al3Sc in binary Al-Sc alloys," Materials Science and Engineering: A, vol. 318, no. 1-2, pp. 144-154, Nov. 2001, doi: 10.1016/S0921-5093(01)01326-0.

[7] H. Okamoto, Phase Diagrams of Dilute Binary Alloys. ASM International, 2002.

[8] J. L. Murray, "The Al-Sc (aluminum-scandium) system," JPE, vol. 19, no. 4, pp. 380-384, Aug. 1998, doi: 10.1361/105497198770342120.

[9] S. I. Fujikawa, "Impurity Diffusion of Scandium in Aluminium," Defect and Diffusion Forum, vol. 143-147, pp. 115-120, 1997, doi: 10.4028/www.scientific.net/DDF.143-147.115.

[10] C. B. Fuller, D. N. Seidman, and D. C. Dunand, "Mechanical properties of Al(Sc,Zr) alloys at ambient and elevated temperatures," Acta Materialia, vol. 51, no. 16, pp. 4803-4814, Sep. 2003, doi: 10.1016/S1359-6454(03)00320-3. 
[11] K. E. Knipling, D. N. Seidman, and D. C. Dunand, "Ambient- and HighTemperature Mechanical Properties of Isochronally Aged Al-0.06Sc, Al-0.06 Zr, and Al-0.06Sc-0.06Zr Alloys (at.\%)," Acta Materialia, vol. 59, no. 3, pp. 943-954, 2011, doi: 10.1016/j.actamat.2010.10.017.

[12] K. E. Knipling, D. C. Dunand, and D. N. Seidman, "Nucleation and Precipitation Strengthening in Dilute Al-Ti and Al-Zr Alloys," Metall and Mat Trans A, vol. 38, no. 10, pp. 2552-2563, Oct. 2007, doi: 10.1007/s11661-007-9283-6.

[13] Y. Harada and D. C. Dunand, "Microstructure of Al3Sc with ternary transition-metal additions," Materials Science and Engineering: A, vol. 329-331, pp. 686-695, Jun. 2002, doi: 10.1016/S0921-5093(01)01608-2.

[14] K. E. Knipling and D. C. Dunand, "Creep resistance of cast and aged Al-0.1Zr and Al-0.1Zr-0.1Ti (at.\%) alloys at 300-400 ${ }^{\circ}$ C," Scripta Materialia, vol. 59, no. 4, pp. 387-390, Aug. 2008, doi: 10.1016/j.scriptamat.2008.02.059.

[15] S.-I. Fujikawa, "Solid state diffusion in light metals. I," Journal of Japan Institute of Light Metals (Japan), vol. 46, no. 4, pp. 202-215, 1996.

[16] J. G. Grammatikakis, K. Eftaxias, S. Patapis, and V. Hadjicontis, "A simple model applied to the elastic properties of the lead-thallium and magnesium-lithium alloys," Journal of Physics and Chemistry of Solids, vol. 49, no. 8, pp. 965-967, Jan. 1988, doi: 10.1016/0022-3697(88)90014-5.

[17] K. Hirano and S. I. Fujikawa, "Impurity diffusion in aluminum," Journal of Nuclear Materials, vol. 69, pp. 564-566, Feb. 1978, doi: 10.1016/0022-3115(78)90275-1.

[18] S. Fujikawa, K. Hirano, and Y. Fukushima, "Diffusion of silicon in aluminum," MTA, vol. 9, no. 12, pp. 1811-1815, Dec. 1978, doi: 10.1007/BF02663412.

[19] S. I. Fujikawa and K. Hirano, "Impurity-Diffusion of Copper in Aluminum," Defect and Diffusion Forum, vol. 66-69, p. 447, 1991.

[20] E. Clouet, L. Laé, T. Épicier, W. Lefebvre, M. Nastar, and A. Deschamps, “Complex precipitation pathways in multicomponent alloys," Nature Materials, vol. 5, no. 6, pp. 482-488, Jun. 2006, doi: 10.1038/nmat1652. 
[21] A. Tolley, V. Radmilovic, and U. Dahmen, "Segregation in Al3(Sc,Zr) precipitates in Al-Sc-Zr alloys," Scripta Materialia, vol. 52, no. 7, pp. 621-625, Apr. 2005, doi: 10.1016/j.scriptamat.2004.11.021.

[22] P. W. Voorhees, “Alloys: Scandium overtakes zirconium," Nature Materials, vol. 5, no. 6, pp. 435-436, Jun. 2006, doi: 10.1038/nmat1663.

[23] L. S. Toropova, Advanced Aluminum Alloys Containing Scandium: Structure and Properties. Gordon and Breach Science Publishers, 1998.

[24] A. J. Ardell, "Precipitation hardening," MTA, vol. 16, no. 12, pp. 2131-2165, Dec. 1985, doi: 10.1007/BF02670416.

[25] T. H. Courtney, Mechanical Behavior of Materials: Second Edition. Waveland Press, 2005.

[26] A. S. Argon and E. Orowan, Physics of strength and plasticity. Cambridge : M.I.T. Press, 1969.

[27] E. Nembach, "Precipitation hardening caused by a difference in shear modulus between particle and matrix," phys. stat. sol. (a), vol. 78, no. 2, pp. 571-581, Aug. 1983, doi: 10.1002/pssa.2210780223.

[28] H. J. Frost and M. F. Ashby, Deformation-Mechanism Maps: The Plasticity and Creep of Metals and Ceramics, 1st edition. Oxford Oxfordshire; New York: Pergamon Press, 1982.

[29] J. Røyset and N. Ryum, "Scandium in aluminium alloys," International Materials Reviews, vol. 50, no. 1, pp. 19-44, Feb. 2005, doi: 10.1179/174328005X14311. [30] J. Čadek, Creep in metallic materials. Elsevier, 1988.

[31] Z. Xu and Y. Zhang, "Quench rates in air, water, and liquid nitrogen, and inference of temperature in volcanic eruption columns," Earth and Planetary Science Letters, vol. 200, no. 3, pp. 315-330, Jun. 2002, doi: 10.1016/S0012-821X(02)00656-8.

[32] M. J. Aziz, "Model for solute redistribution during rapid solidification," Journal of Applied Physics, vol. 53, no. 2, pp. 1158-1168, Feb. 1982, doi: 10.1063/1.329867.

[33] M. Brochu and G. Portillo, "Grain Refinement during Rapid Solidification of Aluminum-Zirconium Alloys Using Electrospark Deposition," Materials Transactions, vol. 54, no. 6, pp. 934-939, 2013, doi: 10.2320/matertrans.MD201228. 
[34] A. K. Ghosh and C. Gandhi, "Grain refinement and superplastic forming of an aluminum base alloy," US4770848A, Sep. 13, 1988.

[35] E. K. loannidis and T. Sheppard, "Influence of powder metallurgical processing on production and properties of rapidly solidified $\mathrm{Al}-5 \mathrm{Cr}-2 \mathrm{Zr}$, $\mathrm{Al}-6 \cdot 43 \mathrm{Cr}-1 \cdot 67 \mathrm{Zr}$, and Al-4Cr-1Fe extrudates," Materials Science and Technology, vol. 6, no. 8, pp. 749754, Aug. 1990, doi: 10.1179/mst.1990.6.8.749.

[36] J. J. Gilman, J. A. Champion, and R. W. Cahn, "Rapidly Solidified Materials," Philosophical Transactions of the Royal Society of London. Series A, Mathematical and Physical Sciences, vol. 322, no. 1567, pp. 425-438, 1987.

[37] P. K. Domalavage, N. J. Grant, and Y. Gefen, "Structure and properties of rapidly solidified 7075 P/M aluminum alloy modified with nickel and zirconium," MTA, vol. 14, no. 8, pp. 1599-1606, Aug. 1983, doi: 10.1007/BF02654387.

[38] S. Srinivasan, P. B. Desch, and R. B. Schwarz, "Metastable phases in the Al3X (X= $\mathrm{Ti}, \mathrm{Zr}$, and Hf) intermetallic system," Scripta Metallurgica et Materialia, vol. 25, no. 11, pp. 2513-2516, Nov. 1991, doi: 10.1016/0956-716X(91)90059-A.

[39] X. Meng, D. Zhang, Weiwen Zhang, Cheng Qiu, G. Liang, and J. Chen, "Microstructure and mechanical properties of a high- $\mathrm{Zn}$ aluminum alloy prepared by melt spinning and extrusion," Journal of Alloys and Compounds, vol. 819, p. 152990, Apr. 2020, doi: 10.1016/j.jallcom.2019.152990.

[40] Y. Kawamura, A. Inoue, K. Sasamori, and T. Masumoto, "High-strength powder metallurgy aluminum alloys in glass-forming Al-Ni-Ce-(Ti or Zr) systems," Scripta Metallurgica et Materialia, vol. 29, no. 2, pp. 275-280, 1993.

[41] F. Alshmri, "Rapid Solidification Processing: Melt Spinning of Al-High Si Alloys," Advanced Materials Research, vol. Vols. 383-390 (2012), p. pp 1740-1746, Jan. 2012, doi: 10.4028/www.scientific.net/AMR.383-390.1740.

[42] W. Szymański, M. Bigaj, M. Gawlik, M. Mitka, and M. Szymanek, "Consolidation by Continuous Rotary Extrusion of Aluminium Alloys Cast by the Melt Spinning Process," Archives of Metallurgy and Materials, vol. 59, Jan. 2014, doi: 10.2478/amm-2014-0050. 
[43] N. Berndt, P. Frint, and M. F.-X. Wagner, "Influence of Extrusion Temperature on the Aging Behavior and Mechanical Properties of an AA6060 Aluminum Alloy," Metals, vol. 8, no. 1, p. 51, Jan. 2018, doi: 10.3390/met8010051.

[44] W. D. Callister and D. G. Rethwisch, Fundamentals of Materials Science and Engineering: An Integrated Approach. John Wiley \& Sons, 2012.

[45] Y. S. Sato, M. Urata, H. Kokawa, and K. Ikeda, "Hall-Petch relationship in friction stir welds of equal channel angular-pressed aluminium alloys," Materials Science and Engineering: A, vol. 354, no. 1, pp. 298-305, Aug. 2003, doi: 10.1016/S09215093(03)00008-X.

[46] G. K. Williamson and R. E. Smallman, "Dislocation densities in some annealed and cold-worked metals from measurements on the X-ray debye-scherrer spectrum," The Philosophical Magazine: A Journal of Theoretical Experimental and Applied Physics, vol. 1, no. 1, pp. 34-46, Jan. 1956, doi: 10.1080/14786435608238074.

[47] I. M. Lifshitz and V. V. Slyozov, "The kinetics of precipitation from supersaturated solid solutions," Journal of Physics and Chemistry of Solids, vol. 19, no. 1, pp. 3550, Apr. 1961, doi: 10.1016/0022-3697(61)90054-3.

[48] C. Wagner, "Theorie der Alterung von Niederschlägen durch Umlösen (OstwaldReifung)," Zeitschrift für Elektrochemie, Berichte der Bunsengesellschaft für physikalische Chemie, vol. 65, no. 7-8, pp. 581-591, 1961, doi: 10.1002/bbpc. 19610650704.

[49] A. Umantsev and G. B. Olson, "Ostwald ripening in multicomponent alloys," Scripta Metallurgica et Materialia, vol. 29, no. 8, pp. 1135-1140, Oct. 1993, doi: 10.1016/0956-716X(93)90191-T.

[50] C. J. Kuehmann and P. W. Voorhees, "Ostwald ripening in ternary alloys," MMTA, vol. 27, no. 4, pp. 937-943, Apr. 1996, doi: 10.1007/BF02649761.

[51] K. Deane, "INVESTIGATION AND MODELING OF Al3(Sc, Zr) PRECIPITATION STRENGTHENING IN THE PRESENCE OF ENHANCED SUPERSATURATION AND WITHIN Al-Cu BINARY ALLOYS," Dissertations, Master's Theses and Master's Reports, Jan. 2016, [Online]. Available: https://digitalcommons.mtu.edu/etdr/261. 
[52] E. Clouet, J. M. Sanchez, and C. Sigli, "First-principles study of the solubility of Zr in Al," Phys. Rev. B, vol. 65, no. 9, p. 094105, Feb. 2002, doi:

10.1103/PhysRevB.65.094105.

[53] J. Murray, A. Peruzzi, and J. P. Abriata, "The Al-Zr (aluminum-zirconium) system," JPE, vol. 13, no. 3, pp. 277-291, Jun. 1992, doi: 10.1007/BF02667556.

[54] S. Iwamura and Y. Miura, "Loss in coherency and coarsening behavior of Al3Sc precipitates," Acta Materialia, vol. 52, no. 3, pp. 591-600, Feb. 2004, doi: 10.1016/j.actamat.2003.09.042.

[55] T. Ohashi and R. Ichikawa, "Grain refinement in aluminium-zirconium and aluminium-titanium alloys by metastable phases," Zeitschrift fuer Metallkunde, vol. 64, pp. 517-521, 1973.

[56] W. Dahl, W. Gruhl, G. Ibe, W. G. Burchard, and C. Dumitrescu, "Solidification and precipitation in aluminium-zirconium alloys. Pt. 2," Zeitschrift fuer Metallkunde, vol. 68, no. 3, pp. 188-194, 1977.

[57] A. F. Norman, P. B. Prangnell, and R. S. McEwen, "The solidification behaviour of dilute aluminium-scandium alloys," Acta Materialia, vol. 46, no. 16, pp. 5715-5732, Oct. 1998, doi: 10.1016/S1359-6454(98)00257-2.

[58] W. Soboyejo, Mechanical Properties of Engineered Materials, 1st edition. New York: CRC Press, 2002.

[59] M. J. Couper, A. E. Neeson, and J. R. Griffiths, "Casting Defects and the Fatigue Behaviour of an Aluminium Casting Alloy," Fatigue \& Fracture of Engineering Materials \& Structures, vol. 13, no. 3, pp. 213-227, 1990, doi: https://doi.org/10.1111/j.1460-2695.1990.tb00594.x.

[60] M. J. Jones and F. J. Humphreys, "Interaction of recrystallization and precipitation: The effect of Al3Sc on the recrystallization behaviour of deformed aluminium," Acta Materialia, vol. 51, no. 8, pp. 2149-2159, May 2003, doi: 10.1016/S13596454(03)00002-8.

[61] D. G. McCartney, "Grain refining of aluminium and its alloys using inoculants," International Materials Reviews, vol. 34, no. 1, pp. 247-260, Jan. 1989, doi: 10.1179/imr.1989.34.1.247. 
[62] A. Deschamps, L. Lae, and P. Guyot, "In situ small-angle scattering study of the precipitation kinetics in an Al-Zr-Sc alloy," Acta Materialia, vol. 55, no. 8, pp. 2775-2783, May 2007, doi: 10.1016/j.actamat.2006.12.015.

[63] D. Tabor, "The physical meaning of indentation and scratch hardness," British Journal of Applied Physics, vol. 7, pp. 159-166, May 1956, doi: 10.1088/0508$3443 / 7 / 5 / 301$.

[64] A. B. Spierings et al., "Microstructural features of Sc- and Zr-modified Al-Mg alloys processed by selective laser melting," Materials \& Design, vol. 115, pp. 5263, Feb. 2017, doi: 10.1016/j.matdes.2016.11.040.

[65] A. Y. Churyumov et al., "Microstructure and mechanical properties of a novel selective laser melted Al-Mg alloy with low Sc content," Mater. Res. Express, vol. 6, no. 12, p. 126595, Dec. 2019, doi: 10.1088/2053-1591/ab5bea.

[66] R. Li et al., "Selective Laser Melting of Gas Atomized Al-3.02Mg-0.2Sc-0.1Zr Alloy Powder: Microstructure and Mechanical Properties," Advanced Engineering Materials, vol. 21, no. 3, p. 1800650, 2019, doi: 10.1002/adem.201800650.

[67] A. Tolley, V. Radmilovic, and U. Dahmen, "Segregation in A13(Sc,Zr) precipitates in Al-Sc-Zr alloys,” Scripta Materialia, vol. 52, no. 7, pp. 621-625, Apr. 2005, doi: 10.1016/j.scriptamat.2004.11.021.

[68] P. Voorhees, “Alloys: Scandium overtakes zirconium,” Nature materials, vol. 5, pp. 435-6, Jul. 2006, doi: 10.1038/nmat1663.

[69] E. Clouet, L. Laé, T. Épicier, W. Lefebvre, M. Nastar, and A. Deschamps, "Complex precipitation pathways in multicomponent alloys," Nat Mater, vol. 5, no. 6, pp. 482488, Jun. 2006, doi: 10.1038/nmat1652.

[70] C. B. Fuller, D. N. Seidman, and D. C. Dunand, "Mechanical properties of Al (Sc, Zr) alloys at ambient and elevated temperatures," Acta Materialia, vol. 51, no. 16, pp. 4803-4814, 2003.

[71] K. E. Knipling, R. A. Karnesky, C. P. Lee, D. C. Dunand, and D. N. Seidman, "Precipitation Evolution in Al-0.1Sc, Al-0.1Zr, and Al-0.1Sc-0.1Zr (at.\%) Alloys during Isochronal Aging," Acta Materialia, vol. 58, no. 15, pp. 5184-5195, 2010, doi: 10.1016/j.actamat.2010.05.054. 
[72] E. A. Marquis and D. N. Seidman, "Nanoscale structural evolution of Al3Sc precipitates in $\mathrm{Al}(\mathrm{Sc})$ alloys," Acta Materialia, vol. 49, no. 11, pp. 1909-1919, Jun. 2001, doi: 10.1016/S1359-6454(01)00116-1.

[73] Y. Yang, J. J. Licavoli, and P. G. Sanders, "Improved strengthening in supersaturated Al-Sc-Zr alloy via melt-spinning and extrusion," Journal of Alloys and Compounds, vol. 826, p. 154185, Jun. 2020, doi: 10.1016/j.jallcom.2020.154185.

[74] B. Forbord, H. Hallem, J. Røyset, and K. Marthinsen, "Thermal stability of Al3(Scx,Zr1-x)-dispersoids in extruded aluminium alloys," Materials Science and Engineering: A, vol. 475, no. 1, pp. 241-248, Feb. 2008, doi: 10.1016/j.msea.2007.04.054.

[75] C. Fuller and D. Seidman, "Temporal evolution of the nanostructure of $\mathrm{Al}(\mathrm{Sc}, \mathrm{Zr})$ alloys: Part II-coarsening of $\mathrm{Al}(\mathrm{ScZr})$ precipitates," Acta Materialia, vol. 53, pp. 5415-5428, Dec. 2005, doi: 10.1016/j.actamat.2005.08.015.

[76] M. F. Ashby and L. M. Brown, "Diffraction contrast from spherically symmetrical coherency strains," The Philosophical Magazine: A Journal of Theoretical Experimental and Applied Physics, vol. 8, no. 91, pp. 1083-1103, Jul. 1963, doi: 10.1080/14786436308207338.

[77] M. F. Ashby and L. M. Brown, "On diffraction contrast from inclusions," The Philosophical Magazine: A Journal of Theoretical Experimental and Applied Physics, vol. 8, no. 94, pp. 1649-1676, Oct. 1963, doi: 10.1080/14786436308207329. [78] Y. Yang, P. Mukherjee, and P. Sanders, "Precipitation Hardening via Chemically Ordered L12 Precipitates in Al-Sc-Zr Alloys— New Insights Using Combined STEM and EDS Study," Microscopy and Microanalysis, vol. 25, no. S2, pp. 2188-2189, Aug. 2019, doi: 10.1017/S143192761901167X.

[79] C. E. Campbell, L. A. Bendersky, W. J. Boettinger, and R. Ivester, "Microstructural characterization of Al-7075-T651 chips and work pieces produced by high-speed machining," Materials Science and Engineering: A, vol. 430, no. 1, pp. 15-26, Aug. 2006, doi: 10.1016/j.msea.2006.04.122. 
[80] A. M. Brown and M. F. Ashby, "Correlations for diffusion constants," Acta Metallurgica, vol. 28, no. 8, pp. 1085-1101, Aug. 1980, doi: 10.1016/00016160(80)90092-9.

[81] R. W. Balluffi, "On measurements of self-diffusion rates along dislocations in F.C.C. Metals," physica status solidi (b), vol. 42, no. 1, pp. 11-34, 1970, doi: 10.1002/pssb.19700420102.

[82] G. Murch and A. Nowick, "Diffusion in Crystalline Solids," Academic Press, Inc , Orlando, Florida 32887, USA, 1984. 482 pp, p. 482, 1984.

[83] P. K. Footner and B. P. Richards, “Long - term growth of superalloy $\gamma^{\prime}$ particles," $J$ Mater Sci, vol. 17, no. 7, pp. 2141-2153, Jul. 1982, doi: 10.1007/BF00540433.

[84] R. Wagner, R. Kampmann, P. W. Voorhees, and G. Kostorz, "Homogeneous Second Phase Precipitation: Phase Transformations in Materials Science and Technology," 2001, Accessed: Feb. 08, 2020. [Online]. Available: https://www.scholars.northwestern.edu/en/publications/homogeneous-second-phaseprecipitation-phase-transformations-in-m.

[85] K. P. Balanda and H. L. MacGillivray, "Kurtosis: A Critical Review," The American Statistician, vol. 42, no. 2, pp. 111-119, 1988, doi: 10.2307/2684482.

[86] D. Dugar, "Skew and Kurtosis: 2 Important Statistics terms you need to know in Data Science,” Medium, Jul. 18, 2020. https://codeburst.io/2-important-statisticsterms-you-need-to-know-in-data-science-skewness-and-kurtosis-388fef94eeaa (accessed Jul. 28, 2020).

[87] A. J. Ardell, "The effect of volume fraction on particle coarsening: theoretical considerations," Acta Metallurgica, vol. 20, no. 1, pp. 61-71, Jan. 1972, doi: 10.1016/0001-6160(72)90114-9.

[88] P. K. Sen, "Estimates of the Regression Coefficient Based on Kendall's Tau," Journal of the American Statistical Association, vol. 63, no. 324, pp. 1379-1389, Dec. 1968, doi: 10.1080/01621459.1968.10480934.

[89] H. Theil, "A rank-invariant method of linear and polynomial regression analysis. I," Nederl. Akad. Wetensch., Proc., vol. 53, pp. 386-392 = Indagationes Math. 12, 85-91 (1950), 1950. 
[90] C. B. Fuller, J. L. Murray, and D. N. Seidman, “Temporal evolution of the nanostructure of $\mathrm{Al}(\mathrm{Sc}, \mathrm{Zr})$ alloys: Part I - Chemical compositions of A13(Sc1-xZrx) precipitates," Acta Materialia, vol. 53, no. 20, pp. 5401-5413, Dec. 2005, doi: 10.1016/j.actamat.2005.08.016.

[91] P. Shewmon, Diffusion in Solids, 2 edition. Warrendale, Pa: Wiley-TMS, 1991.

[92] K. S. Vecchio and D. B. Williams, "Convergent beam electron diffraction study of Al3Zr in Al-Zr AND Al-Li-Zr alloys," Acta Metallurgica, vol. 35, no. 12, pp. 29592970, Dec. 1987, doi: 10.1016/0001-6160(87)90295-1.

[93] M. Doi, T. Miyazaki, and T. Wakatsuki, "The effect of elastic interaction energy on the morphology of $\gamma$ 'precipitates in nickel-based alloys," Materials Science and Engineering, vol. 67, no. 2, pp. 247-253, Nov. 1984, doi: 10.1016/00255416(84)90056-9.

[94] Quantities, Units and Symbols in Physical Chemistry. 2007.

[95] J. CADEK, “Creep in metallic materials,” Mater. sci. monogr, vol. 48, 1988.

[96] S. Tian, J. Li, J. Zhang, Z. Wulabieke, and D. Lv, "Effect of Zr and Sc on microstructure and properties of 7136 aluminum alloy," Journal of Materials Research and Technology, vol. 8, no. 5, pp. 4130-4140, Sep. 2019, doi: 10.1016/j.jmrt.2019.07.022.

[97] S. Ochiai, Ed., Mechanical Properties of Metallic Composites, 1st edition. New York: CRC Press, 1993.

[98] V. E. Lysaght and A. D. Bellis, Hardness Testing Handbook. American Chain and Cable Company, 1969.

[99] A. C. Fischer-Cripps, "Factors Affecting Nanoindentation Test Data," in Nanoindentation, A. C. Fischer-Cripps, Ed. New York, NY: Springer, 2002, pp. 6182.

[100] E. S. BERKOVICH, “Three Faceted Diamond Pyramid for Micro-Hardness Testing," Industrial Diamond Review, vol. 11, no. 127, p. 129, 1951.

[101] A. J. Bushby and D. J. Dunstan, "Plasticity size effects in nanoindentation," Journal of Materials Research, vol. 19, no. 1, pp. 137-142, Jan. 2004, doi: 10.1557/jmr.2004.19.1.137. 
[102] A. C. Fischer-Cripps, "Critical review of analysis and interpretation of nanoindentation test data," Surface and Coatings Technology, vol. 200, no. 14, pp. 4153-4165, Apr. 2006, doi: 10.1016/j.surfcoat.2005.03.018.

[103] W. C. Oliver and G. M. Pharr, "Measurement of hardness and elastic modulus by instrumented indentation: Advances in understanding and refinements to methodology," Journal of Materials Research, vol. 19, no. 1, pp. 3-20, Jan. 2004, doi: 10.1557/jmr.2004.19.1.3.

[104] N. X. Randall, "Direct measurement of residual contact area and volume during the nanoindentation of coated materials as an alternative method of calculating hardness," Philosophical Magazine A, vol. 82, no. 10, pp. 1883-1892, Jul. 2002, doi: 10.1080/01418610208235700.

[105] "Substrate effects on nanoindentation mechanical property measurement of soft films on hard substrates | Journal of Materials Research | Cambridge Core." https://www.cambridge.org/core/journals/journal-of-materialsresearch/article/substrate-effects-on-nanoindentation-mechanical-propertymeasurement-of-soft-films-on-hardsubstrates/891EE6FA2D3C4231C91D197EAE06FED6 (accessed Nov. 03, 2020). [106] R. W. Balluffi, S. M Allen, W. C. Carter, and R. A Kemper, Kinetics of materials. J. Wiley \& Sons, 2005.

\section{Appendix A. Increasing time exponent $\mathrm{n}$ as a function of evolving precipitate composition}

The precipitate radius $R$ change described in traditional LSW model was defined as:

$$
\frac{d R}{d t}=\frac{2 D \Omega^{2} C_{e q} \gamma}{k T R} \cdot\left(\frac{1}{\langle R\rangle}-\frac{1}{R}\right) \quad \text { Equation A1 }
$$

where $D$ is the diffusivity of solute, $\gamma$ is the interfacial energy, $\Omega$ is the solute atomic volume, $C_{e q}$ is the equilibrium solubility determined by the phase diagram, $k$ is the boltzmann constant and $T$ is the over aging temperature. The precipitate radius change 
depends on the size comparison between the actual precipitate size $R$ and the mean precipitate size $\langle R\rangle$. The time exponent of traditional LSW is 3 according to Equation A1.

The composition of precipitates in melt-spun ribbon versus precipitate radius during annealing is plotted in Figure A1. The concentration of Sc decreased from $19.5 \%$ to $18.9 \%$ and the concentration of $\mathrm{Zr}$ increased from $3.1 \%$ to $3.4 \%$ with precipitate radius coarsened from $7.5 \mathrm{~nm}$ to $12.1 \mathrm{~nm}$. Note that the experimentally measured compositions of precipitate are the average composition of the entire precipitate. The composition change of Sc and $\mathrm{Zr}$ might lead to more significant impact than measured values due to the inhomogeneous distribution of elements.

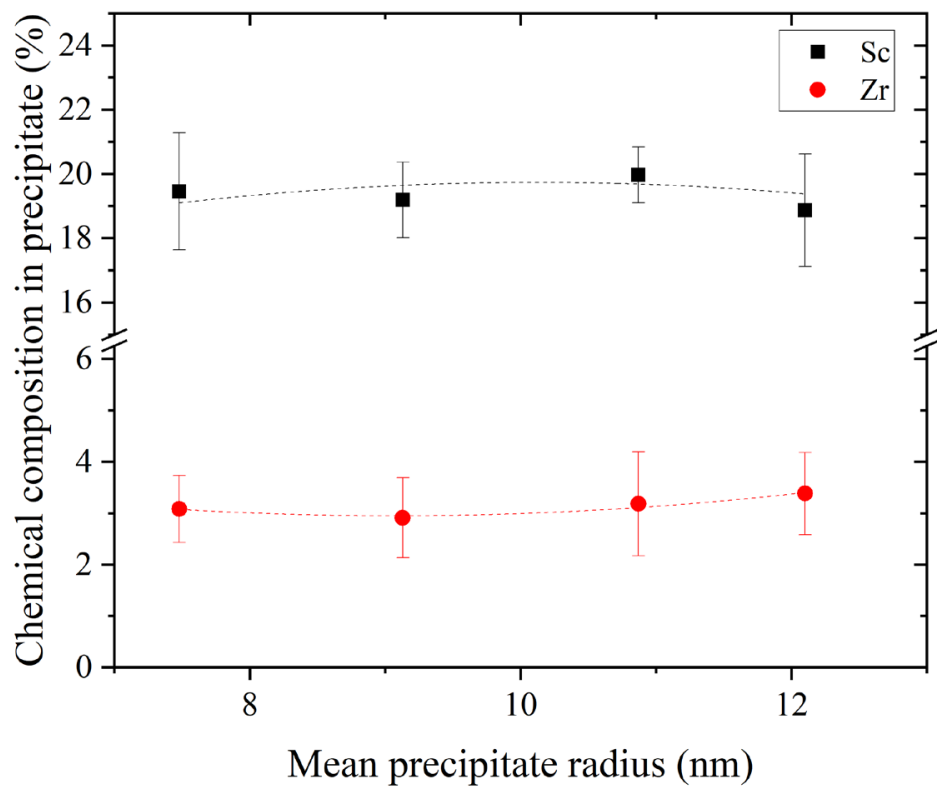

Figure A1. Solute concentration of precipitate in melt-spun ribbon change with precipitate radius aged from $12 \mathrm{~h}$ to $72 \mathrm{~h}$ at $400^{\circ} \mathrm{C}$ (error bars are $95 \%$ standard error of the mean).

The confidence in these reported solutes changes was estimated using the Thiel-Sen estimator which is the median of the slopes through all points (Table A.1). Based on the confidence of solutes changes using data from both supersaturated, the decrease of Sc composition is poorly supported with less than $30 \%$ confidence, and the increase of $\mathrm{Zr}$ 
composition shows at least $70 \%$ confidence. As for the dilute alloys [90], the decrease of Sc composition in precipitate is found to be statistically significant with $95 \%$ confidence, and the increase of $\mathrm{Zr}$ composition shows $85 \%$ confidence. Thus, the composition of $\mathrm{Sc}$ in precipitate is thought decreased and $\mathrm{Zr}$ is increased with annealing.

Table A.1. The confidence of solutes changes for precipitate in supersaturated and dilute alloys using Thiel-Sen estimator.

\begin{tabular}{c|c|c}
\hline & $\begin{array}{c}\text { Sc (confidence of } \\
\text { decrease) }\end{array}$ & $\begin{array}{c}\mathrm{Zr} \text { (confidence of } \\
\text { increase) }\end{array}$ \\
\hline Al-0.4Sc-0.4Zr at. \% Melt-spun ribbon & $<30 \%$ & $>70 \%$ \\
\hline Al-0.4Sc-0.4Zr at. \% Extruded rod & $<30 \%$ & $>90 \%$ \\
\hline Al-0.09Sc-0.047Zr at. \% [90] & $>95 \%$ & $>85 \%$ \\
\hline
\end{tabular}

Using the lattice mismatch difference between $\mathrm{Al}_{3} \mathrm{Zr}$ versus $\mathrm{Al}_{3} \mathrm{Sc}\left(1.32 \%\right.$ for $\mathrm{Al}_{3} \mathrm{Sc}$, $0.75 \%$ for $\mathrm{Al}_{3} \mathrm{Zr}$ ) and the concentrations changes (Table A.1), the lattice mismatch for an average size precipitate decreased $1.6 \%$ after overaging from 12 to $72 \mathrm{~h}$. As the interfacial energy per unit area $\gamma$ decreases with lattice mismatch $\varepsilon$, the interfacial energy change could be estimated in terms of radius change using the chain rule as [106]:

$$
\begin{gathered}
\gamma=\gamma_{0}+\left(\frac{d \varepsilon}{d C_{Z r}} \cdot \frac{d C_{Z r}}{d R}+\frac{d \varepsilon}{d C_{S c}} \cdot \frac{d C_{S c}}{d R}\right) \cdot \frac{d \gamma}{d \varepsilon} \cdot\left(R-R_{0}\right) \\
=\gamma_{0}+\alpha \cdot\left(R-R_{0}\right)
\end{gathered}
$$

where $R_{0}$ and $\gamma_{0}$ are the initial precipitate radius and interfacial energy and $\alpha<0$.

Substituting Equation A2 into Equation A1:

$$
\frac{d R}{d t} \cong \frac{a D \Omega^{2} C_{e q}}{k T} \cdot\left(\gamma_{0}+\alpha \cdot\left(R-R_{0}\right)\right) \cdot\left(\frac{1}{\langle R\rangle}-\frac{1}{R}\right) \cdot \frac{1}{R}
$$

Equation A3

Compared to the traditional LSW theory, Equation A3 introduces an extra term describing the change in interfacial energy with precipitate radius, $\alpha$ (due to the change in $\mathrm{Sc} / \mathrm{Zr}$ concentration with precipitate radius). Examining the specific case for $R=2\langle R\rangle$, which is the radius that has the maximum radial velocity in the LSW treatment:

$$
\frac{d R}{d t} \cong \frac{a D \Omega^{2} C_{e q}}{k T} \cdot\left(\gamma_{0}+\alpha \cdot\left(2\langle R\rangle-R_{0}\right)\right) \cdot\left(\frac{1}{4\langle R\rangle^{2}}\right) \quad \text { Equation A4 }
$$


Integration of Equation A4 gives a hypergeometric solution, which has a closed form Taylor series about $\alpha$ (linear) as:

$$
8\langle R\rangle^{3} \cdot\left(\frac{1}{3 \gamma_{0}}-\frac{\alpha}{\gamma_{0}^{2}}\left(\frac{\langle R\rangle}{2}-\frac{R_{0}}{3}\right)\right)=t \cdot \frac{k T}{a D \Omega^{2} C_{e q}}+\text { constant } \quad \text { Equation A5 }
$$

The precipitate radius $R$ coarsening at $400^{\circ} \mathrm{C}$ described in Equation A5 are plotted in Figure A2 from 0s to 10000s.

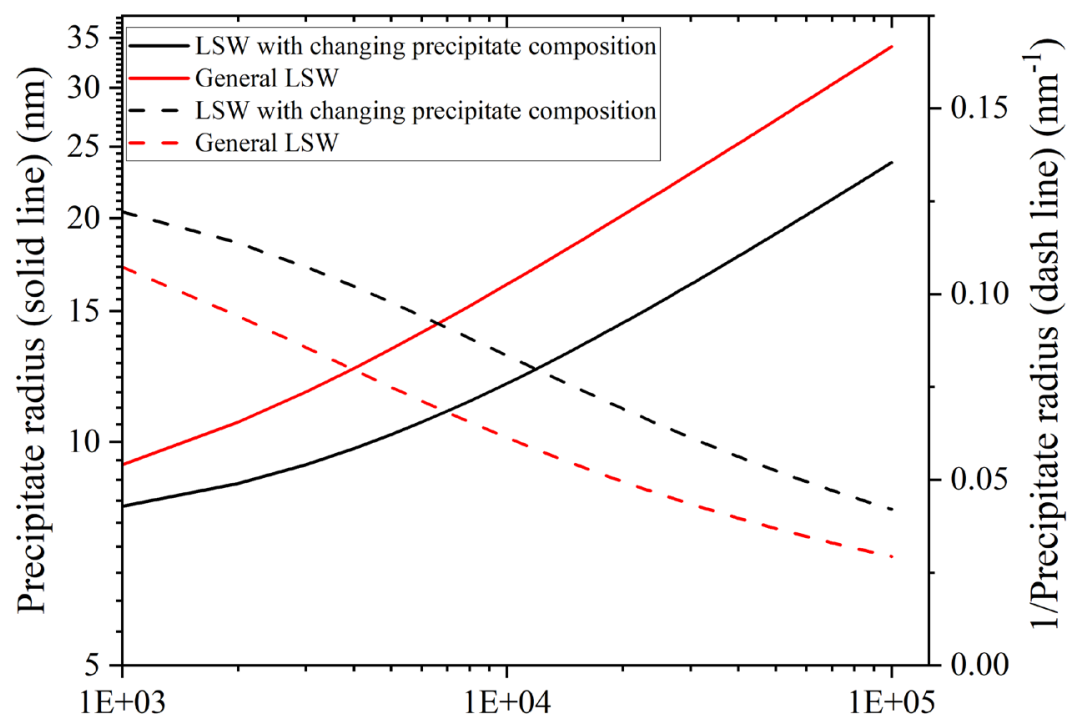

Coarsening time at $400^{\circ} \mathrm{C}(\mathrm{s})$

Figure A2. Precipitate radius predicted using modified LSW versus traditional LSW from $\mathrm{t}=0 \mathrm{~s}$ to $\mathrm{t}=10000 \mathrm{~s}$ at $400^{\circ} \mathrm{C}$.

As the average precipitate radius calculated based on the modified LSW (Equation A5) for $\alpha<0$ is found smaller than the average precipitate radius calculated based on traditional LSW at given annealing duration, the time exponent of radius for the traditional LSW was increased to larger than 3. The increased time exponent was estimated from precipitate size change in modified LSW (Table A.2).

Table A.2. Four precipitate sizes were chosen from modified LSW (Figure A2).

\begin{tabular}{c|c}
\hline Coarsening time (s) & Precipitate radius (nm) \\
\hline 15000 & 13.34 \\
\hline 30000 & 101
\end{tabular}




\begin{tabular}{c|c}
\hline 60000 & 20.20 \\
\hline 90000 & 22.99 \\
\hline
\end{tabular}

The time exponent was found increased to 3.3 for modified LSW plot (Figure A3).

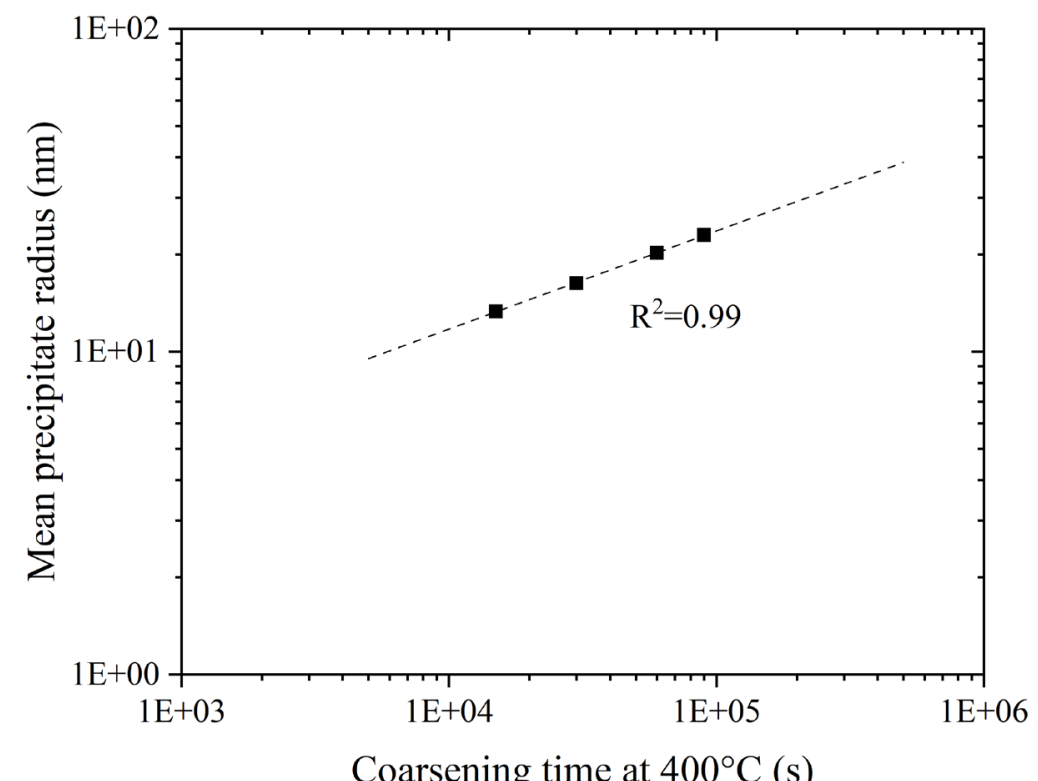

Figure A3. Log-log plot of mean precipitate radii of modified LSW.

\section{Appendix B. Decreasing time exponent $\mathrm{n}$ due to increasing precipitate volume fraction}

Precipitate volume fractions were found to increase during overaging heat treatment of both the melt-spun ribbon and extruded rod. For a small increase in the total volume of the precipitates during coarsening, the traditional LSW approach can be modified into:

$$
\frac{d}{d t} \sum_{\text {part }} \frac{4 \pi}{3} R^{3}=\delta_{1} \quad \text { Equation B1 }
$$

Where $\delta_{1}=0$ in the traditional LSW derivation, but is taken as a positive constant in this modification. Rewriting B1 as: 


$$
\sum_{\text {part }} R^{2} \frac{d R}{d t}=\delta_{2}
$$

where $\delta_{1}$ in Equation $\mathrm{B} 1$ and $\delta_{2}$ in Equation $\mathrm{B} 2$ are non-zero constants. The growth rate of a particle with radius $R$ is still considered as controlled by the mean field average concentration, $\langle c\rangle$ :

$$
\frac{d R}{d t}=-D \frac{c^{e q}-\langle c\rangle}{R} \Omega
$$

where $D$ is the solute diffusivity, $\Omega$ is the atomic volume, $c^{e q}$ is the equilibrium solute concentration at the interface of a particle of radius, $\mathrm{R}$, as determined by the GibbsThompson effect.

Combining Equations B2 and B3 gives:

$$
\sum_{\text {part }} R\left(c^{e q}-\langle c\rangle\right)=-\delta
$$

where $\delta=3 \delta_{1} /(4 \pi D \Omega)$ is a constant. Substituting the Gibbs-Thompson expression $c^{e q}=c^{e q}(\infty) \cdot\left(1+\frac{2 \gamma \Omega}{k T R}\right)$ into Equation B4:

$$
\sum_{\text {part }} R \cdot\left[\langle c\rangle-c^{e q}(\infty) \cdot\left(1+\frac{2 \gamma \Omega}{k T R}\right)\right]=\delta
$$

where $c^{e q}(\infty)$ is the solute concentration from the phase diagram, $\gamma$ is the interfacial energy, and $k$ is the Boltzmann constant. Rearranging Equation B5 gives:

$$
\left(\langle c\rangle-c^{e q}(\infty)\right) \cdot \sum_{\text {part }} R+\frac{2 \gamma \Omega c^{e q}(\infty)}{k T} \cdot \sum_{\text {part }} 1=\delta \quad \text { Equation B6 }
$$

Equation B6 could be further rearranged gives:

$$
\left(\langle c\rangle-c^{e q}(\infty)\right) \cdot\langle R\rangle+\frac{2 \gamma \Omega c^{e q}(\infty)}{k T}=\frac{\delta}{N^{t o t}} \quad \text { Equation B7 }
$$

where $\langle R\rangle$ is the average particle radius, given by:

$$
\langle R\rangle=\frac{\sum_{\text {part }} R}{N^{\text {tot }}}
$$

where $N^{t o t}=\sum_{\text {part }} 1$ is the total number of particles. Based on Equation B7, the average concentration $\langle c\rangle$ is expressed as: 


$$
\langle c\rangle=\frac{\delta}{N^{t o t} \cdot\langle R\rangle}+c^{e q}(\infty) \cdot\left(1+\frac{2 \gamma \Omega c^{e q}(\infty)}{k T \cdot\langle R\rangle}\right)
$$

Substituting Equation B9 into Equation B3 gives:

$$
\frac{d R}{d t}=\frac{D \Omega}{R} \cdot\left(\frac{\delta}{N^{t o t}\langle R\rangle}+\frac{2 \gamma \Omega c^{e q}(\infty)}{k T\langle R\rangle}-\frac{2 \gamma \Omega c^{e q}(\infty)}{k T R}\right)
$$

The total number of particles can be expressed in terms of equilibrium precipitate volume fraction $f_{v}^{e q}$ as:

$$
N^{t o t}=\frac{3}{4\langle R\rangle^{3}} \cdot f_{v}^{e q}
$$

Substituting Equation B11 into Equation B10 gives:

$$
\frac{d R}{d t}=\frac{D \Omega}{R} \cdot\left(\frac{4 \delta\langle R\rangle^{2}}{3 f_{v}^{e q}}+\frac{2 \gamma \Omega c^{e q}(\infty)}{k T\langle R\rangle}-\frac{2 \gamma \Omega c^{e q}(\infty)}{k T R}\right)
$$

Solving for $R_{\max }$ in terms of $\langle R\rangle$ :

$$
\begin{gathered}
\frac{d}{d t}\left(\frac{d R}{d t}\right)=0 \\
=-\frac{D \Omega \cdot\left(4 \delta R\langle R\rangle^{3} k T-12 c^{e q}(\infty) f_{v}^{e q}\langle R\rangle \gamma \Omega+6 c^{e q}(\infty) f_{v}^{e q} R \gamma \Omega\right)}{3 f_{v}^{e q} R^{3}\langle R\rangle k T}
\end{gathered}
$$

Yields an $R_{\max }$ of:

$$
R_{\text {max }}=\frac{6 c^{e q}(\infty) f_{v}^{e q}\langle R\rangle \gamma \Omega}{2 \delta\langle R\rangle^{3} k T+3 c^{e q}(\infty) f_{v}^{e q} \gamma \Omega}
$$

Equation $\mathrm{B} 12$ is arranged by substituting $R=R_{\max }$ :

$$
\frac{d\langle R\rangle}{d t}=\frac{D \Omega \cdot\left(4 \delta\langle R\rangle^{3} k T+6 c^{e q}(\infty) f_{v}^{e q} \gamma \Omega\right)^{2}}{72 c^{e q}(\infty) f_{v}^{2 q^{2}}(R)^{2} k T} \cdot\left[\frac{6 c^{e q}(\infty) f_{f}^{e q} \gamma \Omega}{2 \delta\left\langle\langle\rangle^{3} k T+3 c^{e q}(\infty) f_{v}^{e q} \gamma \Omega\right.}-\frac{144 c^{e q}(\infty) f_{v}^{e q} \gamma \Omega\left\langle\langle\rangle^{3} k T\right.}{\left(4 \delta \left\langle\left(\langle)^{3} k T+6 c^{e q}(\infty) f_{v}^{e q} \gamma \Omega\right)^{2}\right.\right.}\right]^{-1} \quad \text { Equation B15 }
$$

Simplify the above equation by choosing the first order of $\delta$ gives:

$$
\frac{d\langle R\rangle}{d t}=\frac{D \Omega^{2} c^{e q}(\infty) \gamma}{4 k T\langle R\rangle^{2}}+\frac{2 D \Omega^{2}\langle R\rangle \gamma}{k T f_{v}^{e q}}
$$

Integrating Equation B16 gives the evolution duration $t$ :

$$
t=\frac{f_{v}^{e q} \cdot \ln \left(\langle R\rangle^{3}+\frac{c^{e q}(\infty) f_{v}^{e q} \gamma \Omega}{4 \delta k T}\right)}{3 D \Omega \delta}+C
$$

where $C$ is a constant that at $t=0$ has a value of: 


$$
C=-\frac{f_{v}^{e q} \cdot \ln \left(\left\langle R_{0}\right\rangle^{3}+\frac{c^{e q}(\infty) f_{v}^{e q} \gamma \Omega}{4 \delta k T}\right)}{3 D \Omega \delta}
$$

Rearranging Equation B17 gives:

$$
\begin{gathered}
t=\frac{f_{v}^{e q} \cdot \ln \left(\langle R\rangle^{3}+\frac{c^{e q}(\infty) f_{v}^{e q} \gamma \Omega}{4 \delta k T}\right)}{3 D \Omega \delta} \\
-\frac{f_{v} \cdot \ln \left(\left\langle R_{0}\right\rangle^{3}+\frac{c^{e q}(\infty) f_{v}^{e q} \gamma \Omega}{4 \delta k T}\right)}{3 D \Omega \delta}
\end{gathered}
$$

Equation B19 is rearranged and simplified by choosing first order of $\delta$ to obtain:

$$
\begin{aligned}
& t
\end{aligned}
$$

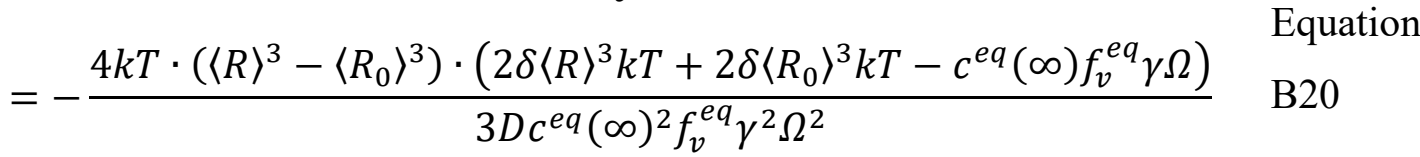

Equation $\mathrm{B} 20$ is changed into the general LSW when $\delta=0$ :

$$
t=\frac{4 k T \cdot\left(\langle R\rangle^{3}-\left\langle R_{0}\right\rangle^{3}\right) \cdot c^{e q}(\infty) f_{v}^{e q} \gamma \Omega}{3 D c^{e q}(\infty)^{2} f_{v}^{e q} \gamma^{2} \Omega^{2}}
$$

An experimental value for $\delta=3 \delta_{1} /(4 \pi D \Omega)$ is determined as $1.2 \times 10^{14} \mathrm{~mol} / \mathrm{m}^{2}$. The precipitate radius $R$ coarsening at $400^{\circ} \mathrm{C}$ described in Equation B20 and Equation B21 are plotted in Figure B1 from 0s to 10000s. 


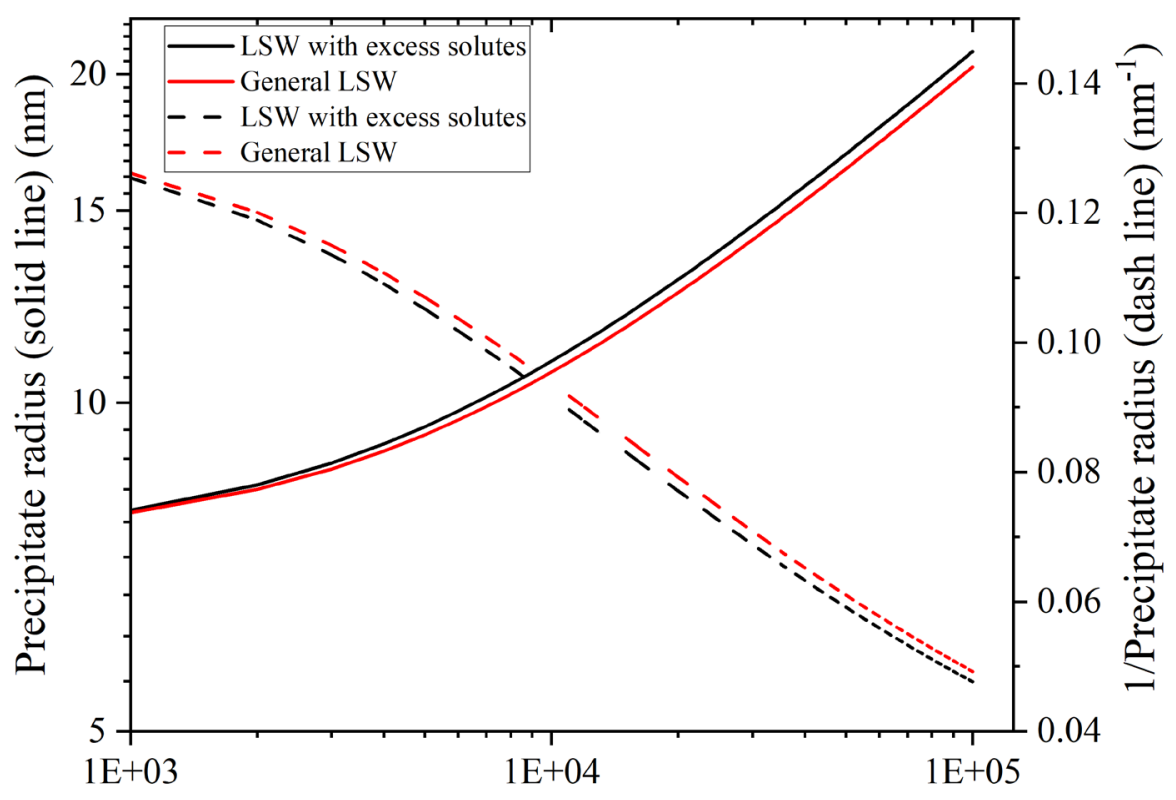

Coarsening time at $400^{\circ} \mathrm{C}(\mathrm{s})$

Figure B1. Precipitate radius predicted using modified LSW versus traditional LSW from $\mathrm{t}=0 \mathrm{~s}$ to $\mathrm{t}=10000 \mathrm{~s}$ at $400^{\circ} \mathrm{C}$.

The precipitate radius calculated by modifying LSW to consider increasing precipitate volume fraction is found to be larger than the general LSW, so the time exponent of radius for the modified LSW was decreased to smaller than 3. Based on the discussions of time exponent in Appendix A and B, the values of time exponent in melt-spun ribbon and extruded rod compromised to the changed precipitate composition and increased precipitate volume fraction during annealing.

\section{Appendix C. Copyright permission}

This dissertation contains partial materials published in a peer-reviewed journal. The reprint permission was obtained from publisher Elsevier with license 201026-002511. The reference of the published paper refers to:

Journal of Alloys and Compounds, vol. 826, Y. Yang, J. J. Licavoli, and P. G. Sanders, "Improved strengthening in supersaturated Al-Sc-Zr alloy via melt-spinning and extrusion”, p. 154185, Copyright Elsevier (2020). 